\title{
CREATING A POVERTY MAP FOR AZERBAIJAN ${ }^{1}$
}

\author{
Angela Baschieri * \\ Jane Falkingham * \\ Duncan Hornby ** \\ Craig Hutton **
}

* S3RI, University of Southampton

** Geodata Institute, University of Southampton

World Bank Policy Research Working Paper 3793, December 2005

The Policy Research Working Paper Series disseminates the findings of work in progress to encourage the exchange of ideas about development issues. An objective of the series is to get the findings out quickly, even if the presentations are less than fully polished. The papers carry the names of the authors and should be cited accordingly. The findings, interpretations, and conclusions expressed in this paper are entirely those of the authors. They do not necessarily represent the view of the World Bank, its Executive Directors, or the countries they represent. Policy Research Working Papers are available online at http://econ.worldbank.org.

\footnotetext{
${ }^{1}$ This research was funded under the TFESSD from the Norwegian and Finnish governments as part of the Azerbaijan Poverty and Environment Mapping work. The work was task managed by Karin Foch (ECSSD). The authors gratefully acknowledge the constructive advice and assistance from Professor Chris Elbers at Vrije University of Amsterdam, from Karin Foch, Irina Klytchnikova (ECSSD), Julian Lampietti (ECSSD), Peter Lanjouw (DERG) and Aleksandra Posarac (ECSHD) and at the World Bank, and from colleagues at Southampton University, particularly Ben Barton at the GeoData Institute. The team is also grateful to the collaboration given by the State Statistical Committee, particularly by Faig Jalilov who prepared the files for the analysis of census data and supervised the enumeration area matching of the settlement map and the census code and by Yashar Pashar who provided numerous insights into the 2002 Azerbaijan Household Budget Survey.
} 


\section{Contents}

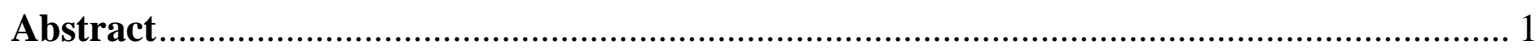

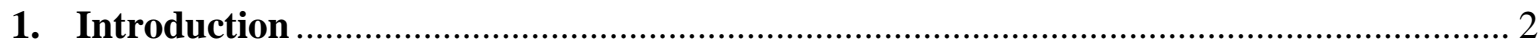

2. Creating a poverty map using the 'imputed welfare' method .......................................... 3

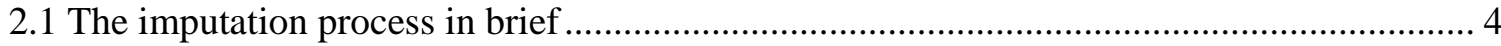

2.2 A cautionary note: issues regarding the reliability of poverty estimates for geographical

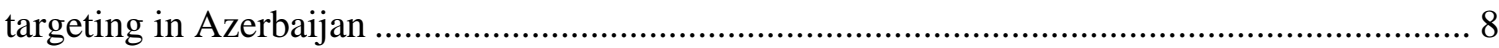

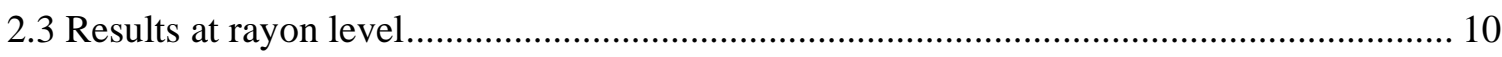

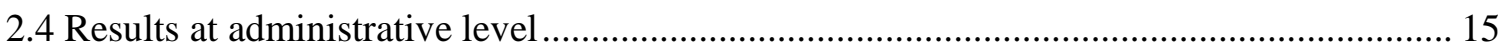

3. Alternative measures of welfare - the asset index method .......................................... 18

4 Comparing alternative indicators of welfare at the spatial level................................... 20

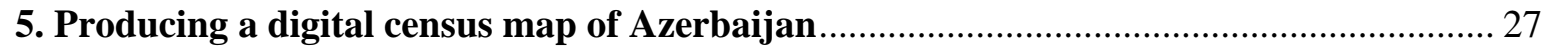

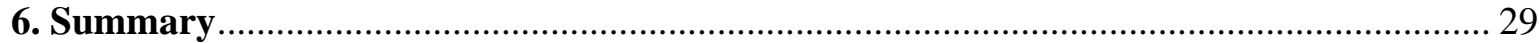

Technical Note 1: Creating a poverty map using the imputed consumption method .......... 30

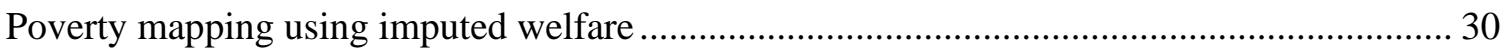

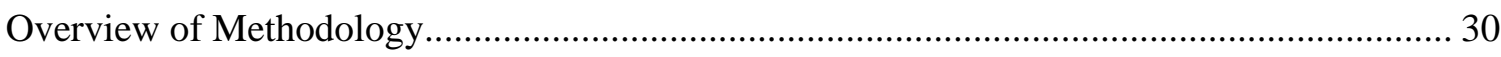

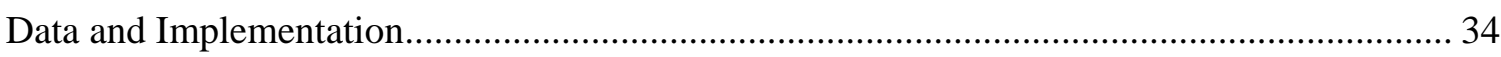

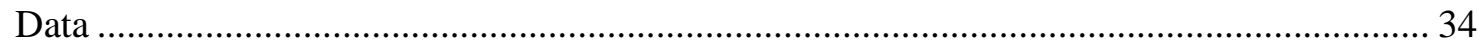

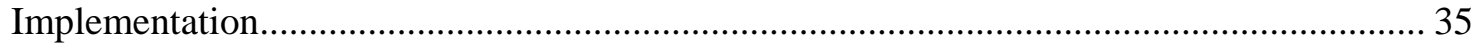

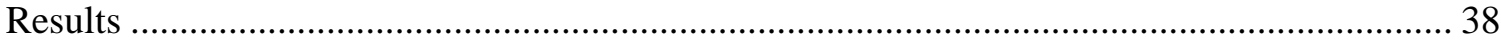

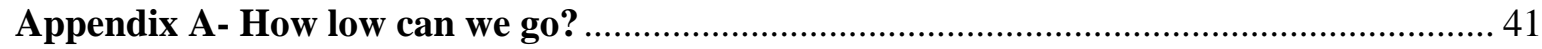

Appendix B - Comparing national average value and rayon level estimates...................... 45

Appendix C - Descriptive statistics of selected common indicators and models for the

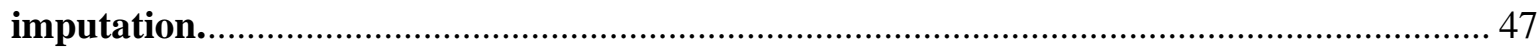

Technical Note 2: Creating a poverty map using the Asset index method ......................... 57

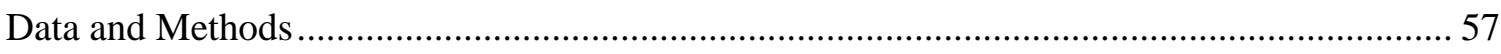

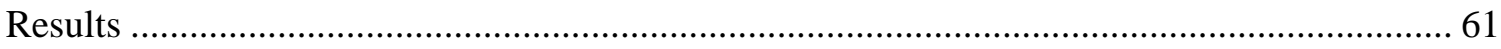

Appendix A: Constructing separate asset indices for urban and rural areas..................... 65

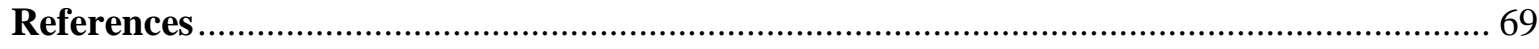

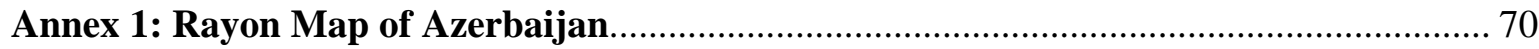




\title{
CREATING A POVERTY MAP FOR AZERBAIJAN
}

\begin{abstract}
'Poverty maps', that is graphic representations of spatially disaggregated estimates of welfare, are being increasingly used to geographically target scare resources. The development of detailed poverty maps in many low resource settings is, however, hampered due to data constraints. Data on income or consumption are often unavailable and, where they are, direct survey estimates for small areas are likely to yield unacceptably large standard errors due to limited sample sizes. Census data offer the required level of coverage but do not generally contain the appropriate information. This has led to the development of a range of alternative methods aimed either at combining survey data with unit record data from the Census to produce estimates of income or expenditure for small areas or at developing alternative welfare rankings, such as asset indices, using existing Census data. This report develops a set of poverty maps for Azerbaijan which can be used by different users. Two alternative approaches to the measurement and mapping of welfare are adopted. First a map is derived using imputed household consumption. This involves combining information from the 2002 Household Budget Survey (HBS) with 1999 Census data. Secondly an alternative map is constructed using an asset index based on data from the 1999 Census to produce estimates of welfare at the rayon level. This provides a unique opportunity to compare the welfare rankings obtained at the regional level under the two alternative approaches. In order to visually present the spatially disgaggregated estimates of welfare in Azerbaijan, this project has also involved the production of a digital census map of Azerbaijan. This involved matching the Census enumeration areas to a digital settlement map of Azerbaijan. An important externality of the research is that is now possible for the State Statistical Committee of Azerbaijan to display graphically the results of the 1999 Census of Azerbaijan along with other data.
\end{abstract}




\section{CREATING A POVERTY MAP FOR AZERBAIJAN}

\section{Introduction}

'Poverty maps', that is graphic representations of spatially disaggregated estimates of welfare, are being increasingly used to geographically target scare resources (Bigman and Deichmann 2002). There is also growing recognition that location itself is an important determinant of welfare, with the local agro-ecological resource endowment, access to input and output markets, and availability of educational and health facilities all influencing the well being of households. Conversely, household welfare may also have an important effect on the locality, for example local levels of consumer demand, patterns of cropping and deforestation. The development of detailed poverty maps in many settings is, however, hampered due to data constraints. Data on income or consumption are often unavailable and, where they are, direct survey estimates for small areas are likely to yield unacceptably large standard errors due to limited sample sizes. Census data offer the required level of coverage but do not generally contain the appropriate information. This has led to the development of a range of alternative methods aimed either at combining survey data with unit record data from the Census to produce estimates of income or expenditure for small areas or at developing alternative welfare rankings, such as asset indices, using existing census data ${ }^{2}$.

This study aims to develop a set of poverty maps for Azerbaijan which can be used by different users. Two alternative approaches are adopted. Firstly, a map is derived using imputed household consumption, combining information from the 2002 Household Budget Survey (HBS) with 1999 Census data (Section 2). Secondly an alternative map is constructed using an asset index based on data from the 1999 Census to produce reliable estimates of welfare at the district

\footnotetext{
${ }^{2}$ http://www.worldbank.org/poverty/health/wbact/health_eq_tn04.pdf. See also http://www.healthsystemsrc.org/publications/Issues_papers/Measuring healthpoverty.pdf
} 
(rayon) level (Section 3). This provides a unique opportunity to compare the welfare rankings obtained at the district and administrative level under the two approaches (Section 4). Furthermore, census enumeration areas have been matched with a digital settlement map of Azerbaijan, producing a digital census map which it is linked to the 1999 census enumeration areas (see Section 5 for details).

\section{Creating a poverty map using the 'imputed welfare' method}

Individual and household welfare can be measured in many ways. Conventionally economists argue that individual's material welfare is best measured by their consumption. The main source of information on consumption in Azerbaijan is the Household Budget Survey (HBS). However, the HBS only provides statistically reliable spatial estimates of welfare at the regional (oblast) level, separately for urban and rural areas. The census, which can provide more disaggregated data, does not contain any information on consumption. The first method applied to derived a poverty map for Azerbaijan is therefore based on a statistical procedure developed by Elbers et al. (2002) that combines household survey data with population census data. This technique uses the strength of both the detailed information about living standards available in the household budget survey and the more extensive coverage of a census to derived spatially disaggregated poverty estimates based on a consumption indicator of welfare.

For the implementation of this technique we combine the AHBS 2002 survey, which covers 8,157 households and 33,000 individuals, and the 1999 Census which covers around 1.7 million households containing around 8 million individuals. Administratively Azerbaijan has 9 economic regions (oblast), 73 districts (rayons) and around 1,000 administrative units. For the census data collection, the State Statistical Committee considered around 4,500 enumeration areas. Each administrative unit comprises 3-5 enumeration areas. The AHBS 2002 has been 
linked to the census at the enumeration area level. The present analysis is limited to 65 rayons, as it was not possible to include the rayons in the occupied zone.

\subsection{The imputation process in brief}

HBS data are used to estimate a prediction model for consumption, employing a set of explanatory variables which are common to both the survey and the census. The parameters from this model are then applied to census data to derive an imputed value for consumption. This then allows us to derive a set of welfare indicators based upon consumption, such as headcount poverty. Finally, these welfare indicators are constructed for geographically defined subgroups of the population.

The procedure is implemented in three stages. In the first stage we select a set of variables common to the survey and the census. The choice of variables is informed by the comparability of the question wording between the census and HBS questionnaires. Only where it is clear that their 'meaning' is the same in the two data sources are variables selected. The choice is further refined by then comparing the distribution of the variable in the two sources and restricted to only those variables where there is no significant difference in the average (mean) value between the two. Only those variables which are found to be comparable on both these counts are then considered in the second stage.

In the second stage, using the HBS and the variables selected in the first stage, we derive a model for predicting the household consumption. In the final stage, the model of consumption derived in the second stage is applied to the census data set (see Technical Note 1 for a detailed description of this methodology).

One of the key assumptions of this technique is that the census and the survey represent the same population. For this reason it is important to choose a household budget survey which is collected around the year of the census data collection. 
The State Statistical Committee (SSC) of Azerbaijan has carried out a regular household budget survey since independence in 1991. However, the survey design which it inherited from the Soviet period did not allow it to supply reliable data on living standards. Since 1999 the SSC, in collaboration with a group of international technical experts, has been working on improving the HBS design in order to produce nationally representative data (Marnie, Lapins and Zaidi 2001). In designing the new survey, the team has attempted to rectify the faults of the old HBS, while limiting the additional human and financial resources required, since the survey has to be sustainable for the future. The 2001 Household Budget Survey was the first year of a newly designed survey. During the first year the SSC received technical assistance both from the World Bank and the Asian Development Bank (ADB) to further improve the methodology (SPPRED 2004). As a result of this further collaboration the way in which information on consumption expenditure was collected changed, and as a result the values of consumption obtained from the 2001 and 2002 surveys are not comparable. The 2002 Household Budget Survey is now considered as the baseline for future poverty monitoring (SPPRED 2004). We therefore use the 2002 HBS for our imputation in the census ${ }^{3}$.

However, using the 2002 HBS creates a series of problems for the practical implementation of this methodology due to the fact that between the year of census data collection (1999) and the 2002 HBS, Azerbaijan has experienced a sharp drop in fertility levels with the Total Fertility Rate (TFR) decreasing from around 2 children in 1999 to 1.8 children per women in 2001 (UNICEF 2003). For this reason we have had to modify our measure of

\footnotetext{
${ }^{3}$ The World Bank is currently undertaking a Programmatic Poverty Assessment in Azerbaijan. The Azerbaijan Programmatic Poverty Assessment is a three-year program comprising technical assistance, capacity building and analytical work to be carried out jointly with Azeri counterparts. The technical assistance includes consultations on modifying the methodology for the consumption aggregate estimates and poverty line calculations. Potential changes include adjustments for differences in food prices, the usage cost (rental value) of durable goods, and exclusion of health expenditure. Such adjustments are unlikely to be evenly distributed across deciles suggesting that they would lead to a different welfare ranking. No formal agreement on revising the consumption aggregate had been reached when undertaking the poverty mapping study, which therefore relies on the welfare aggregate used by the SPPRED (2004). This consumption includes nominal expenditures on food, durables, health, and rent for housing.
} 
consumption. Instead of using a per capita monthly consumption measure, we use adult equivalence expenditure and employ an equivalence scale which gives a low weight to young children. This minimizes the impact of the drop in the number of young children in the household between the census and the time of the 2002 HBS. It is important to note that there are a number of alternative equivalence scales in use in Azerbaijan and that the choice here does not reflect any preferred measure but is simply designed to ameliorate the influence effect of recent fertility decline.

Two indicators of community welfare are computed: i) mean adult equivalent monthly consumption of the region - giving an indication of the average level of living standards the population of the region enjoys; and ii) the proportion of individuals living in poverty, where poverty is defined as living in a household with consumption in the bottom two quintiles of the population (i.e. with adult equivalent incomes below the $40^{\text {th }}$ percentile or $215,235.2$ Manat per month). This gives a measure of relative poverty.

The 'imputed welfare’ poverty mapping procedure produces estimates of welfare at the rayon, administrative level and enumeration area. However, the estimates are only considered to be reliable for areas containing more than 1,000 households. Estimates at both the rayon level and administrative level could be potentially useful for geographical targeting; however there are some issues regarding the reliability of those estimates for purpose of geographical targeting in the special case of Azerbaijan. These issues are discussed in Section 2.2. Section 2.3 then shows the results at rayon level, whilst results at the administrative level are presented in Section 2.4.

One further issue which need to be adressed is whether the imputed welfare map refers to the time of collection of the survey data (2002) or the time of collection of the census (1999). A key assumption of the imputation procedure is that the two datasets refer to the same population and implicitly the same point in time, which is clearly not the case here. In determining which year the poverty map refers to, there are two aspects of the inputation procedure which deserve 
consideration. The variation in consumption observed in the poverty map reflects variations in the household characteristics as observed in the 1999 Census, and so from this perspective, the poverty map might be seen as referring to the Census year. On the other hand, the parameter estimates for the prediction model of the welfare are based on the household characteristics observed in the 2002 survey. Given that the "zero" stage exercise ensured that only variables with the same meaning and distribution across the two datasets were selected for the regression, it made be inferred that the procedure is imputing 2002 consumption into the 1999 census. Thus the map can be argued to be presenting a picture of the 2002 spatial distribution of poverty. In reality the map presents a picture of poverty in neither 1999 or 2002. During the period between1999 and 2002 there has been both a reduction in fertility, which in turn has had an impact on household size and composition, and extensive internal and external migration. Hence both the imputed welfare regression (which comes form the household budget) and the spatial distribution of the population (which comes from the census) are likely to have changed between the two years. Thus it is best to interpret the map as providing a guide to the spatial distribution of welfare at the end of the twentieth century i.e. over the period 1999-2002. 


\subsection{A cautionary note: issues regarding the reliability of poverty estimates for geographical targeting in Azerbaijan}

As discussed above, the imputation of the welfare estimates in the census relies upon parameters derived from the 2002 Household Budget Survey. The new sample design that was fully implemented in the 2002 survey has several characteristics which have the potential to affect the reliability of spatially disaggregated estimates of welfare. Amongst the most important of these are issues related to the choice of Primary Sampling Units (PSU) and the allocation of the households to a specific interview area of fieldwork.

The sample design of the HBS of Azerbaijan selects 84 PSU from master sampling frame of 484 PSU, each of which are based on areas with a population size of about 15,000. Taking such large areas as a PSU has the potential of jeopardising the selection of a random sample of the population which forms the basis for the design of a nationally representative survey, and can potentially affect the reliability of the spatially disaggregated estimates of welfare.

Furthermore, with the redesigning of the new survey, the SSC has increased the number of interviewers from 64 to 84 . Each interviewer has been assigned one of the 84 selected PSU for the survey data collection. This has the potential of creating an 'interviewer effect' in the collection of the data as each interviewer will tend to interpret the questionnaire and collect the data in his or her own 'personal' way. As each interviewer works exclusively in one location, it is not possible to separate out the effect of the interviewer from the impact of the location itself. Unfortunately, it is not possible to estimate the size of the error due to the interviewer effect and thus to statistically account for this specific sort of error associated with the disaggregated estimates.

In the light of these shortcomings, it is suggested to interpret results with caution and not to exclusively rely on poverty maps for geographical targeting. Rather, they should be used with caution and together with other targeting approaches. We will graphically present the results at 
rayon level and administrative level. However the results at the administrative level are only presented for areas which contain sufficiently large numbers of households to be reliable. We will then only use the administrative level results which turn out to be 'statistically significant' from the point of view of the model when we compare those results with the asset index method (see Section 4). 


\subsection{Results at rayon level}

The 2002 Household Budget Survey allows spatial analysis of poverty only at oblast (economic region) level with urban and rural breakdown. According to the annual report of Azerbaijan's progress toward the MDGs (SPPRED 2004), poverty rates (using the monthly per capita consumption measure of welfare) are higher in urban areas compared to rural areas, the highest poverty incidence being found in Nakhchivan AR. Poverty in the Shaki-Zagatala region is close to the average level and poverty in large cities is noticeably less than in smaller towns.

Our findings confirmed those results and previous findings from the recent Azerbaijan Poverty Assessment (Dowsett-Coirolo 2003). However, comparing the regional poverty measures from the AHBS 2002 and the estimates of welfare obtained from the census, we also find marked geographical variation in poverty rates at the rayon level within each major region, as well as at administrative areas within rayons.

Figures 1 and 2 show the proportion of people below the poverty line (taken as the 40th percentile of the national distribution) in rural and urban areas. If there was no spatial variation in poverty, we would expect 40 percent of each area to be poor. Several findings stand out. First, there is a higher incidence of poverty in urban areas as compared to rural areas. Second, urban areas also show a higher degree of spatial variation in headcount poverty. Headcount poverty shows an homogeneous picture for the rural population with headcount poverty ranging around 30 to 40 per cent in most regions except higher level in rural Nakhchyvan AR and to a lesser extent in rural areas of Ganja-Gazakh and Absheron-Guba. However, headcount poverty measures in urban areas show a strong spatial heterogeneity ranging from 20 to 60 per cent. Headcount poverty is well below average in urban areas of Jalilabad , Hajigabul, Gusar , Uiar and Dashkasan rayons and poverty levels are well above average in urban areas of Fuzuli, Khyzy, Aghstafa and Gazakh rayons with the more than half of the urban population below the 
poverty line of 40 per cent of the lowest quintile (see Figures 1 and 2). A map showing the names of each rayon is presented in Annex 1.

Figure 1: Poverty rates in rural areas (poverty line: $40^{\text {th }}$ percentile $(215,235.2$ Manat))

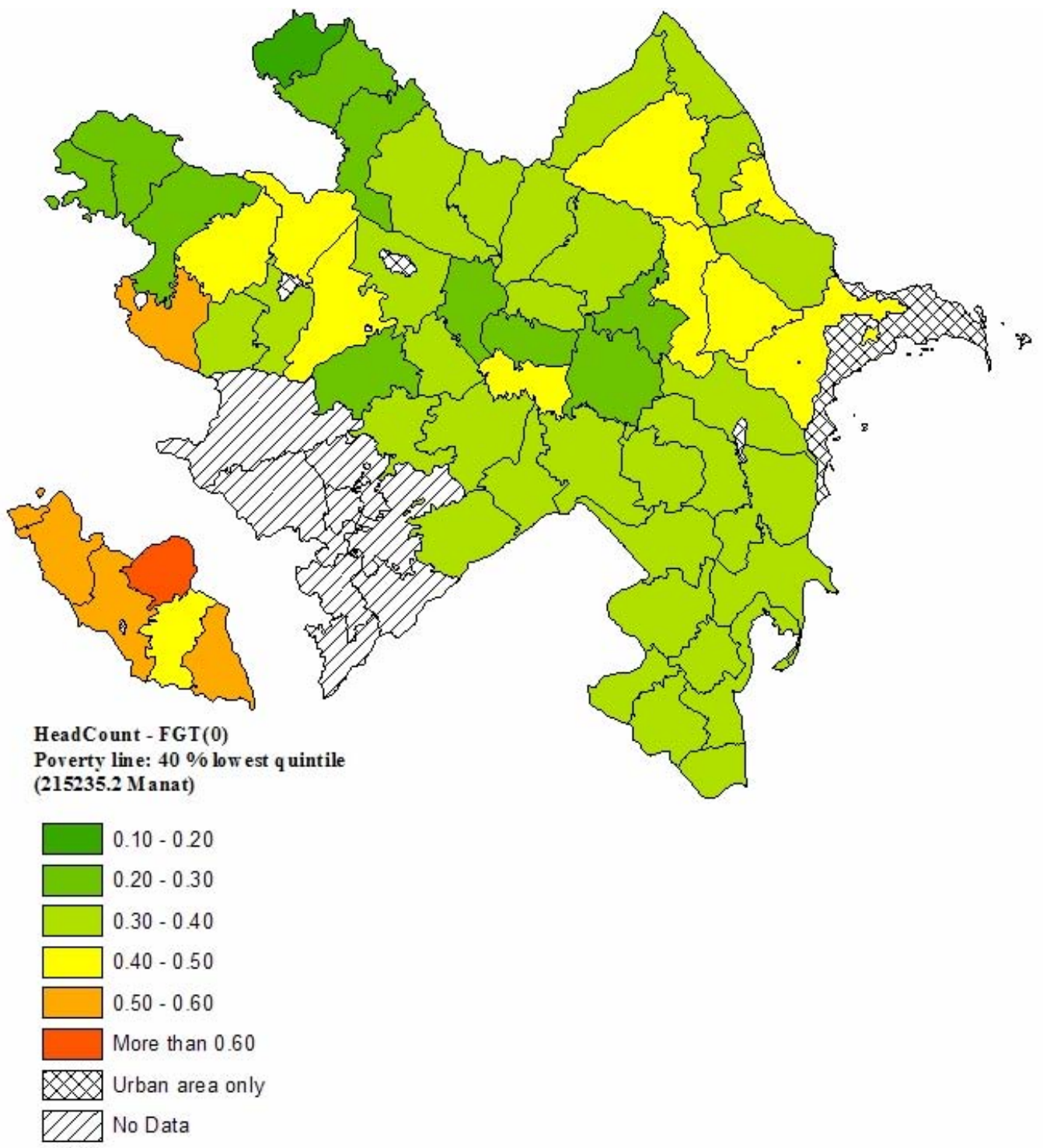


Figure 2: Poverty rates in urban areas (poverty line: $40^{\text {th }}$ percentile $(215,235.2$ Manat))

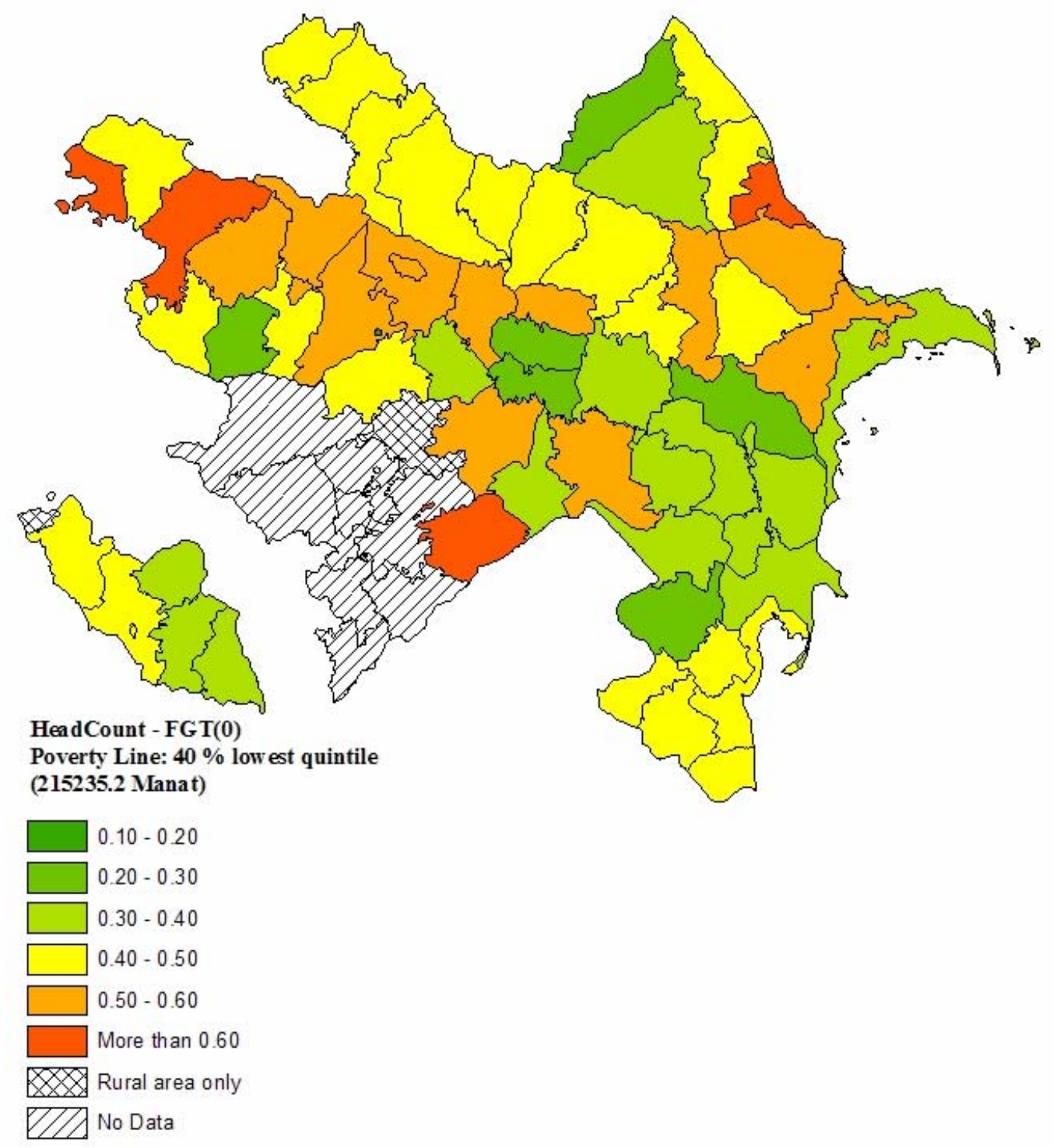

Poverty rates are a function of both the level and distribution of consumption. Higher values of average adult equivalent consumption are recorded in rural areas than in urban areas (Figures 3 and 4). This is despite the fact that rural households are, on average, larger than urban ones. This may be explained in part by the equivalent scale used, which gives a lower weighting to children than adults, resulting in higher average equivalent consumption in households with many children than that given by a simple per capita measure. Alternatively, it may be that this is a function of the way in which the value of consumption of home production was imputed, in 
particular the prices used ${ }^{4}$. Thirdly, the difference may reflect real urban-rural differentials in welfare. Such urban-rural differences are worthy of further investigation.

Figure 3: Average Monthly Consumption per Adult Equivalent in Manat, rural area.

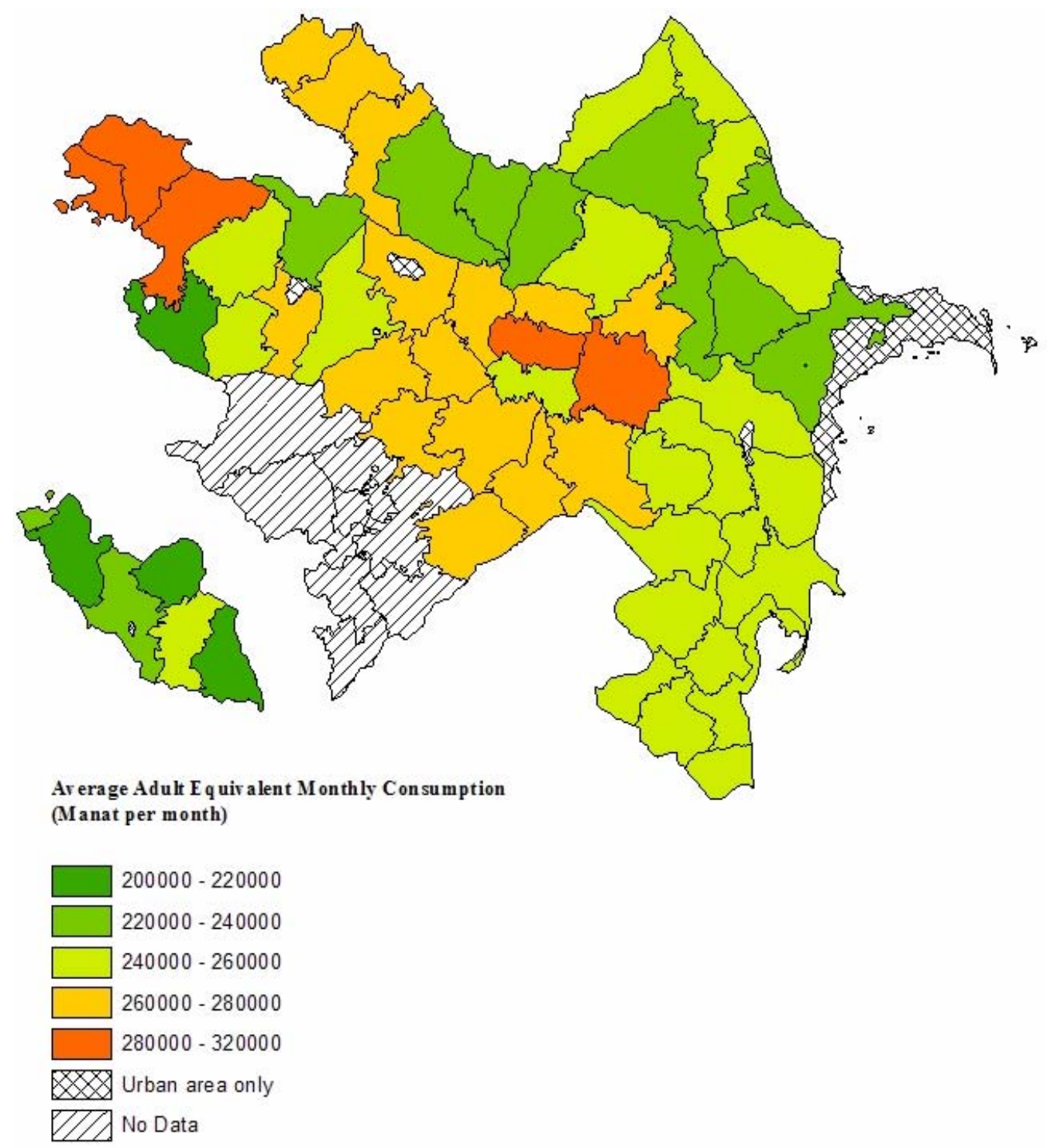

\footnotetext{
${ }^{4}$ This study employed the derived total household consumption variable created by the Azeri State Statistical Committee and used in the recent World Bank Poverty Assessment Update.
} 
Figure 4: Average Monthly Consumption per Adult Equivalent in Manat, urban area.

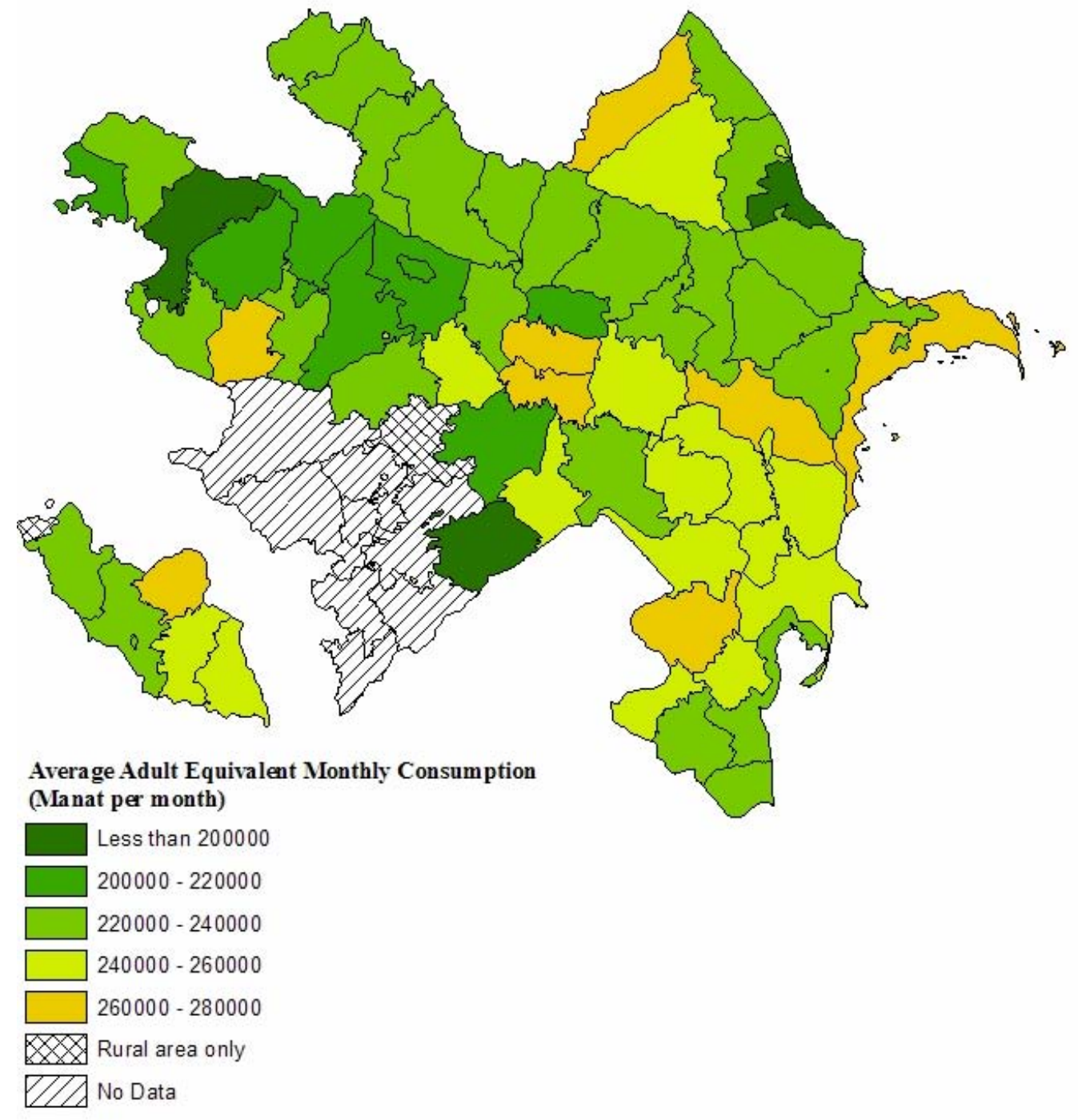

Once again, Figure 4 confirms substantial spatial variation in average levels of adult equivalent consumption across rayon within urban areas.

How reliable are these results at the rayon level? One of the key advantages of this technique is that as well as obtaining estimates of welfare, we can also derive standard errors associated with those estimates (See Technical Note 1 for further details). Further analysis of the estimates reliability (see Appendix A in Technical Note 1) suggest that rayon level estimates are fairly robust for estimates of mean adult equivalent consumption and headcount, with exception of estimates of headcount poverty within urban areas which need to be considered with more 
caution. However, overall more than two third of urban area rayon level estimates can be considered fairly reliable.

\subsection{Results at administrative level}

Moving below the rayon level, the standard errors become wider and the estimates of headcount poverty become unreliable. However the analysis suggests that the estimates of mean adult equivalent consumption remain fairly robust at the level of administrative districts, but not at the level of individual census enumeration areas. Although the results are available for all the administrative units for both urban and rural areas, we only visually plot the results for administrative units which contain at least 1000 households. Only a quarter of the administrative units in rural areas contain at least 1000 households, with an average of 5000 individuals. Urban administrative units tend to be much larger in size, and only a third are not sufficiently large. Currently there is no digital map of Azerbaijan showing boundaries at the administrative level. Thus in order to visually represent the results for administrative units for urban and rural areas we have created a map based on the centroid of the Thiessen polygons for each administrative area (see Section 5 for details about the Thiessen polygons map). We then created a buffer (which is a zone of a specific distance around a feature or point) of size proportional to the population size of each administrative polygons. We then assigned to each buffer the estimate of the adult equivalent consumption for each administrative unit. Thus the map does not represent the actual administrative boundaries, which are still under discussion by the Government. It does, however allow a visual representation of poverty at this lower level of geography.

Figure 5 and 6 show the mean adult equivalent consumption expenditure at administrative level, for urban and rural area respectively. Although the results for administrative units might not be as reliable as the rayon level estimates, there are nevertheless some mporatnt findings. In particular the results at administrative level suggest that there is a significant degree of variation 
of headcount poverty within rayons. Thus results at the rayon level may mask heterogeneity at the administrative level.

Figure 5: Average Monthly Consumption per Adult Equivalent in Manat, rural area.

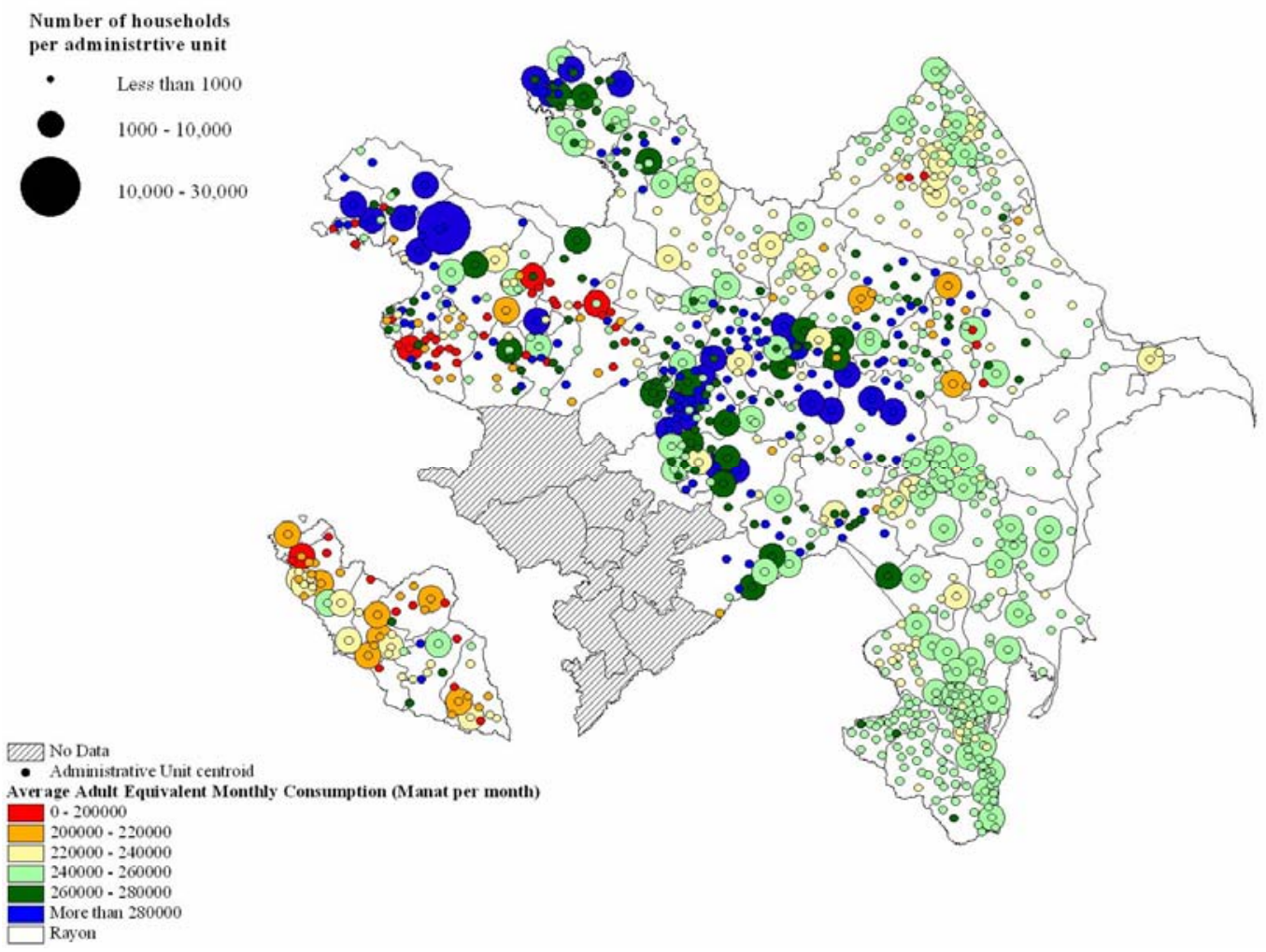


Figure 6: Average Monthly Consumption per Adult Equivalent in Manat, urban

area.

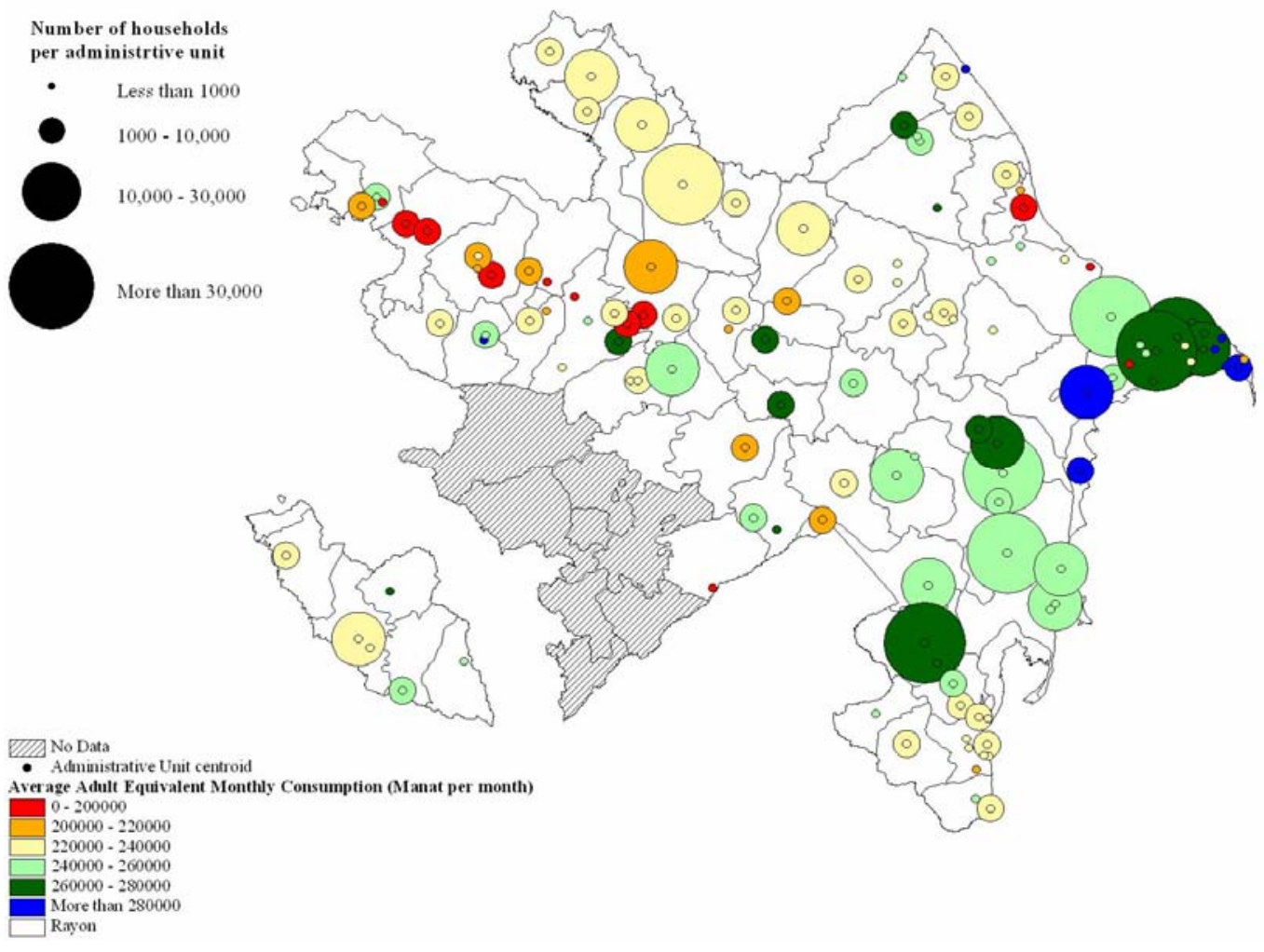




\section{Alternative measures of welfare - the asset index method}

Given the well known problems in measuring income and expenditure, increasing use is now being made of alternative wealth rankings based on the household ownership of assets, such as car, refrigerator or television, as well as characteristics of the household dwelling such as type of flooring materials, type of toilet and access to basic services including clean water and electricity. In order to create an index from the information on asset ownership it is necessary to aggregate the individual responses. A number of different techniques have been used. The simplest approach is to assign equal weights to the ownership of each asset or presence of each household dwelling. However, such a simple additive approach assumes the welfare value of each element is equivalent e.g. having a radio has the same welfare impact as having access to a flush toilet. As an alternative to simply calculating an index based on the sum of the assets, it is possible to use statistical techniques to determine the weights in the index. The two most common approaches for doing this are principal components analysis and factor analysis (Bollen, Glanville and Stecklov 2001; Gwatkin et al. 2000).

Using the 1999 census, we used information on household ownership of assets and characteristics of the household dwelling to create an index of welfare for Azerbaijan. The list of items included in the index is shown in Table 1 in Technical Note 2. It is important to note that with this technique the socio-economic status of the households is defined in terms of asset or wealth, rather than in terms of income and consumption (see Technical Note 2, for further details of the implementation of this method).

Figure 7 shows the spatial distribution of the proportion of people living in the poorest 40 percent of household ranked using the asset index method. 
Figure 7: Rayon map of the proportion of people living in the poorest 40 percent of households as ranked using an asset index, 1999 Azerbaijan Census

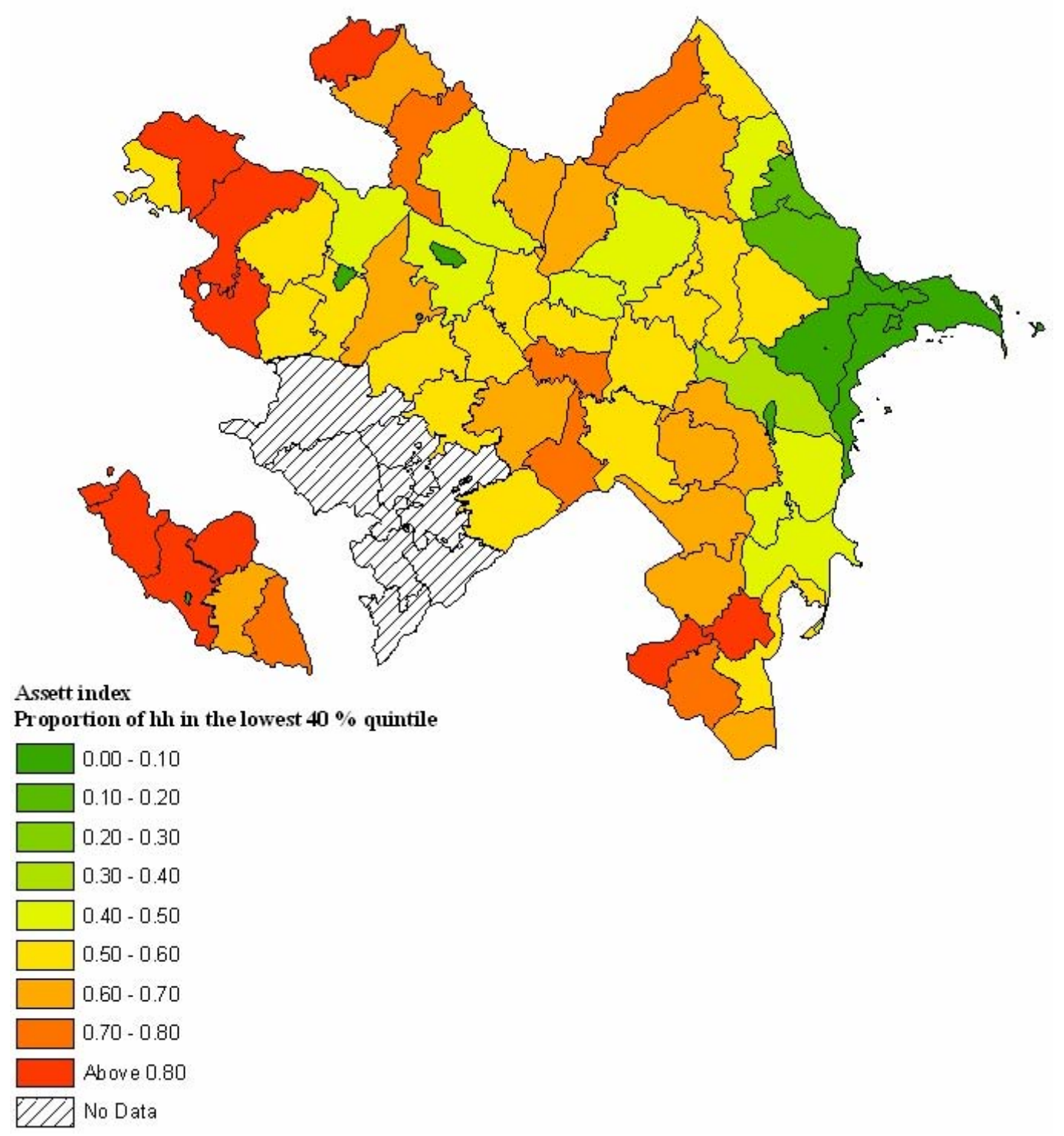




\section{Comparing alternative indicators of welfare at the spatial level}

As discussed above in recent years, growing attention has been given to derivation of alternative measures of household welfare. Expenditure and income data often suffer from a variety of measurement errors (Sahn and Stifel 2001), and are expensive to collect on regular basis. One practical alternative that has been growing in popularity is the use of data on the ownership of assets and dwelling characteristics to create an asset index.

Few studies have attempted to verify the extent to which the asset indicator being used is a good proxy for household consumption, the main reason being that such verification requires a data set that contains both metric measure of household consumption and the components of the asset index.

Montgomery et al. (2000) evaluated the performance of proxy measures in relation to consumption expenditures per adult, the latter being their preferred measure of living standards. They found that proxy variables were weak predicators of consumption per adult, with extremely low partial $\mathrm{R}^{2}$ values. However, in subsequent analyses of fertility, child schooling and mortality, the proxy-based coefficient estimates compared favourably to those obtained using consumption, providing a generally reliable guide to sign and magnitude of the preferred estimates. Sahn and Stifel (2001) also found the correlation of their asset with household expenditure to be weak.

In contrast Filmer and Pritchett (2001), who validated their asset index using data from the Indonesian, Pakistani and Nepalese LSMS, concluded that the asset index had 'reasonable coherence' with current consumption expenditures and worked 'as well or better, than traditional expenditure-based measures in predicting enrolment status'. They also note that their asset index is a better proxy for long-run household wealth than current per capita consumption. 
Bollen at al. (2001) examined the performance of several alternative proxies for economic status. They conclude that if researchers' focus is on economic status itself (as is the case when using proxies to identify the poor), then the choice of proxy can make a difference. If, however, attention lies on other variables with economic status being used as a control, then the noneconomic status variables are relatively robust to the choice of proxy.

This study has the unique opportunity to evaluate the ranking at a regional level, and administrative level using both an asset index derived using census data and imputed consumption. Using the urban and rural dummies used in the asset index, it is possible to construct separate maps for the proportion of household in the poorest 40 per cent quintile as ranked by the asset index (Figures 8 and 9). Those maps are directly comparable with the headcount FGT(0) using the Poverty line as the 40 per cent of lowest quintile (215,235.2 Manat per month) (Figures 1 and 2). From a simple comparison of the maps it is clear that that the two approaches produce significantly different rankings at the rayon level. 
Figure 8: Rayon map of the proportion of household in the poorest 40 percent quintile as ranked using an asset index, rural area, 1999 Azerbajian Census.

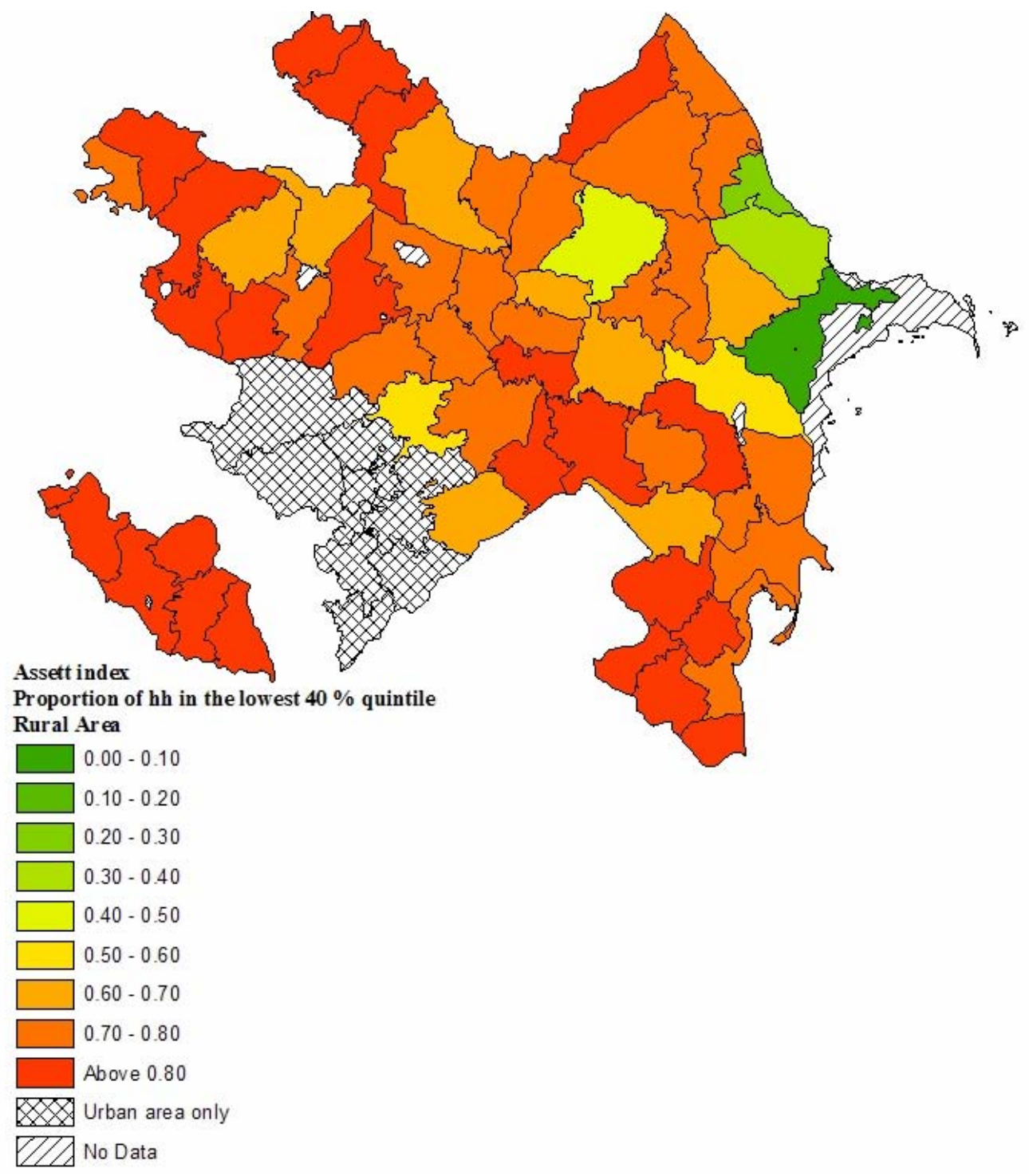


Figure 9: Rayon map of the proportion of household in the poorest 40 percent quintile as ranked using an asset index, urban area, 1999 Azerbajian Census.

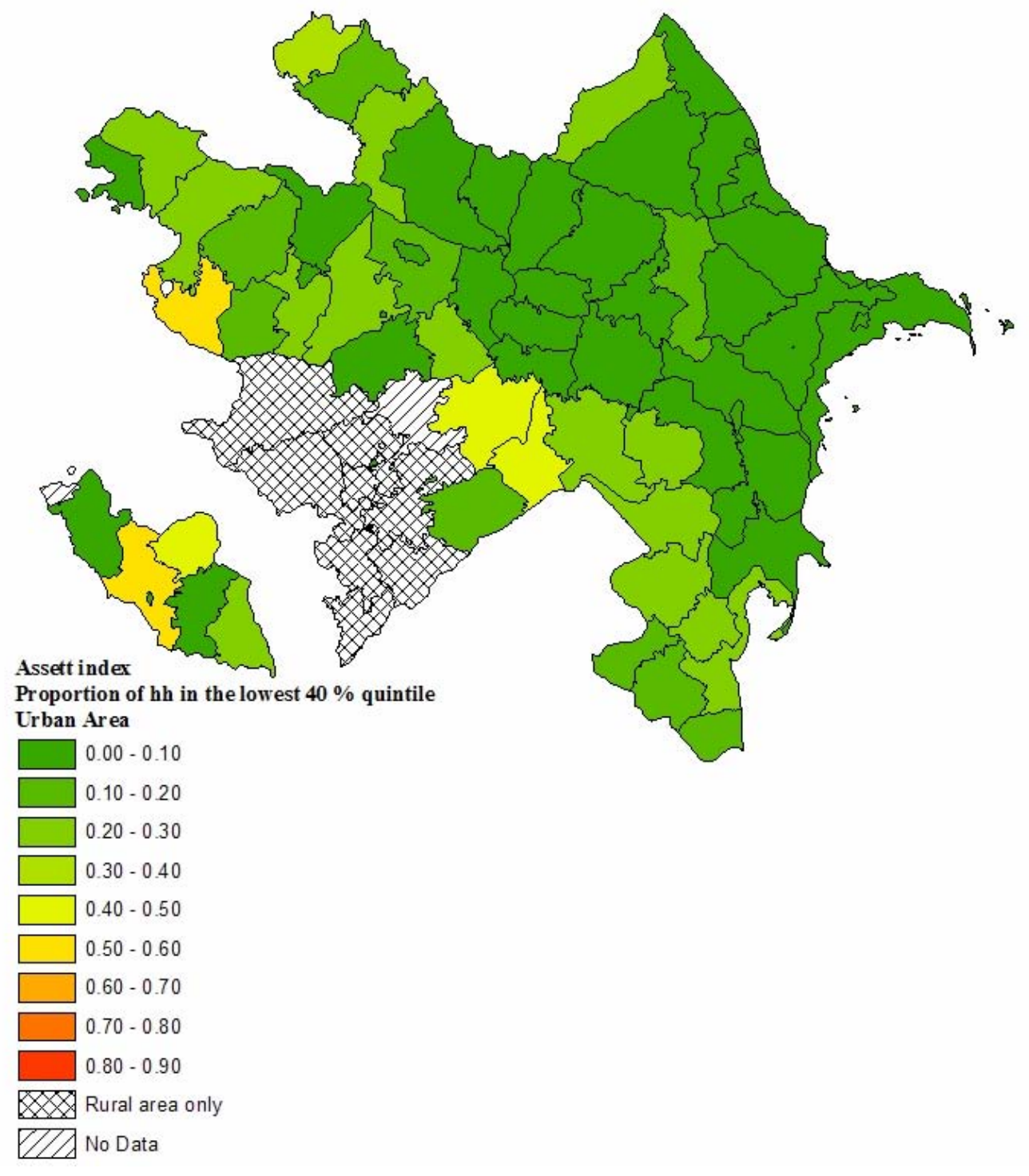

In order to investigate this further, Figures 10 and 11 present scatter diagrams of the welfare indicators at the rayon level by the two different methodologies, along with the spearman rank correlations. It is clear that there is no significant correlation between the welfare ranking by the two methods. This is especially true for rural areas, where it appears that the asset index does not reflect the same heterogeneity between regions that is captured by the imputed consumption. This is because many of the components of the asset index are directly related to rural-urban location. It may also be that patterns of ownership of assets and access to services 
reflect patterns of ownership and infrastructure development laid down during the soviet era. Given this is it not surprising that the asset index appears to be only weakly associated with current levels of consumption

Figure 10: Scatter plot of average adult equivalent consumption per month in Manat and factor score, rural rayon

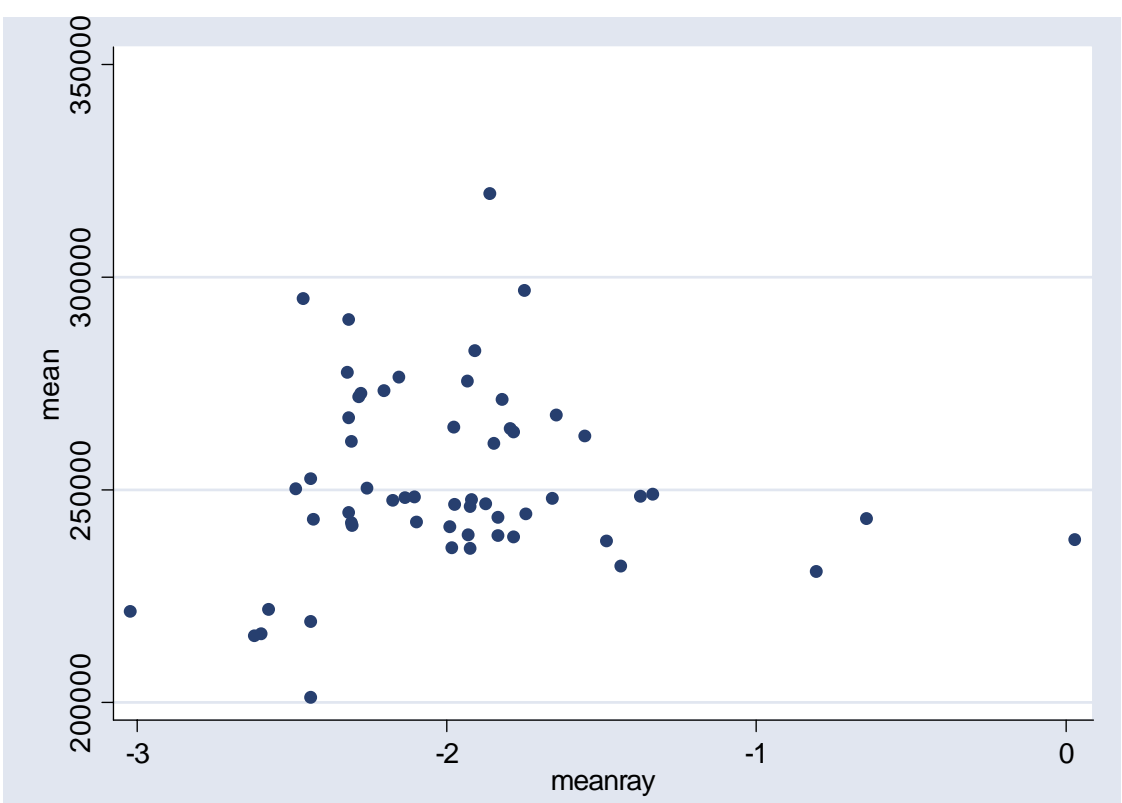

Note: Number of observation=56, Spearman's rho=0.044, Test of Ho: mean consumption and factor score are independent Prob>0.6343 
Figure 11: Scatter plot and average adult equivalent consumption per month in Manat and

\section{factor score, urban rayon}

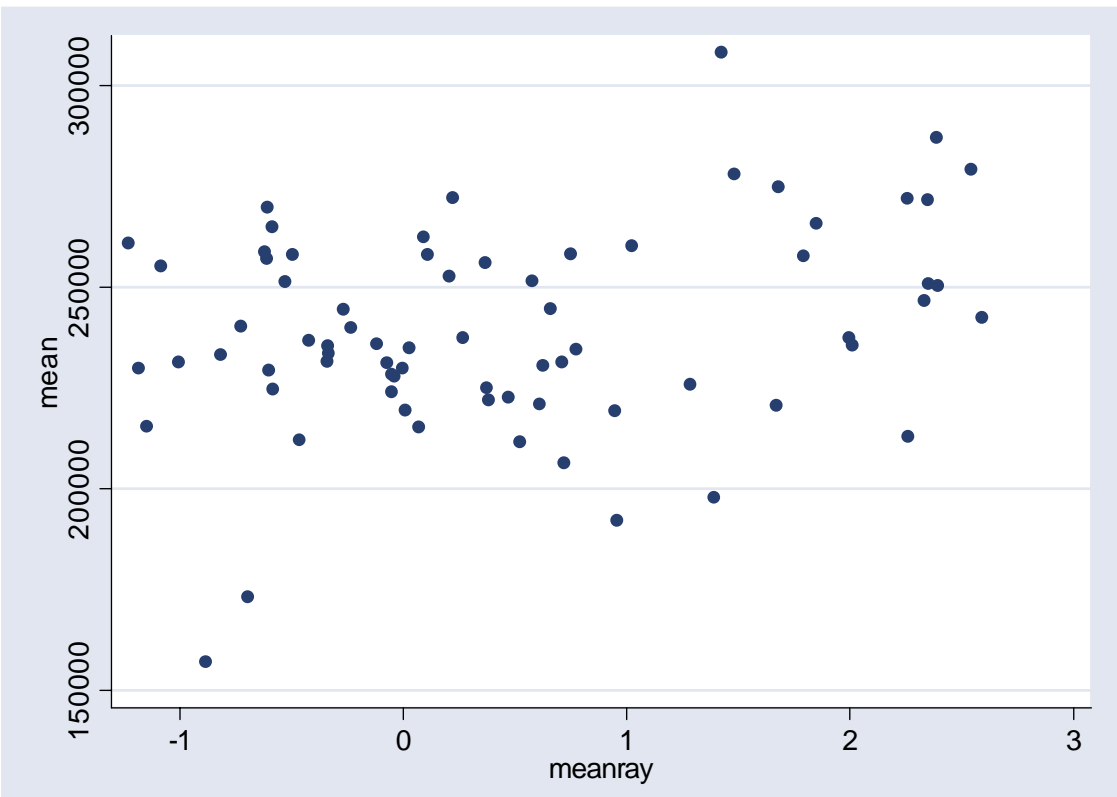

Note: Number of observation=73, Spearman's rho=0.2034, Test of Ho: mean consumption and factor score are independent Prob $>0.0843$

Figure 12 and 13 show the scatter diagrams for the welfare rankings at the administrative

level. The correlation coefficient is again low. The results indicate that an asset index may be a poor indicator of welfare in spatial poverty analysis in Azerbaijan ${ }^{5}$. These results, though, do not rule out the possibility that an asset based index might be a good welfare measure in other countries.

\footnotetext{
${ }^{5}$ Note that there are a number of alternative approaches to deriving a welfare ranking using asset indices. These are further discussed in Appendix A of Technical Note 2. Deriving separate asset indices for rural and urban areas change the correlation coefficients but do not affect that overall conclusions.
} 
Figure 12: Scatter plot and average adult equivalent consumption per month in

Manat and factor score, rural administrative units

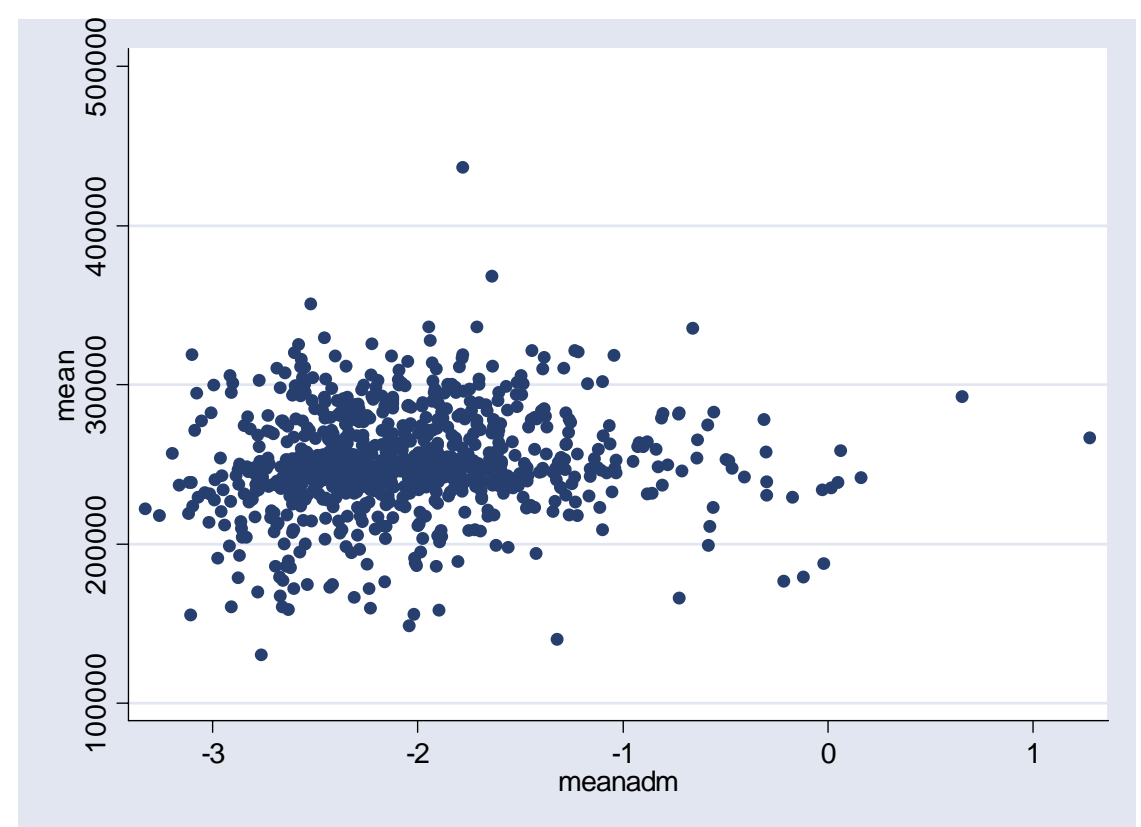

Note: Number of observation=876, Spearman's rho=0.132 ,

Figure 13: Scatter plot and average adult equivalent consumption per month in Manat and factor score, urban administrative units

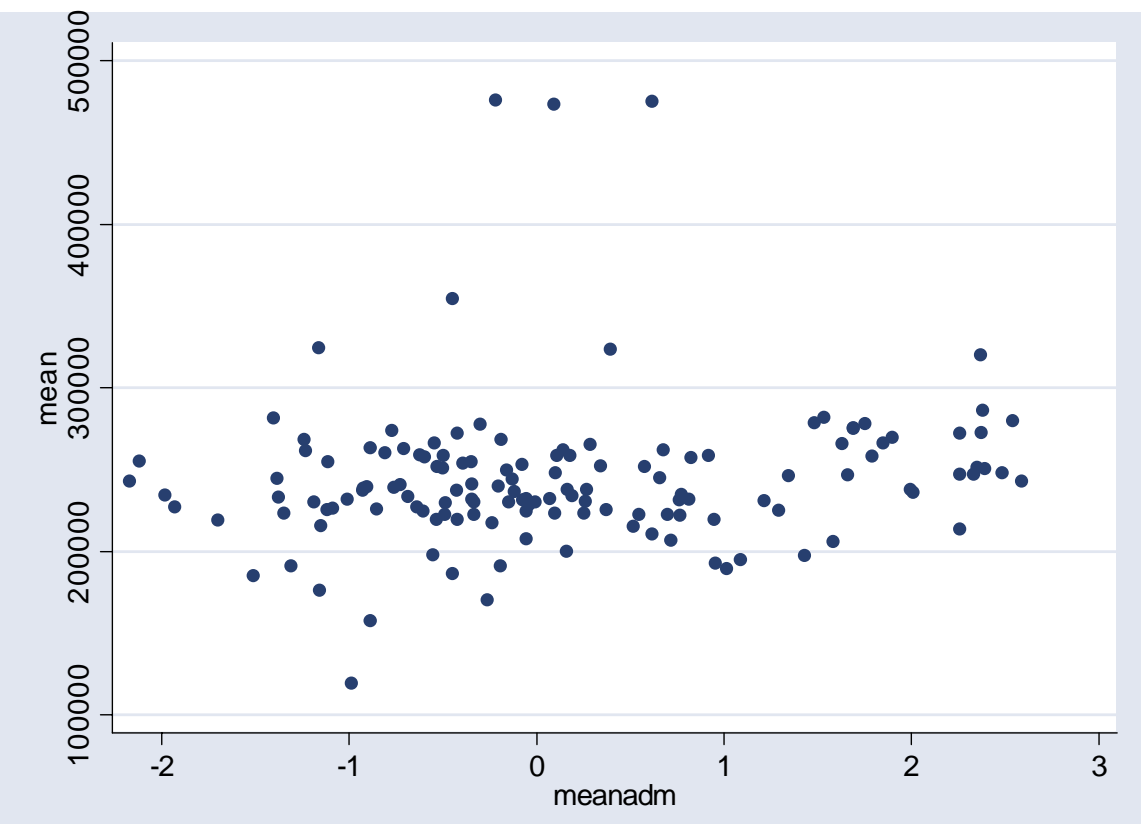

Note: Number of observation=140, Spearman's rho $=0.1752$ 


\section{Producing a digital census map of Azerbaijan}

In order to present the results visually it is necessary to have a digital map of Azerbaijan that reflects the enumeration areas used in the Census. Unfortunately no such map existed prior to the project and so the project team worked with the SCC to produce one. This involved taking a settlement map of Azerbaijan that graphically displays settlement location and size (see Figure 14). The State Statistical Committee of Azerbaijan then assigned an enumeration area code to each settlement. Although in theory each settlement should have matched with an enumeration area code, in the practical implementation of this exercise there has been some incongruity. However overall 98 per cent of all the census enumeration area have been matched and the map can be now be used by the SSC both for updating census listing for the 2009 Census and displaying the results of the 1999 Census.

\section{Figure 14: Settlement map of Azerbaijan}

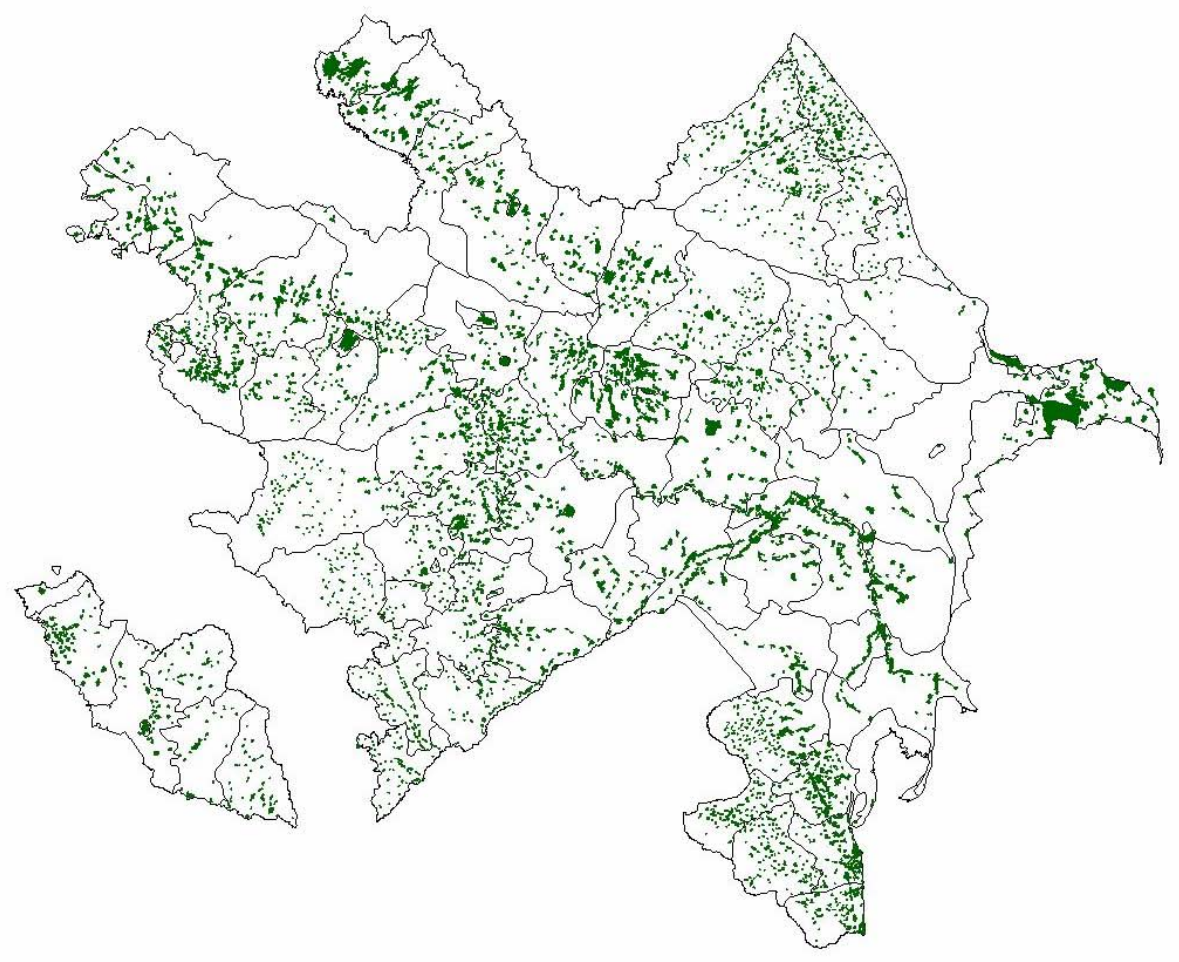


At the time of writing this report an up to date digital map showing the boundaries of the administrative units for Azerbaijan does not exist. This is mainly due to the fact that several administrative boundaries are under the process of approval from the government. To enable the SSC to plot the 1999 census results at administrative level, we use the digital settlement census map of Azerbaijan which takes into account the aggregation of a number of enumeration areas. Using the 'Thiessen Polygon' method, we then derived a notional boundary for the administrative units. Thus the 'administrative unit' here comprises of a group of settlements, one of which is the administrative centre. The boundaries derived with this method are not to be considered to be official boundaries but they can be used to visualize the results of the 1999 census of Azerbaijan (see Figure 15).

\section{Figure 15: 'Thiessen polygons' for administrative boundaries in rural areas}

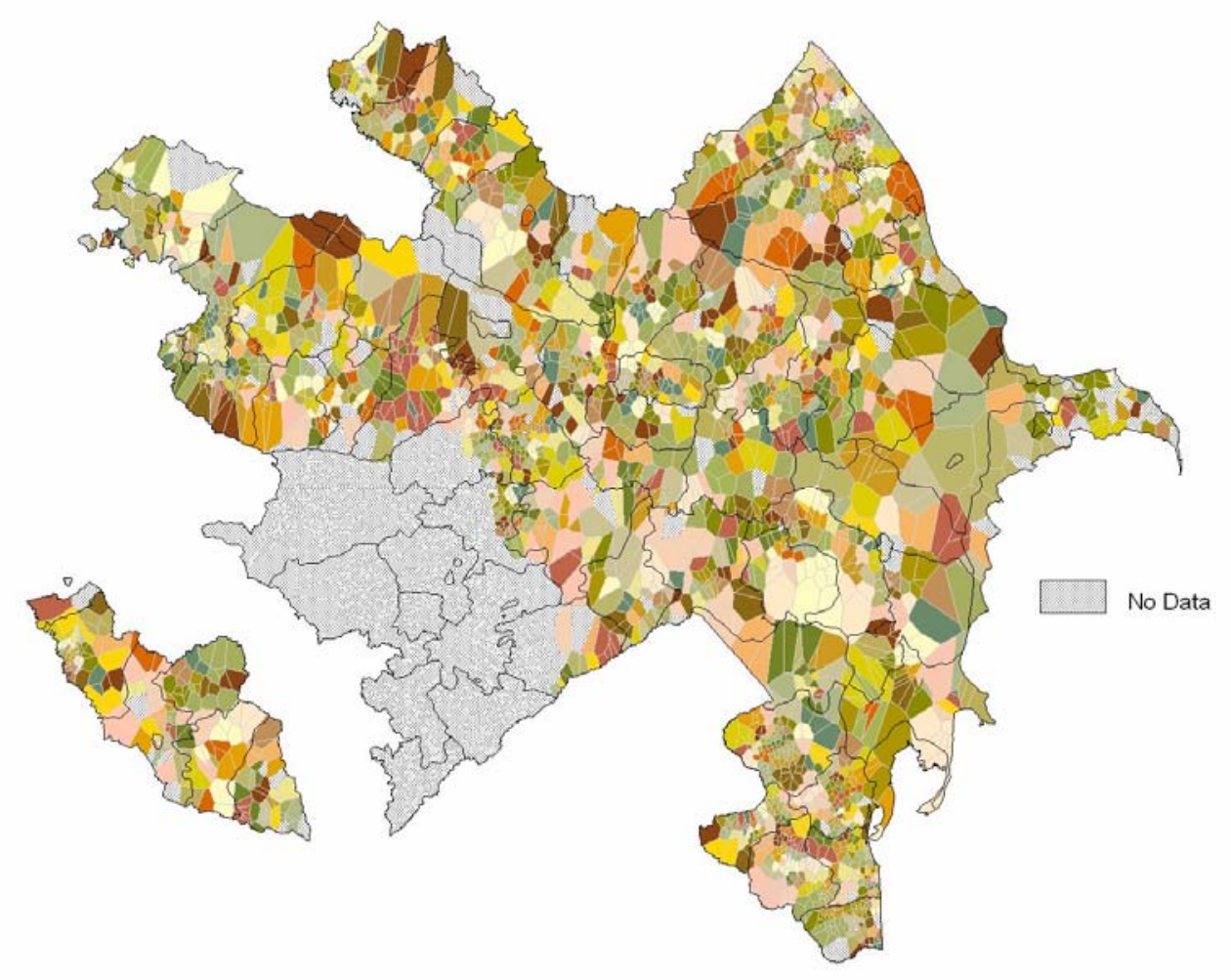




\section{Summary}

By combining information from the 2002 Household Budget Survey and the 1999 Census it is possible to produce spatially disaggregated estimates of welfare based on consumption at the sub-oblast level. The key findings are:

In general, there is a higher incidence of relative poverty in urban areas as compared to rural areas.

However, there is a high degree of variation in poverty across urban areas, with the proportion of the population living below the relative poverty line varying between 20 and 60 per cent.

The picture in rural areas is more homogeneous, with relative poverty rates in most rayons varying between 30 and 40 percent.

There is also a significant degree of variation within rayons, with some pockets of deprivation within more affluent areas.

Comparing the spatial estimates of welfare derived using consumption with those derived using an asset index highlights that the two measures are capturing different dimensions of welfare.

The asset index largely reflects patterns of ownership of household assets and access to services laid down during Soviet era and is not a good proxy for current levels of welfare in Azerbaijan.

It is important to note that the spatially disaggregated estimates of welfare presented here should be interpreted with caution. There remain problems in the HBS in Azerbaijan that are currently the focus of on-going collaborative work. However this paper presents a positive step forward in the analysis of poverty in Azerbaijan both by demonstrating that it is possible to produce statistically reliable estimates of poverty at the sub-rayon level and through the production of a digit map that will allow the visual representation of census results at the administrative level. 


\section{Technical Note 1: Creating a poverty map using the imputed consumption method}

\section{Poverty mapping using imputed welfare}

The 'imputed welfare’ poverty mapping technique developed by Elbers et al.(2002) uses the strength of both the detailed information about living standards available in the household budget survey and the more extensive coverage of a census to derive spatially disaggregated poverty estimates based on a consumption welfare indicator.

\section{Overview of Methodology}

Survey data are first used to estimate a prediction model for consumption and then the parameters are applied to census data to derive an imputed value for consumption, employing a set of explanatory variables which are common to the survey and the census. This allows defining a set of welfare indicators based on consumption such as headcount poverty. Finally, the welfare indicators are constructed for geographically defined subgroups of the population using these predictions.

Although the approach is conceptually simple, properly accounting for spatial autocorrelation in the first stage model and estimating standard errors for the welfare estimates requires additional elaboration. The method can be thought of as being divided into three stages. There is a commonly defined "zero stage", which involves the careful selection of a set of comparable variables common to both the survey and census (this stage is discussed further under implementation in section). The first stage of analysis then involves the use of survey data to derive a model for predicting household welfare. This model is then applied to the census dataset in the final stage. Stages one and two are further elaborated below. 


\section{First Stage}

In the "first stage" of analysis a model of consumption is developed using household survey data and those variables that have been selected in the zero stage. In previous application of this methodology the log of per capita consumption has commonly been used as dependent variable; in this application we modify the definition of the dependent variable and use the log of per adult equivalent consumption (see the implementation section for a detailed explanation).

The log of adult equivalent household consumption, $y_{c h}$ is related to a set of observable characteristics, $x_{c h}{ }^{6}$ :

$$
\ln y_{c h}=E\left[\ln y_{c h} \mid x_{c h}\right]+u_{c h}
$$

Using a linear approximation, we model the observed log per adult equivalent consumption per household h as:

$$
\ln y_{c h}=x_{c h}^{\prime} \beta+u_{c h}
$$

where $\beta$ is a vector of parameters, and $\mathbf{u}$ a vector of disturbances, distributed $F(0, \Sigma)$. The model (2) is estimated by Generalized Least Squares using data from the 2002 Azerbaijan household budget survey. In order to estimate by GLS model, it is first necessary to produce an estimate of $\sum$, the associated error covariance matrix. We model individual disturbances as:

$$
u_{c h}=\eta_{c}+\varepsilon_{c h}
$$

\footnotetext{
${ }^{6}$ This section summarizes the discussion in Elbers et al. (2002).
} 
where $\eta_{c}$ is a location component and $\varepsilon_{c h}$ is a household component. This error structure allows for both spatial autocorrelation, i.e. a "location effect" for households in the same area, and heteroskedasticity in the household component of the disturbance. The two components are independent of one another and uncorrelated with observable characteristics.

In order to estimate $\Sigma$, we need to calculate the variance of the location component $\hat{\sigma}_{\eta}^{2}$, the location component $\eta_{c}$, variance of the household residuals $\hat{\sigma}_{\varepsilon, c h}^{2}$ and household residuals $\left.\varepsilon_{c h}\right)^{7}$

To obtain those parameters we first estimated a OLS, and the residuals from this regression serve as estimates of overall disturbances, given by $\hat{u}_{c h}$. We decompose these into uncorrelated household and location components:

$$
\hat{u}_{c h}=\hat{\eta}_{c}+e_{c h}
$$

where $\hat{\eta}_{c}$ are the within-cluster means of the overall residuals, $e_{c h}$, household component estimates are the overall residuals net of location components.

The Elbers et al. (2002) procedure allows for heteroskedasticity in the household component. In the case of Azerbaijan, heteroskedasticity was found not to be a problem. Given this, we then decide to model only the location component where possible.

\footnotetext{
${ }^{7}$ See Appendix 2 of Elbers et al. (2002) for details.
} 


\section{Second Stage}

In the "second stage" the parameter estimates of the consumption model developed in the first stage are applied to data from the 1999 Census of Azerbaijan to obtain predicted consumption for each household within the Census.

We construct a series of simulations, where for each simulation $r$ we draw a set of first stage parameters from their corresponding distribution estimated in first stage.

Thus we draw a set of beta and, $\tilde{\beta}^{r}$ from the multivariate normal distributions described by the first stage point estimates and their associated variance-covariance matrices. Additionally we draw $\left(\tilde{\sigma}_{\eta}^{2}\right)^{r}$ a simulated value of the variance of the location error component.

For each household we draw simulated disturbance terms, $\tilde{\eta}_{c}^{r}$ and $\stackrel{\sim}{\mathcal{E}}_{c h}^{r}$, from their corresponding distribution. We simulate a value of expenditure for each household, $\hat{y}_{c h}^{r}$, based on both predicted log expenditure, $x_{c h}^{\prime} \tilde{\beta}^{r}$ and their disturbance terms:

$\hat{y}_{c h}^{r}=\exp \left(x_{c h}^{\prime} \tilde{\beta}^{r}+\tilde{\eta}_{c}^{r}+\tilde{\varepsilon}_{c h}^{r}\right)$. Finally, the full set of simulated per adult equivalent expenditures, $\hat{y}_{c h}^{r}$ are used to calculate the estimate of the welfare measure for each spatial subgroup. We repeat this procedure 100 times drawing a new $\tilde{\alpha}^{r}, \tilde{\beta}^{r},\left(\tilde{\sigma}_{\eta}^{2}\right)^{r}$ and disturbance terms for each simulation. For each subgroup, we take the mean and standard deviation of each welfare measure over 100 simulations. 
For any given location, these means constitute our point estimates of welfare measure, while the standard deviations are the standard errors of these estimates.

\section{Data and Implementation}

\section{$\underline{\text { Data }}$}

The technique combines data from the 2002 Azerbaijan Household Survey (AHBS 2002) and the 1999 Census collected by the State Statistical Committee of Azerbaijan Republic (Goskomstat). The Census covers around 1.7 million households containing 8 million individuals ${ }^{8}$. Administratively Azerbaijan has 9 economic regions, 73 rayon and 4,500 villages. Between village and rayon level there is an additional layer of administrative units, usually combining 3-5 villages together. It has been possible to combine the Census data and AHBS at the village level. The present analysis is limited to the 65 rayon, as it was not possible to include rayons in the occupied zone.

The AHBS 2002 survey covers 8,157 households and 33,000 individuals. The survey provides detailed information on a wide range of topics, including food consumption, non-food consumption, labour activities etc. The survey design incorporates stratification by region (economic zones and urban and rural strata). As has been previously mentioned in the main part of the paper, the HBS in its current format and sample design it is relatively new to the SSC. Since 1999 a group of international technical experts have been working on improving the HBS design in order to produce nationally representative data (Marnie et al. 2001). In designing the new survey, the team has attempted to rectify the faults of the old HBS, while limiting the additional human and financial resources required, since the survey has to be sustainable for the future. For these reasons the new HBS adopts a full quarterly rotation of households. The interviewers, instead of being involved in the collection of data from the same household over a

\footnotetext{
${ }^{8}$ We consider the present population as it has been the population considered for the sample design of the Household Budget
} 
year period, follow a group of households over a quarter and interview a new group of households at the beginning of each quarter. Each quarter around 2,000 households are selected; resulting in a total sample of 8,157 households in the 2002 AHBS.

Following the redesign of the HBS, the total number of permanent staff employed as interviewers has risen from 64 to 84 . The new design allows the selection of 84 territorial units (or Primary Sampling units), and a single interviewer is responsible for the conduct of all household interviews within a particular area. Unfortunately, the dependence upon a single interviewer has the potential to introduce an 'interviewer effect' that is impossible to isolate from other 'location effects'. This may be particularly significant for the production of spatially disaggregated statistics of the kind employed in this study.

\section{Implementation}

In the 'zero' stage we first carefully compare the questions of household budget and census to identify a set of variables that are common to both sources of data. These variables are then compared on a statistical basis by considering the mean values in the two dataset. This second type of checks is important as even when the survey and census questions are identically worded, subtle differences in the way the questions are asked, or different ordering of questions may cause the information content to differ between the survey and the census. Tables 1 and 2 in Appendix $C$ show the tabulation of the mean values in the HBS and the Census. Those variables for which the census mean was within the 95 confidence interval of the mean in the HBS were then selected for inclusion in the model.

In comparison of mean household size during this ‘zero' stage it became clear that Azerbaijan had experienced significant fluctuations in fertility during the three years between 1999 Census and 2002 HBS. The mean household size showed a decrease of almost one member per household and this trend was found across all regions. Following further investigation and 
discussion with SSC experts, it was determined that the dramatic fall in the number of births between 1999 and 2003 was in part an 'echo effect' of the sharp drop in fertility and high death rate during the Second World War. The low fertility and high death rates during WW2 resulted in a much smaller birth cohort during this period. The population pyramids for Azerbaijan have since been marked by a regular drop in the number of births from this cohort (and their offspring) in a 25 years cycle. The period between 1999 and 2002-3 coincided with the second 25 years cycle. As we can see from Figure 1, there has been a sharp decline in the Total Fertility Rate from 1999 to 2001.Comparison of household size and age structure between the census and the HBS revealed a systematic change in both size and age structure, with a significant drop in the number of young children in the household.

One of the key assumptions inherent in the poverty mapping procedure outlined by Elbers et al. (2002) is that the models estimated from the survey data apply to census observations. Given the sharp drop in fertility between the implementation of the 1999 Census and HBS 2002, it was decided to modify the dependent variable and to use adult equivalent monthly household consumption as the welfare indicator as opposed to the commonly used average per capita consumption (Elbers et al. 2003; Mistiaen et al. 2002). The equivalence scale used gives less weight to young children than other household members and so is less sensitive to changes in the numbers of young children compared to a more straightforward per capita measure ${ }^{9}$. This minimizes the impact of the drop in the number of young children in the household at the time of the 2002 HBS.

\footnotetext{
${ }^{9}$ Adult Equivalent: children aged below the age of six have been assigned a weight of 0.2 , children aged between 7 to 12 have been assigned a weight of 0.3 , children age 13 to 17 have been assigned a weight of 0.5 , and a weight of 1.0 if the household member is older than 17 years. The equivalence scale is designed to account for differences in 'need' due to age and sex. It does not however account for economies of scale of household size as each adult carries the same weight on 1.0. The World Bank's 2003 Poverty Profile for Azerbaijan undertaken within the Programmatic Poverty Assessment, proposes a different per adult-equivalent consumption measure that assumes a scale parameter of 0.8 and that the cost of a child (individuals of age 18 and below) is $70 \%$ of the cost of an adult. This study was completed earlier and therefore did not use this definition.
} 


\section{Figure 1: Total Fertility Rates in Azerbaijan, 1996-2001}

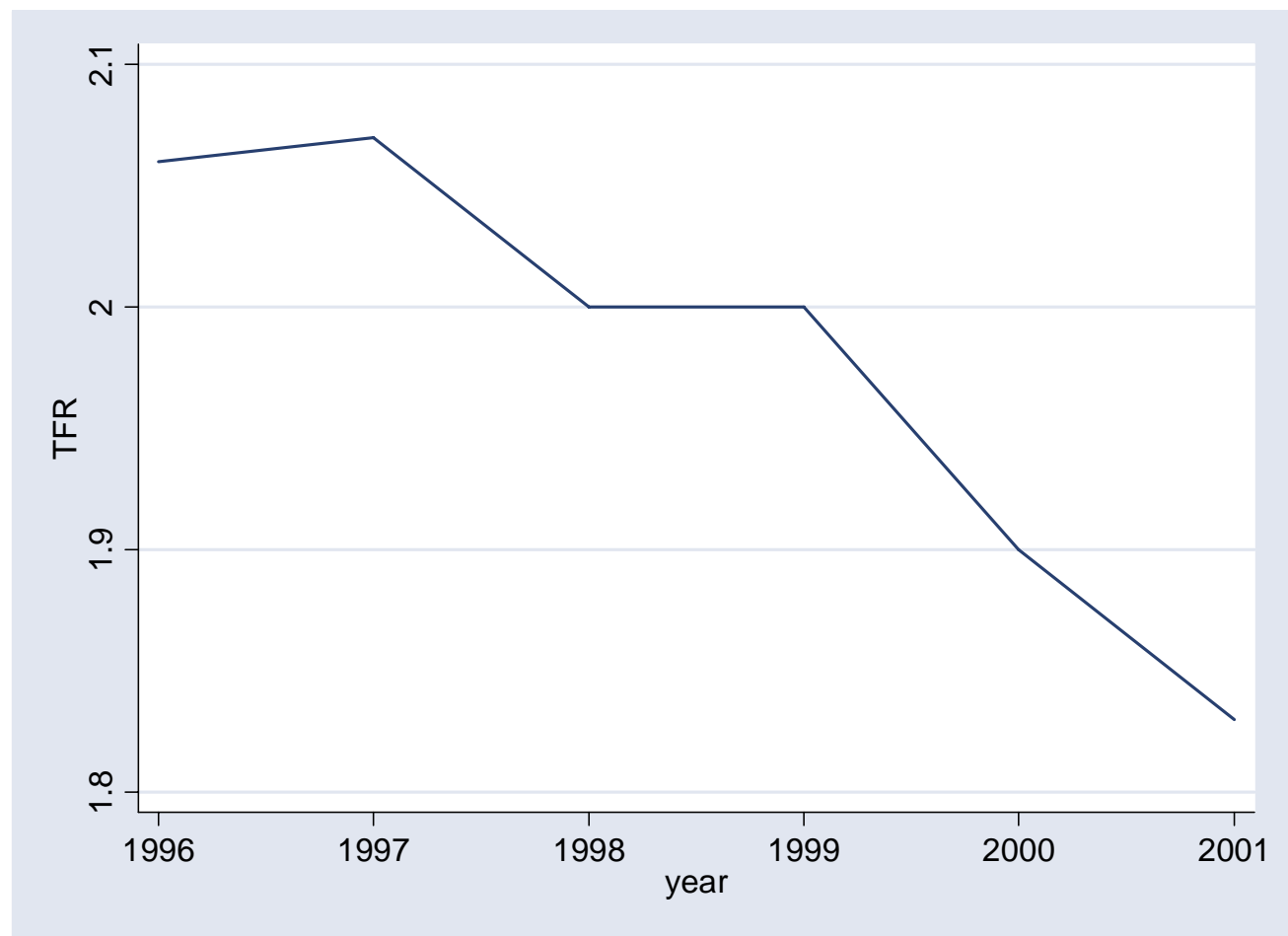

Source: Unicef (2003) Transmonee Project, Social Monitor 2003, Table 2.9 page 62

The consumption model was derived using only independent variables that were similar in both wording and distribution in both data sets. In some strata, where the selected variables on the strict test of comparability did not yield a reasonable high R square, the criteria for selection of the regression variables were relaxed ${ }^{10}$. A set of three dummies for the quarter in which the household has been interviewed, was included to control for fluctuations in household consumption due to the different quarter of the year ${ }^{11}$. The final specification included only those variable that were significant at least at 90 per cent level and the quarterly dummy variables.

Following this, a set of census means at the village level were then merged with the HBS data. The location residuals were then regressed on a set of census means at village level. A selection criteria of significance at $95 \%$ was applied, along with a ceiling for the maximum number of census means. Following the inclusion of these additional variables the OLS

\footnotetext{
${ }^{10}$ In few cases we selected variable that were within two standard deviation from the mean value in the census.

${ }^{11}$ When we proceed for the imputation in the census we construct three variables with the value of 0.25.
} 
regression was re-estimated in order to reduce the size of the location effect. These regression models and the relevant diagnostics for the urban and rural strata are summarized in Table 3 and 4 in the Appendix C respectively. Examining those tables, we find that the regression models quite successfully explain the variation in monthly adult equivalent consumption. The R-Square ranges from 0.29 to 0.56 in urban areas to 0.24 to 0.52 in rural areas.

Using the parameters estimates derived in the first stage modelling, we then proceed with the census imputation ${ }^{12}$, as described in the methodology section above (see table 3 and 4 in the Appendix C for results of OLS regression for stage 1). A relative poverty line of 40 per cent lowest quintile was used which corresponds to 215,235.2 Manat per month.

\section{Results}

Table 1 below presents the results for average adult equivalent consumption, the headcount index (FGT(0)) taking the value of the 40th percentile as the poverty line for both the HBS and the Census for each strata. Comparison of results from the Census and HBS shows that the prediction model seems to perform relatively well at this level, with exception of the rural area of Karabah and urban area of Mugan and Shirvan where the census imputation of the adult equivalent consumption is above the one estimated by the HBS and where the headcount measure imputed in the census is below the headcount estimated by the HBS.

Table: 1 Average adult equivalent, poverty and inequality in Azerbaijan, by regions

\section{(strata)}

\begin{tabular}{lrrrr}
\hline & \multicolumn{2}{l}{ Mean Adult } & \multicolumn{2}{c}{ Poverty line 40\% lowest } \\
& Census & HBS & \multicolumn{2}{c}{ Census } \\
Rural & & & & HBS \\
Nakhchivan & 219146 & 218726 & 0.52 & 0.51 \\
& $(6191)$ & $(4575)$ & $(0.038)$ & $(0.038)$ \\
Absheron-Guba & 239589 & 247547 & 0.40 & 0.36 \\
& $(3930)$ & $(5685)$ & $(0.024)$ & $(0.034)$ \\
Mugan-Salyan & 245288 & 243113 & 0.37 & 0.37 \\
& $(3045)$ & $(3927)$ & $(0.016)$ & $(0.027)$ \\
Ganja-Gazakh & 264507 & 266946 & 0.36 & 0.30 \\
\hline
\end{tabular}

\footnotetext{
${ }^{12}$ For the census imputation we use the application Povmap Version 1.1a developed by Qingua Zhao, from the Development Research Group of The World Bank.
} 


\begin{tabular}{|c|c|c|c|c|}
\hline & \multicolumn{2}{|c|}{ Mean Adult } & \multicolumn{2}{|c|}{ Poverty line $40 \%$ lowest } \\
\hline & Census & HBS & Census & HBS \\
\hline & (6801) & (4273) & $(0.023)$ & $(0.024)$ \\
\hline \multirow[t]{2}{*}{ Sheki } & 253816 & 248874 & 0.31 & 0.34 \\
\hline & (5653) & (4156) & $(0.023)$ & $(0.029)$ \\
\hline \multirow[t]{2}{*}{ Lanakaran } & 245929 & 241499 & 0.35 & 0.37 \\
\hline & (2679) & (3432) & $(0.014)$ & $(0.025)$ \\
\hline \multirow[t]{2}{*}{ Shirvan } & 255715 & 252779 & 0.34 & 0.335 \\
\hline & (3761) & (4922) & $(0.014)$ & $(0.032)$ \\
\hline \multirow[t]{2}{*}{ Karabah } & 271245 & 258223 & 0.31 & 0.39 \\
\hline & (6814) & (4111) & $(0.025)$ & $(0.021)$ \\
\hline \multicolumn{5}{|l|}{ Urban } \\
\hline \multirow[t]{2}{*}{ Nakhchivan } & 239444 & 237958 & 0.44 & 0.43 \\
\hline & (4679) & (5993) & $(0.020)$ & $(0.040)$ \\
\hline \multirow[t]{2}{*}{ Absheron-Guba } & 242869 & 242368 & 0.42 & 0.41 \\
\hline & (2815) & (4024) & $(0.012)$ & $(0.024)$ \\
\hline \multirow[t]{2}{*}{ Mugan-Salyan } & 259218 & 241078 & 0.30 & 0.38 \\
\hline & (10062) & (5398) & $(0.046)$ & $(0.038)$ \\
\hline \multirow[t]{2}{*}{ Ganja-Gazakh } & 214910 & 216514 & 0.55 & 0.54 \\
\hline & (2297) & (2766) & $(0.015)$ & $(0.027)$ \\
\hline \multirow[t]{2}{*}{ Sheki } & 227578 & 222539 & 0.44 & 0.56 \\
\hline & (8695) & (4516) & $(0.065)$ & $(0.037)$ \\
\hline \multirow[t]{2}{*}{ Lanakaran } & 233407 & 232017 & 0.46 & 0.45 \\
\hline & (4238) & (5217) & $(0.020)$ & $(0.038)$ \\
\hline \multirow[t]{2}{*}{ Shirvan } & 222600 & 209556 & 0.50 & 0.58 \\
\hline & (4488) & (3843) & $(0.027)$ & $(0.041)$ \\
\hline \multirow[t]{2}{*}{ Karabah } & 228797 & 231541 & 0.48 & 0.45 \\
\hline & (3676) & (4218) & (0.019) & $(0.031)$ \\
\hline \multirow[t]{2}{*}{ Baku } & 261656 & 253530 & 0.39 & 0.42 \\
\hline & (10782) & (2551) & $(0.03)$ & (0.013) \\
\hline
\end{tabular}

Note: Standard errors in parenthesis. Household survey figures are calculated using weights that are the product of household weights and household size. Census-based figures are calculated weighing by household size.

Figures A1-A8 in Appendix A illustrate to what extent the estimates of the three welfare indicators are to be considered reliable. Figure A1 for example ranks urban rayons by the coefficient of variation. Considering the coefficient of variation derived by the survey stratum estimate as a cut off point for the level of error we allow, we can see that for the estimates of the headcount in urban area at rayon level around two thirds of those estimates are above the coefficient of variation obtained from the survey, whereas for estimates of mean adult equivalent monthly consumption those estimates are below or around the coefficient of variation obtained from the survey (Figure A2 in Appendix A). For the two welfare indicators, the rayon estimates for rural areas are below or around the stratum level value suggesting that those estimates are to 
be considered reliable (Figure A5, A6 in Appendix A). For administrative areas, both for urban and rural areas, the headcount measures are well above the coefficients of variation obtained from the survey (A3 ad A7 in Appendix A). Consequently, for administrative areas, we only consider the mean adult equivalent monthly consumption (A4 and A8 in Appendix A).

The standard errors associated with those estimates do not account for the possible model errors which are due to a misspecification of the model we have used for the imputation in the census. Estimates based on area units below 1,000 households will also have an error associated with them due to the low number of observations in each area. As far as the enumeration area is concerned, despite the fact that the procedure technically allows estimating welfare indicators for this level of disaggregation, the model errors associated with those estimate will be too high as several enumeration areas have less than 1,000 households. As far as the administrative area is concerned a quarter of the rural administrative units are area of aggregation above 1000 household, and for urban area about two-third of the urban administrative units are above 1000 household $^{13}$. Hence administrative level results could only be considered reliable for those larger administrative areas.

Overall the rayon level estimates of the three chosen welfare indicators are to be considered robust, whereas for administrative areas only mean adult equivalent monthly consumption for larger area are to be considered fairly realiable. The decrease in robustness associated with higher disaggregation levels is probably due to the sampling procedure adopted in the HBS that resulted in limited clustering in the sampling process.

Figures B1-B4 in Appendix B show the spatial heterogeneity of poverty for rayon welfare estimates and compare those estimates and their associated confidence interval with the national level value.

\footnotetext{
${ }^{13} 186$ out of 896 rural administrative area are larger than a 1000 households, whereas for urban area 93 out of 140 administrative area are larger than a 1000 households.
} 


\section{Appendix A- How low can we go?}

\section{URBAN Rayon Estimates}

Figure A1: Standard Error as Percentage of point estimate: Urban Area Azerbaijan, FTT(0) Comparing survey based stratum-level estimates to census based rayon-level estimates (62 rayon plus 11 districts in Baku)

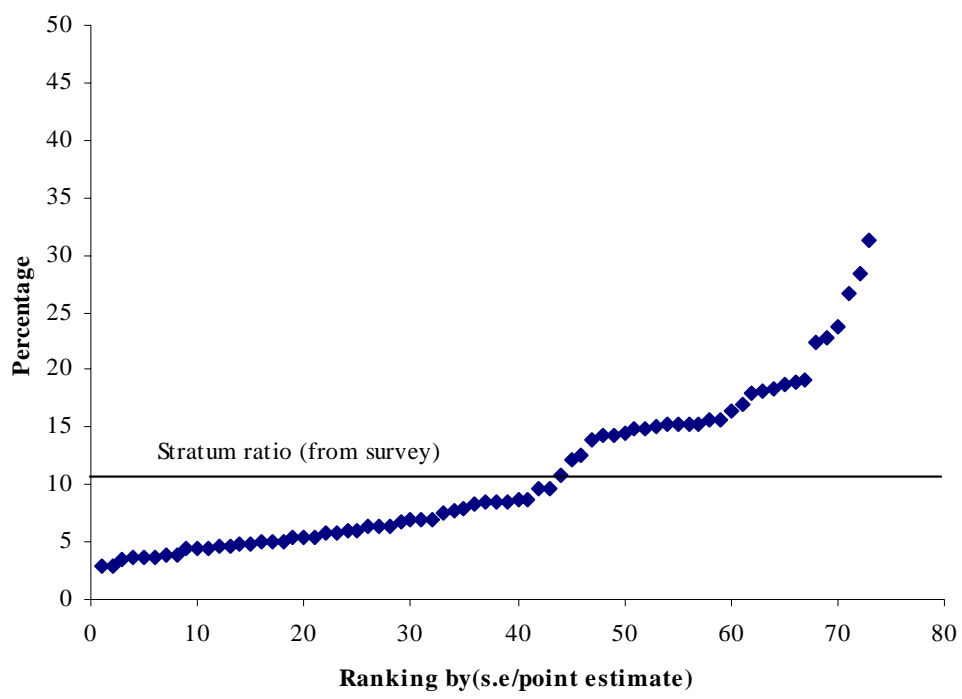

Figure A2: Standard Error as Percentage of point estimate: Urban Area Azerbaijan, monthly mean adult equivalent consumption Comparing survey based stratum-level estimates to census based rayon-level estimates (62 rayon plus 11 districts in Baku).

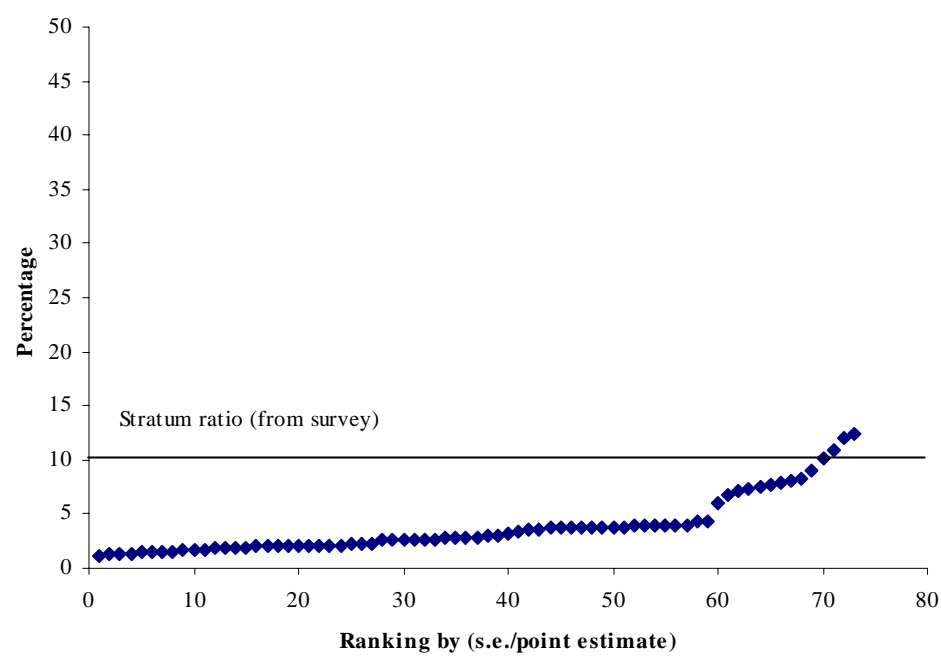




\section{URBAN Administrative Units}

Figure A3: Standard Error as Percentage of point estimate: Urban Area Azerbaijan, FTG(0). Comparing survey based stratum-level estimates to census based administrative units-level estimates (140 administrative units).

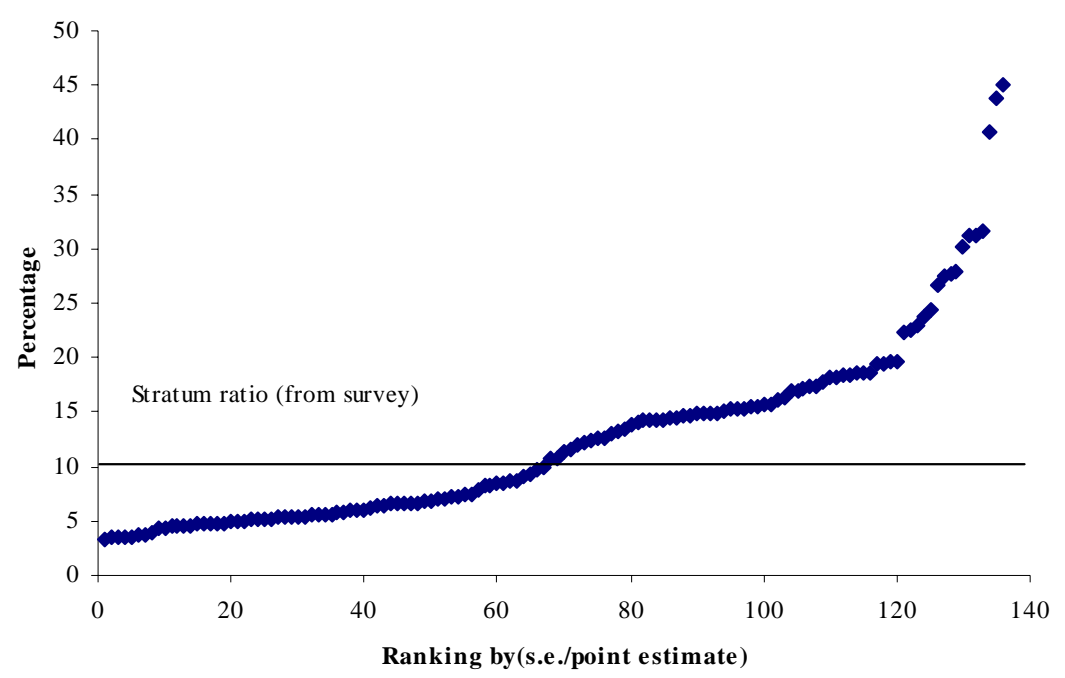

Figure A4: Standard Error as Percentage of point estimate: Urban Area Azerbaijan, monthly mean adult equivalent consumption Comparing survey based stratum-level estimates to census based administrative units-level estimates (140 administrative units).

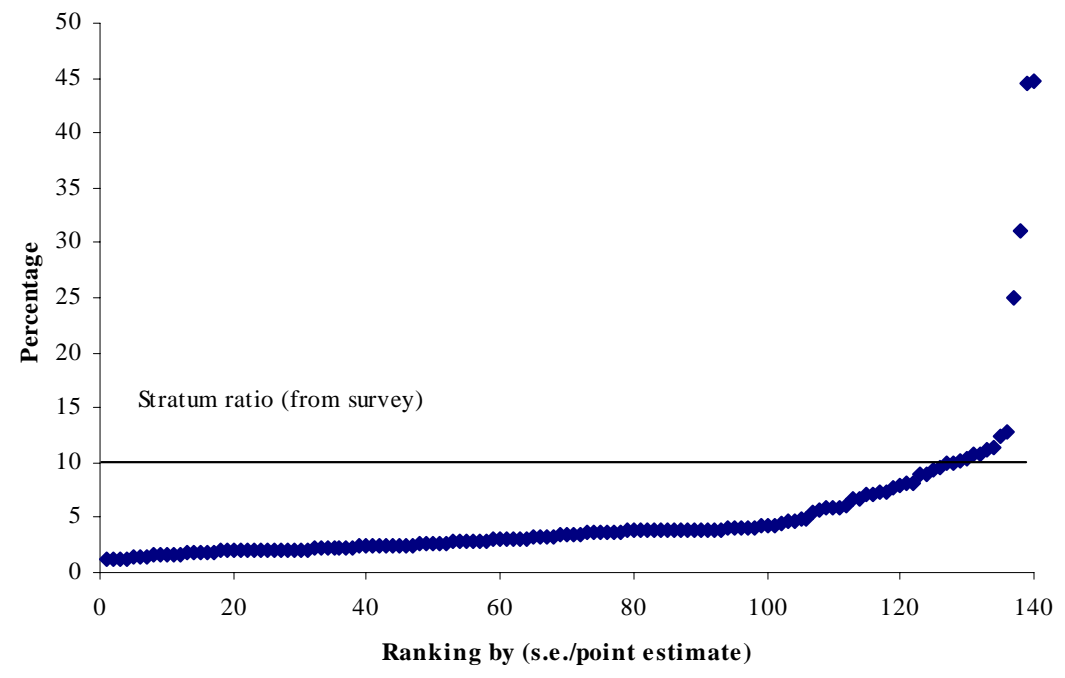




\section{RURAL Rayon Estimates}

Figure A5: Standard Error as Percentage of point estimate: Rural Area Azerbaijan, FTG(0) Comparing survey based stratum-level estimates to census based raion-level estimates (58 rayons)

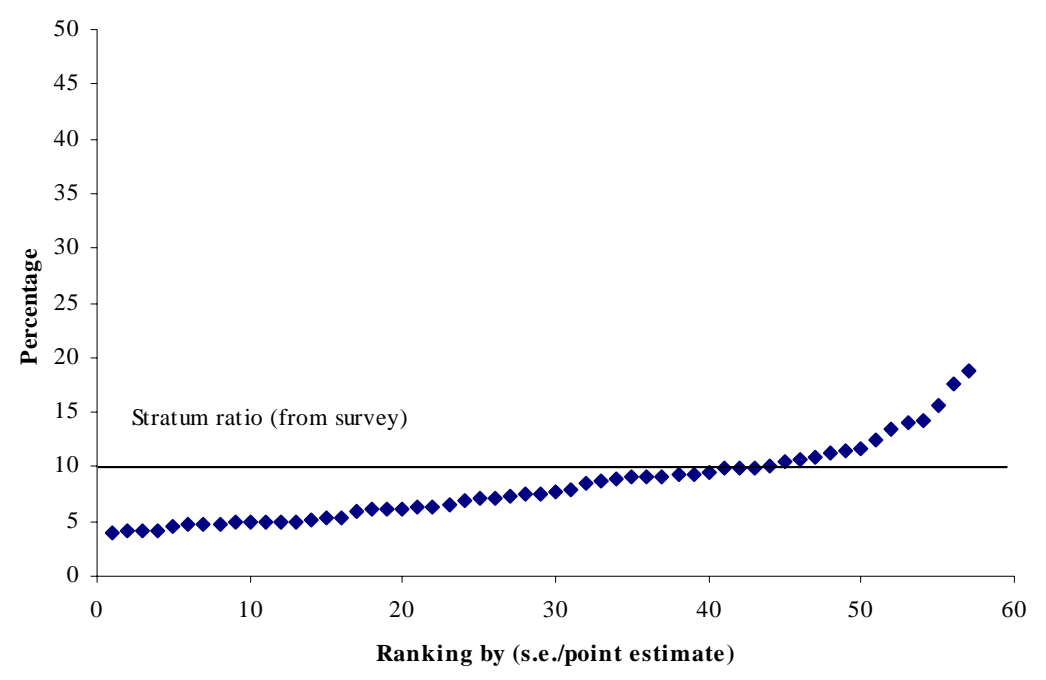

Figure A6: Standard Error as Percentage of point estimate: Rural Area Azerbaijan, monthly mean adult equivalent consumption Comparing survey based stratum-level estimates to census based rayon-level estimates (58 rayons)

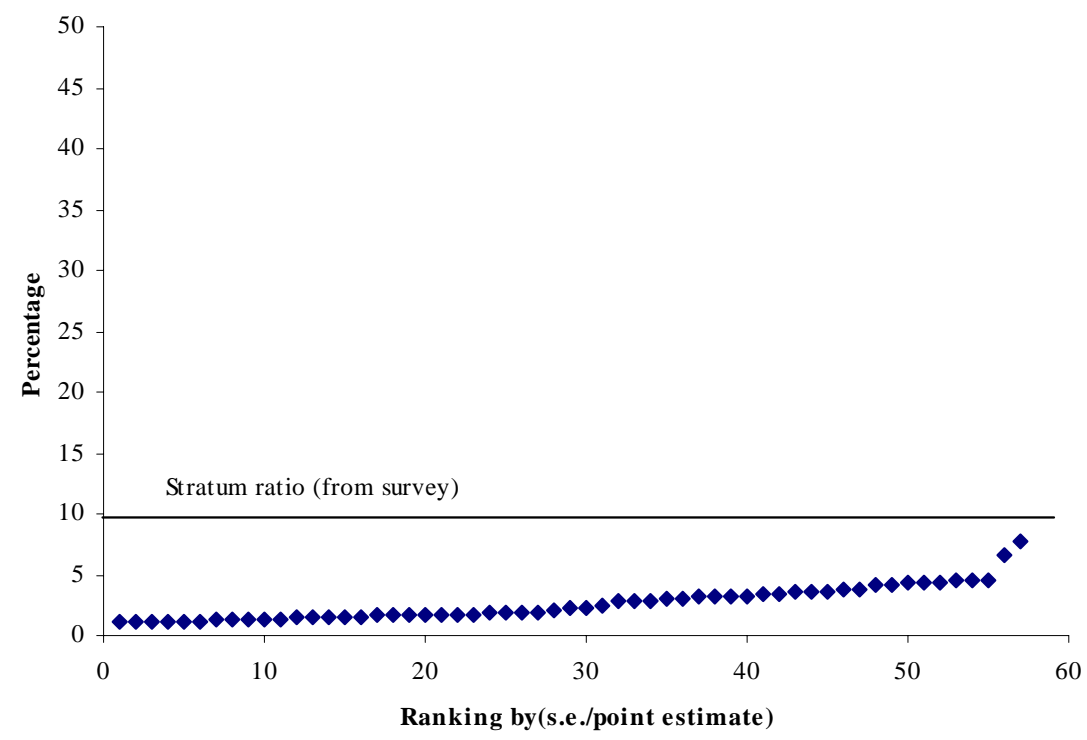




\section{RURAL Administrative Units}

Figure A7: Standard Error as Percentage of point estimate: Rural Area Azerbaijan, FTG(0) Comparing survey based stratum-level estimates to census based administrative level estimates (896 administrative level)

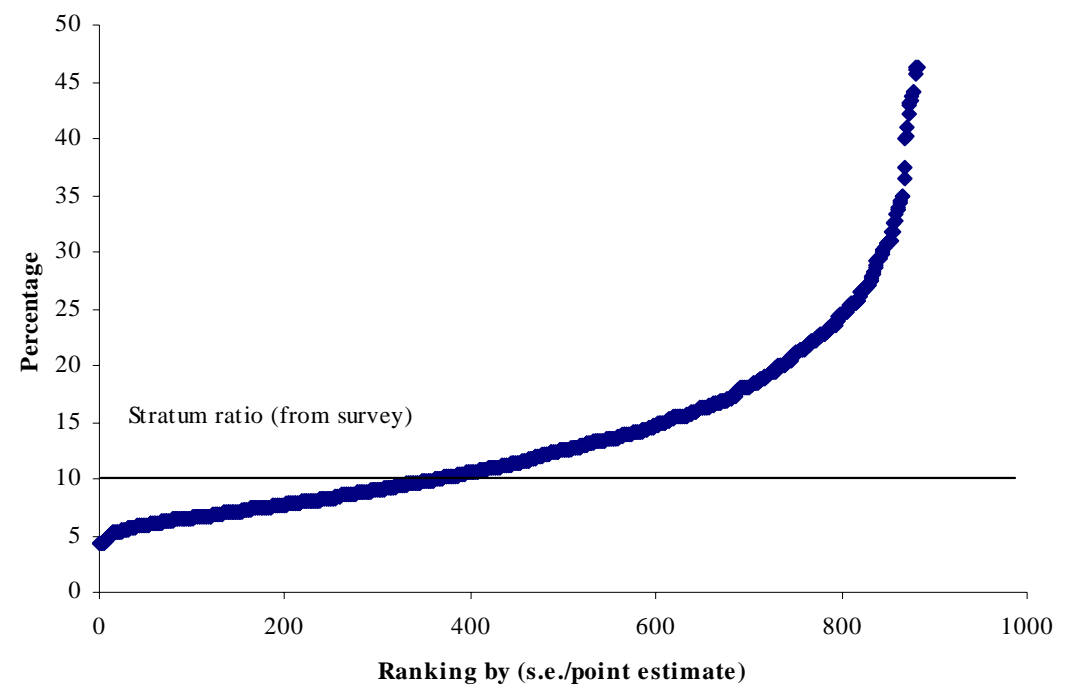

Figure A8: Standard Error as Percentage of point estimate: Rural Area Azerbaijan, mean adult equivalent consumption Comparing survey based stratum-level estimates to census based administrative level estimates (896 administrative level)

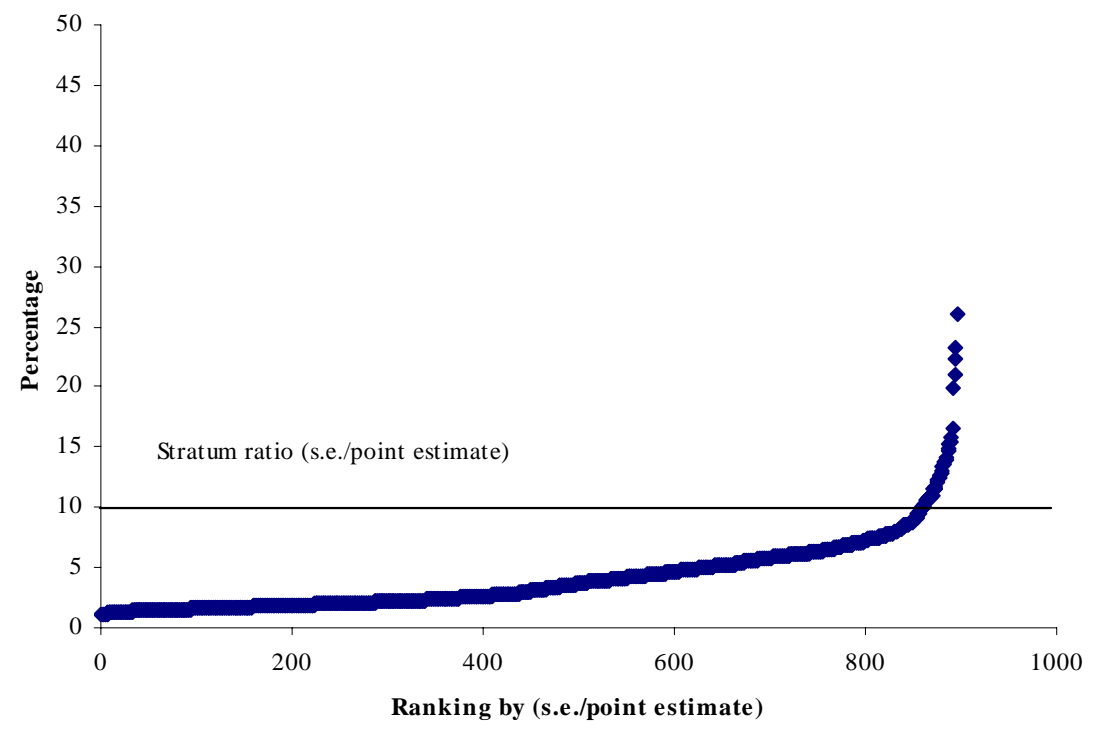




\section{Appendix B - Comparing national average value and rayon level estimates}

Figure B1: Distribution of monthly mean adult equivalent consumption by rayon, urban area

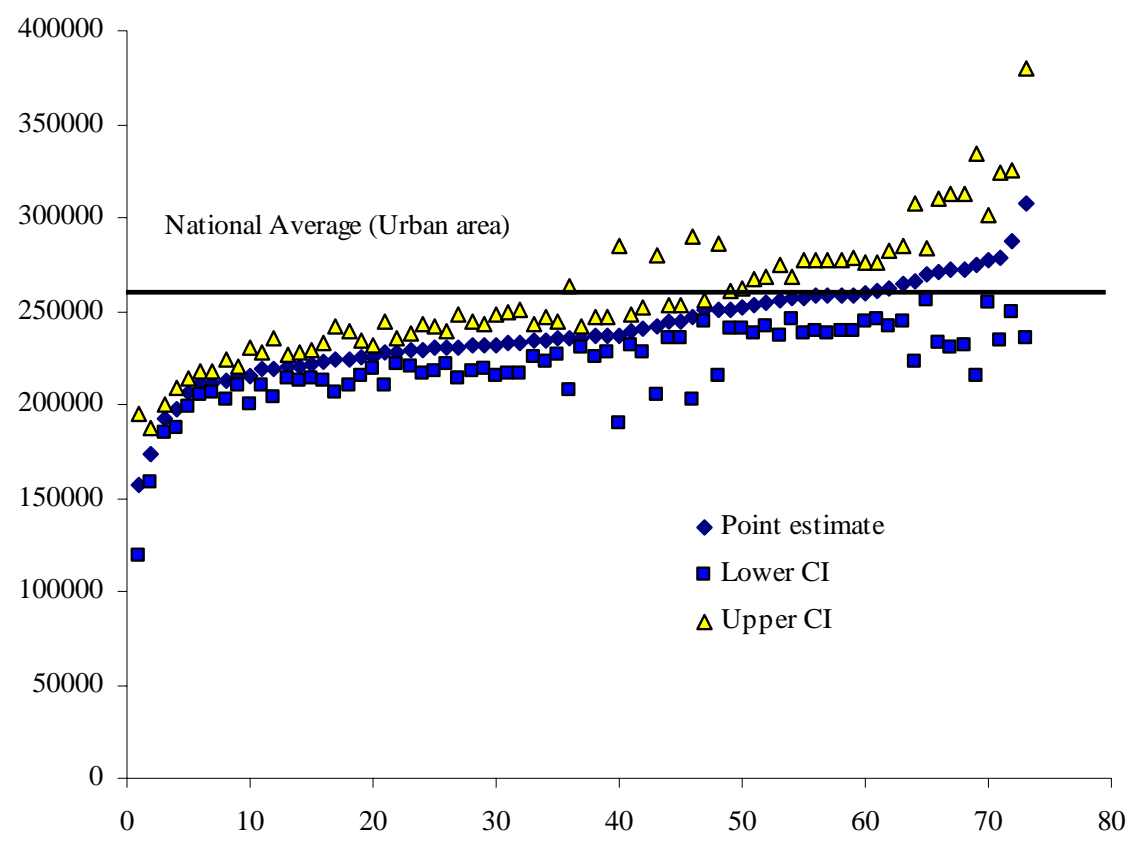

Figure B2: Distribution of headcount at rayon level, urban area

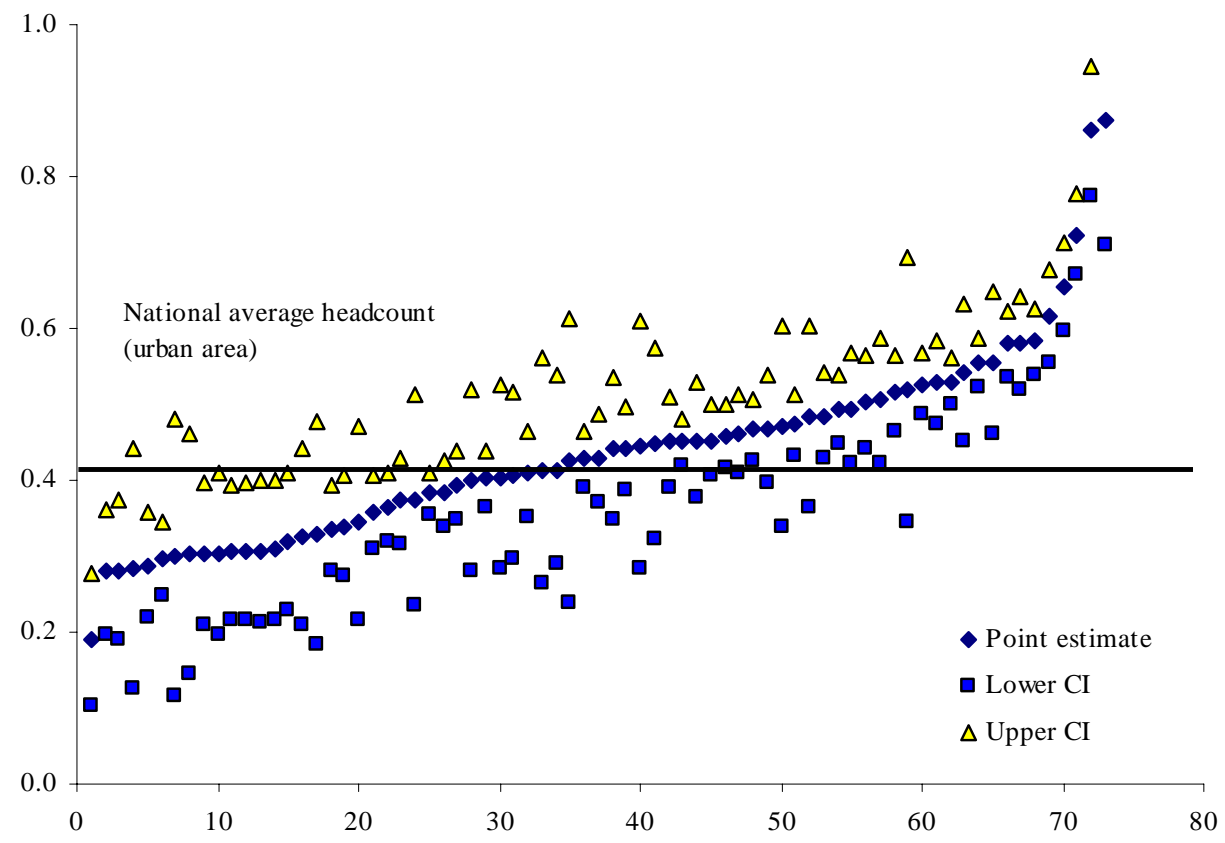


Figure B3: Distribution of monthly mean adult equivalent consumption by rayon, rural urban area.

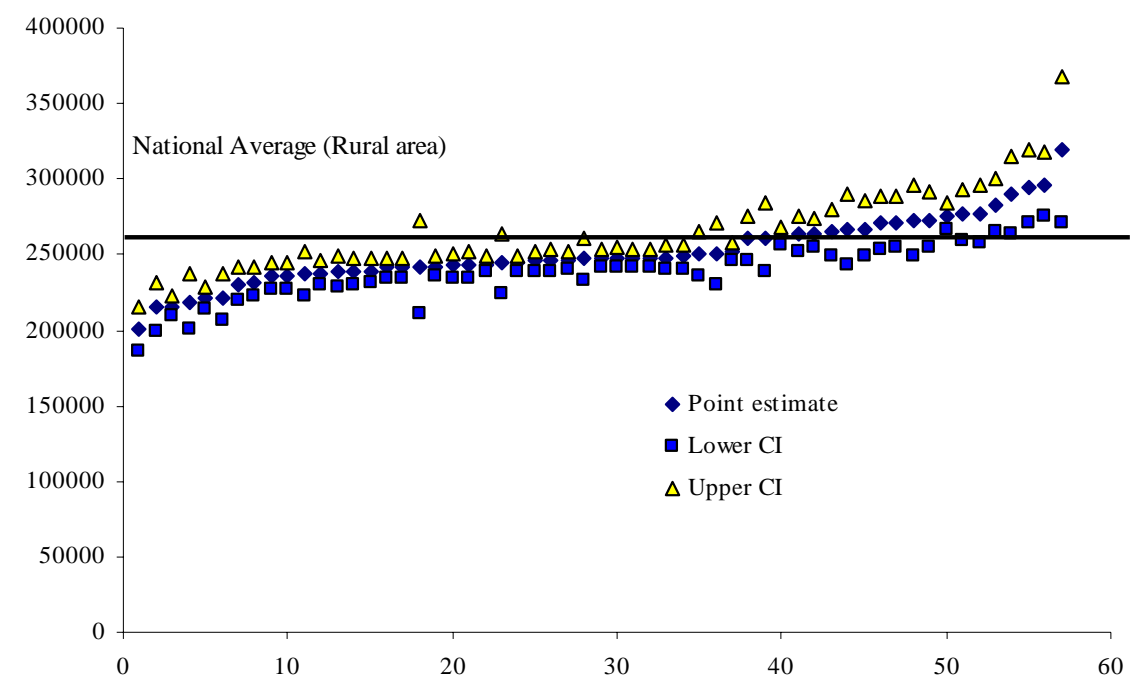

Figure B4: Distribution of headcount at rayon level, rural urban area.

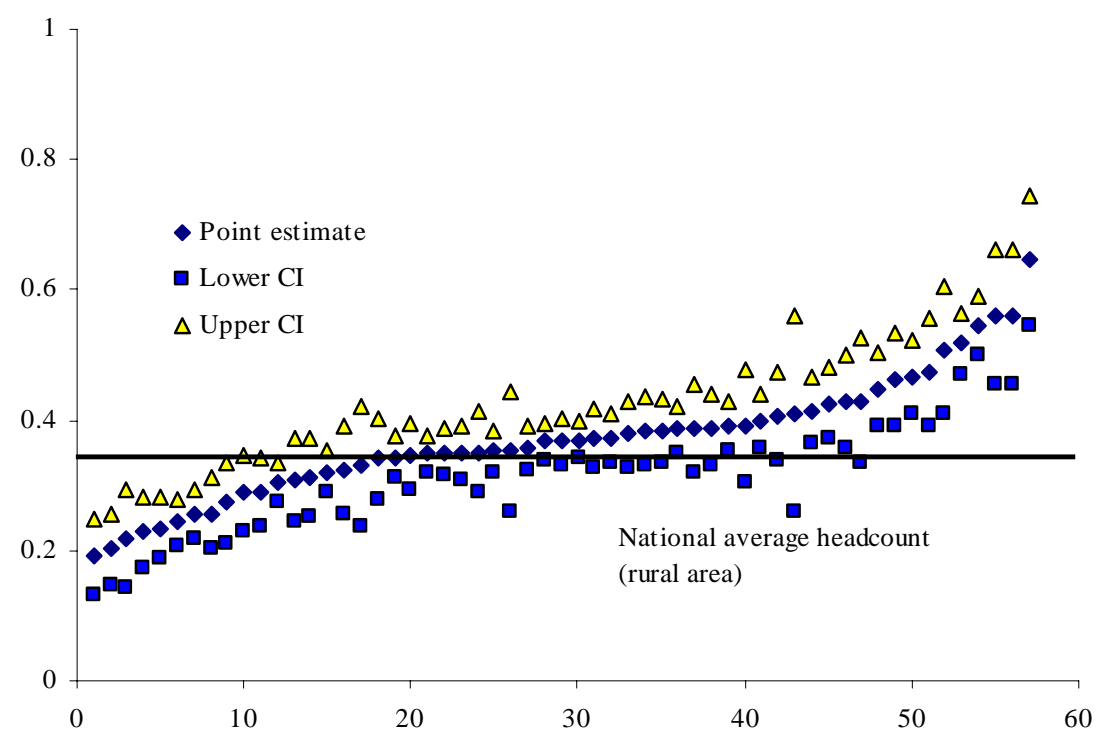


Appendix C - Descriptive statistics of selected common indicators and models for the imputation.

Table 1: Descriptive statistisc-urban strata

\begin{tabular}{|c|c|c|c|c|c|c|c|c|c|c|c|c|c|c|c|c|c|c|c|c|}
\hline & \multicolumn{2}{|c|}{ Nakhchivan-AR } & \multicolumn{7}{|c|}{ Absheron-Guba } & \multicolumn{4}{|c|}{ Mugan-Salyan-Urban } & \multicolumn{7}{|c|}{ Ganja-Gazakh-urban } \\
\hline & Census & HBS & 195b & u95b & & Census & HBS & $195 b$ & U95b & & Census & HBS & L95b & u95b & & Census & HBS & 195b & u95b & \\
\hline HH_size & 4.59 & 4.20 & 3.96 & 4.44 & 0 & 4.72 & 4.00 & 3.59 & 4.13 & 0 & 5.13 & 4.09 & 3.90 & 4.27 & 0 & 4.94 & 4.12 & 3.96 & 4.28 & 0 \\
\hline Hh_female & 0.28 & 0.21 & 0.15 & 0.27 & 0 & 0.24 & 0.27 & 0.24 & 0.31 & 1 & 0.23 & 0.23 & 0.18 & 0.28 & 1 & 0.29 & 0.32 & 0.28 & 0.36 & 1 \\
\hline num_rom & 2.52 & 2.81 & 2.67 & 2.95 & 0 & 2.43 & 2.59 & 2.51 & 2.67 & 0 & 2.61 & 2.51 & 2.41 & 2.62 & 1 & 2.50 & 2.82 & 2.73 & 2.91 & 0 \\
\hline strdwe & 0.58 & 0.57 & 0.53 & 0.67 & 1 & 0.32 & 0.41 & 0.37 & 0.45 & 0 & 0.66 & 0.44 & 0.38 & 0.50 & 0 & 0.58 & 0.77 & 0.74 & 0.81 & 0 \\
\hline owndwe & 0.72 & 0.96 & 0.94 & 0.99 & 0 & 0.50 & 0.56 & 0.52 & 0.60 & 0 & 0.73 & 0.84 & 0.79 & 0.88 & 0 & 0.70 & 0.97 & 0.95 & 0.98 & 0 \\
\hline eleove & 0.66 & 0.55 & 0.48 & 0.62 & 0 & 0.11 & 0.32 & 0.28 & 0.36 & 0 & 0.29 & 0.16 & 0.12 & 0.20 & 0 & 0.53 & 0.50 & 0.46 & 0.55 & 1 \\
\hline telep & 0.42 & 0.70 & 0.63 & 0.76 & 0 & 0.30 & 0.58 & 0.54 & 0.62 & 0 & 0.27 & 0.47 & 0.41 & 0.52 & 0 & 0.34 & 0.71 & 0.67 & 0.75 & 0 \\
\hline gascyl & 0.48 & 0.80 & 0.74 & 0.85 & 0 & 0.07 & 0.05 & 0.03 & 0.06 & 0 & 0.19 & 0.07 & 0.07 & 0.04 & 0 & 0.43 & 0.43 & 0.39 & 0.47 & 1 \\
\hline gasline & 0.26 & 0.11 & 0.06 & 0.15 & 0 & 0.87 & 0.99 & 0.98 & 1.00 & 0 & 0.72 & 0.85 & 0.81 & 0.89 & 0 & 0.68 & 0.91 & 0.88 & 0.93 & 0 \\
\hline haeti & 0.11 & 0.13 & 0.08 & 0.18 & 1 & 0.07 & 0.26 & 0.23 & 0.30 & 0 & 0.08 & 0.02 & 0.00 & 0.03 & 0 & 0.03 & 0.03 & 0.02 & 0.05 & 0 \\
\hline water & 0.75 & 0.56 & 0.48 & 0.63 & 0 & 0.90 & 0.98 & 0.96 & 0.99 & 0 & 0.73 & 1.00 & 0.99 & 1.00 & 0 & 0.81 & 0.82 & 0.79 & 0.86 & 1 \\
\hline hotwa & 0.04 & 0.20 & 0.14 & 0.26 & 0 & 0.07 & 0.65 & 0.61 & 0.69 & 0 & 0.02 & 0.31 & 0.26 & 0.37 & 0 & 0.03 & 0.67 & 0.62 & 0.71 & 0 \\
\hline sewa & 0.63 & 0.61 & 0.54 & 0.68 & 1 & 0.73 & 0.29 & 0.25 & 0.33 & 0 & 0.36 & 0.41 & 0.35 & 0.46 & 1 & 0.61 & 0.66 & 0.62 & 0.70 & 0 \\
\hline bath & 0.60 & 0.55 & 0.48 & 0.62 & 1 & 0.65 & 0.85 & 0.82 & 0.87 & 0 & 0.38 & 0.88 & 0.84 & 0.92 & 0 & 0.54 & 0.79 & 0.75 & 0.83 & 0 \\
\hline under15 & 0.28 & 0.23 & 0.20 & 0.27 & 0 & 0.28 & 0.24 & 0.22 & 0.26 & 1 & 0.31 & 0.26 & 0.24 & 0.29 & 0 & 0.29 & 0.24 & 0.22 & 0.26 & 0 \\
\hline b15to59 & 0.61 & 0.62 & 0.58 & 0.66 & 1 & 0.61 & 0.61 & 0.58 & 0.63 & 1 & 0.59 & 0.59 & 0.56 & 0.62 & 1 & 0.60 & 0.58 & 0.55 & 0.60 & 1 \\
\hline aboave60 & 0.10 & 0.15 & 0.11 & 0.19 & 1 & 0.11 & 0.15 & 0.13 & 0.18 & 0 & 0.11 & 0.15 & 0.12 & 0.18 & 0 & 0.12 & 0.19 & 0.16 & 0.22 & 0 \\
\hline prun15 & 0.14 & 0.13 & 0.10 & 0.15 & 1 & 0.15 & 0.13 & 0.12 & 0.14 & 0 & 0.16 & 0.14 & 0.12 & 0.16 & 0 & 0.15 & 0.12 & 0.11 & 0.14 & 0 \\
\hline pr15to59 & 0.31 & 0.28 & 0.25 & 0.31 & 0 & 0.29 & 0.27 & 0.25 & 0.29 & 1 & 0.28 & 0.26 & 0.24 & 0.28 & 1 & 0.28 & 0.26 & 0.24 & 0.28 & 1 \\
\hline pr60ab & 0.04 & 0.06 & 0.04 & 0.09 & 1 & 0.05 & 0.06 & 0.05 & 0.07 & 1 & 0.04 & 0.05 & 0.04 & 0.07 & 1 & 0.04 & 0.07 & 0.05 & 0.08 & 0 \\
\hline practive & 0.35 & 0.44 & 0.40 & 0.48 & 0 & 0.30 & 0.37 & 0.35 & 0.39 & 0 & 0.32 & 0.41 & 0.38 & 0.44 & 0 & 0.32 & 0.39 & 0.36 & 0.41 & 0 \\
\hline tot_area & 60.40 & 78.69 & 74.42 & 82.96 & 0 & 59.00 & 61.18 & 59.3 & 63.11 & 0 & 70.76 & 65.92 & 62.95 & 68.88 & 0 & 69.46 & 80.79 & 78.5 & 83.0 & 0 \\
\hline thh6 & 0.51 & 0.30 & 0.21 & 0.39 & 0 & 0.47 & 0.26 & 0.22 & 0.31 & 0 & 0.60 & 0.42 & 0.33 & 0.50 & 0 & 0.55 & 0.25 & 0.20 & 0.31 & 0 \\
\hline thh7_12 & 0.65 & 0.58 & 0.46 & 0.71 & 1 & 0.66 & 0.51 & 0.45 & 0.58 & 0 & 0.75 & 0.53 & 0.44 & 0.62 & 0 & 0.70 & 0.50 & 0.43 & 0.56 & 0 \\
\hline thh13_17 & 0.39 & 0.34 & 0.25 & 0.44 & 1 & 0.41 & 0.39 & 0.33 & 0.44 & 1 & 0.45 & 0.34 & 0.27 & 0.42 & 0 & 0.43 & 0.48 & 0.42 & 0.54 & 1 \\
\hline thhabo60 & 2.91 & 2.96 & 2.77 & 3.14 & 1 & 3.04 & 2.81 & 2.71 & 2.92 & 0 & 3.17 & 2.78 & 2.63 & 2.93 & 0 & 3.13 & 2.87 & 2.76 & 2.99 & 0 \\
\hline ae & 3.41 & 3.37 & 3.18 & 3.56 & 1 & 3.55 & 3.22 & 3.11 & 3.33 & 0 & 3.75 & 3.20 & 3.04 & 3.35 & 0 & 3.67 & 3.32 & 3.19 & 3.44 & 0 \\
\hline mar & 0.74 & 0.73 & 0.67 & 0.80 & 1 & 0.78 & 0.70 & 0.67 & 0.74 & 0 & 0.78 & 0.74 & 0.69 & 0.79 & 1 & 0.73 & 0.71 & 0.66 & 0.75 & 1 \\
\hline hh_sec & 0.91 & 0.80 & 0.74 & 0.85 & 0 & 0.86 & 0.82 & 0.79 & 0.85 & 0 & 0.85 & 0.89 & 0.86 & 0.93 & 1 & 0.89 & 0.83 & 0.80 & 0.86 & 0 \\
\hline hh_high & 0.22 & 0.14 & 0.09 & 0.19 & 0 & 0.17 & 0.20 & 0.17 & 0.23 & 1 & 0.13 & 0.18 & 0.13 & 0.22 & 1 & 0.19 & 0.16 & 0.13 & 0.19 & 1 \\
\hline Number of hh & 20661 & 187 & & & 13 & 113997 & 574 & & & 7 & 56407 & 287 & & & 8 & 104279 & 486 & & & 9 \\
\hline
\end{tabular}


Table 1: Continued, urban strata.

\begin{tabular}{|c|c|c|c|c|c|c|c|c|c|c|c|c|c|c|c|c|c|c|c|c|}
\hline & Sheki & & & & & Lankar & & & & & Shirvan & & & & & Karabah & & & & \\
\hline & Census & HBS & 195b & u95b & & Census & HBS & $195 b$ & u95b & & Census & HBS & $195 \mathrm{~b}$ & u95b & & Census & HBS & $195 b$ & u95b & \\
\hline HH_size & 4.57 & 4.44 & 4.19 & 4.69 & 1 & 4.96 & 4.64 & 4.40 & 4.88 & 0 & 5.02 & 4.30 & 4.05 & 4.55 & 0 & 4.71 & 4.11 & 3.97 & 4.25 & 0 \\
\hline Hh_female & 0.28 & 0.28 & 0.22 & 0.35 & 1 & 0.26 & 0.20 & 0.14 & 0.26 & 1 & 0.26 & 0.25 & 0.19 & 0.31 & 1 & 0.25 & 0.23 & 0.18 & 0.27 & 1 \\
\hline num_rom & 2.44 & 3.32 & 3.18 & 3.46 & 0 & 2.57 & 2.65 & 2.54 & 2.78 & 1 & 2.49 & 2.95 & 2.77 & 3.13 & 0 & 2.08 & 2.85 & 2.75 & 2.96 & 0 \\
\hline strdwe & 0.81 & 0.94 & 0.90 & 0.97 & 0 & 0.69 & 0.82 & 0.77 & 0.87 & 0 & 0.83 & 0.54 & 0.49 & 0.59 & 0 & 0.50 & 0.54 & 0.49 & 0.59 & 1 \\
\hline owndwe & 0.87 & 0.10 & 0.95 & 1.00 & 0 & 0.79 & 0.93 & 0.89 & 0.96 & 0 & 0.87 & 0.72 & 0.67 & 0.76 & 0 & 0.59 & 0.72 & 0.67 & 0.76 & 0 \\
\hline eleove & 0.25 & 0.93 & 0.90 & 0.97 & 0 & 0.28 & 0.93 & 0.89 & 0.96 & 0 & 0.10 & 0.41 & 0.36 & 0.46 & 0 & 0.35 & 0.41 & 0.36 & 0.46 & 0 \\
\hline telep & 0.37 & 0.78 & 0.73 & 0.84 & 0 & 0.48 & 0.33 & 0.26 & 0.39 & 0 & 0.40 & 0.45 & 0.40 & 0.50 & 1 & 0.29 & 0.45 & 0.40 & 0.50 & 0 \\
\hline gascyl & 0.43 & 0.16 & 0.11 & 0.21 & 0 & 0.50 & 0.33 & 0.26 & 0.39 & 0 & 0.05 & 0.45 & 0.40 & 0.50 & 0 & 0.25 & 0.45 & 0.40 & 0.50 & 0 \\
\hline gasline & 0.55 & 0.87 & 0.82 & 0.92 & 0 & 0.38 & 0.55 & 0.48 & 0.62 & 0 & 0.89 & 0.87 & 0.84 & 0.90 & 1 & 0.44 & 0.87 & 0.84 & 0.90 & 0 \\
\hline haeti & 0.11 & 0.01 & 0.00 & 0.02 & 0 & 0.05 & 0.48 & 0.41 & $0 . .552$ & 0 & 0.05 & 0.19 & 0.15 & 0.23 & 0 & 0.07 & 0.19 & 0.15 & 0.23 & 0 \\
\hline water & 0.75 & 0.80 & 0.74 & 0.86 & 1 & 0.46 & 0.15 & 0.14 & 0.16 & 0 & 0.71 & 0.77 & 0.73 & 0.81 & 0 & 0.62 & 0.77 & 0.73 & 0.81 & 0 \\
\hline hotwa & 0.00 & 0.26 & 0.20 & 0.32 & 0 & 0.01 & 0.34 & 0.27 & 0.41 & 0 & 0.01 & 0.50 & 0.45 & 0.55 & 0 & 0.05 & 0.50 & 0.45 & 0.55 & 0 \\
\hline sewa & 0.25 & 0.75 & 0.69 & 0.81 & 0 & 0.21 & 0.54 & 0.47 & 0.61 & 0 & 0.44 & 0.58 & 0.53 & 0.62 & 0 & 0.42 & 0.58 & 0.53 & 0.62 & 0 \\
\hline bath & 0.31 & 0.58 & 0.51 & 0.65 & 0 & 0.26 & 0.70 & 0.63 & 0.76 & 0 & 0.40 & 0.61 & 0.56 & 0.66 & 0 & 0.37 & 0.61 & 0.56 & 0.66 & 0 \\
\hline under15 & 0.27 & 0.20 & 0.17 & 0.23 & 0 & 0.28 & 0.26 & 0.23 & 0.29 & 1 & 0.30 & 0.23 & 0.21 & 0.25 & 0 & 0.29 & 0.23 & 0.21 & 0.25 & 0 \\
\hline b15to59 & 0.59 & 0.64 & 0.60 & 0.68 & 0 & 0.62 & 0.61 & 0.57 & 0.65 & 1 & 0.58 & 0.65 & 0.63 & 0.68 & 1 & 0.59 & 0.65 & 0.63 & 0.68 & 0 \\
\hline aboave60 & 0.14 & 0.16 & 0.12 & 0.19 & 1 & 0.11 & 0.13 & 0.09 & 0.17 & 1 & 0.13 & 0.11 & 0.09 & 0.14 & 1 & 0.12 & 0.11 & 0.09 & 0.13 & 1 \\
\hline prun15 & 0.14 & 0.10 & 0.08 & 0.12 & 0 & 0.15 & 0.13 & 0.10 & 0.15 & 1 & 0.16 & 0.11 & 0.10 & 0.13 & 0 & 0.15 & 0.11 & 0.01 & 0.10 & 0 \\
\hline pr15to59 & 0.28 & 0.30 & 0.27 & 0.33 & 1 & 0.29 & 0.29 & 0.26 & 0.31 & 1 & 0.27 & 0.31 & 0.29 & 0.33 & 0 & 0.28 & 0.31 & 0.29 & 0.33 & 0 \\
\hline pr60ab & 0.05 & 0.06 & 0.04 & 0.07 & 1 & 0.04 & 0.05 & 0.03 & 0.06 & 1 & 0.05 & 0.05 & 0.04 & 0.06 & 1 & 0.05 & 0.05 & 0.04 & 0.06 & 1 \\
\hline practive & 0.34 & 0.48 & 0.44 & 0.52 & 1 & 0.33 & 0.40 & 0.37 & 0.43 & 0 & 0.31 & 0.38 & 0.36 & 0.41 & 0 & 0.29 & 0.38 & 0.36 & 0.41 & 0 \\
\hline tot_area & 66.57 & 85.37 & 81.83 & 88.91 & 0 & 70.41 & 71.35 & 67.74 & 74.90 & 1 & 77.04 & 69.98 & 67.40 & 72.56 & 0 & 55.41 & 69.97 & 67.40 & 72.55 & 0 \\
\hline thh6 & 0.46 & 0.23 & 0.15 & 0.30 & 0 & 0.54 & 0.44 & 0.34 & 0.54 & 1 & 0.55 & 0.34 & 0.24 & 0.43 & 0 & 0.50 & 0.30 & 0.23 & 0.36 & 0 \\
\hline thh7_12 & 0.60 & 0.52 & 0.41 & 0.62 & 1 & 0.64 & 0.57 & 0.45 & 0.70 & 1 & 0.70 & 0.40 & 0.30 & 0.49 & 0 & 0.68 & 0.44 & 0.37 & 0.52 & 0 \\
\hline thh13_17 & 0.36 & 0.31 & 0.23 & 0.40 & 1 & 0.41 & 0.37 & 0.27 & 0.47 & 1 & 0.44 & 0.30 & 0.22 & 0.38 & 0 & 0.43 & 0.39 & 0.33 & 0.46 & 1 \\
\hline thhabo60 & 3.03 & 3.36 & 3.17 & 3.55 & 0 & 3.25 & 3.23 & 3.02 & 3.45 & 1 & 3.19 & 3.25 & 3.07 & 3.43 & 1 & 2.97 & 2.95 & 2.83 & 3.08 & 1 \\
\hline ae & 3.49 & 3.72 & 3.52 & 3.92 & 0 & 3.76 & 3.68 & 3.47 & 3.90 & 1 & 3.74 & 3.59 & 3.40 & 3.78 & 1 & 3.49 & 3.35 & 3.23 & 3.47 & 0 \\
\hline mar & 0.74 & 0.65 & 0.58 & 0.72 & 0 & 0.75 & 0.75 & 0.69 & 0.81 & 1 & 0.74 & 0.70 & 0.64 & 0.76 & 1 & 0.77 & 0.76 & 0.72 & 0.81 & 1 \\
\hline hh_sec & 0.82 & 0.83 & 0.78 & 0.88 & 1 & 0.82 & 0.71 & 0.64 & 0.77 & 0 & 0.80 & 0.92 & 0.88 & 0.95 & 0 & 0.86 & 0.88 & 0.85 & 0.91 & 1 \\
\hline hh_high & 0.14 & 0.10 & 0.05 & 0.14 & 1 & 0.14 & 0.08 & 0.04 & 0.12 & 0 & 0.13 & 0.18 & 0.13 & 0.24 & 1 & 0.13 & 0.19 & 0.15 & 0.22 & 0 \\
\hline Number of hh & 28705 & 193 & & & 11 & 24069 & 195 & & & 15 & 26095 & 206 & & & 10 & 88702 & 344.00 & & & 8 \\
\hline
\end{tabular}


Table 1: Continued, urban strata.

\begin{tabular}{|c|c|c|c|c|c|}
\hline & \multicolumn{5}{|l|}{ Baku } \\
\hline & Census & $\begin{array}{l}2002 \\
\text { HBS }\end{array}$ & 195b & u95b & \\
\hline HH_size & 4.14 & 3.64 & 3.57 & 3.71 & 0 \\
\hline Hh_female & 0.32 & 0.27 & 0.25 & 0.29 & 0 \\
\hline num_rom & 2.33 & 2.48 & 2.44 & 2.52 & 0 \\
\hline strdwe & 0.33 & 0.28 & 0.27 & 0.30 & 0 \\
\hline owndwe & 0.52 & 0.74 & 0.72 & 0.76 & 0 \\
\hline eleove & 0.06 & 0.24 & 0.23 & 0.26 & 0 \\
\hline telep & 0.50 & 0.74 & 0.72 & 0.75 & 0 \\
\hline gascyl & 0.02 & 0.04 & 0.04 & 0.05 & 0 \\
\hline gasline & 0.92 & 0.97 & 0.96 & 0.98 & 0 \\
\hline haeti & 0.15 & 0.49 & 0.47 & 0.51 & 0 \\
\hline water & 0.91 & 0.91 & 0.90 & 0.92 & 1 \\
\hline hotwa & 0.10 & 0.71 & 0.69 & 0.73 & 0 \\
\hline sewa & 0.86 & 0.17 & 0.15 & 0.19 & 0 \\
\hline bath & 0.76 & 0.86 & 0.84 & 0.87 & 0 \\
\hline under15 & 0.23 & 0.19 & 0.18 & 0.20 & 0 \\
\hline b15to59 & 0.64 & 0.64 & 0.63 & 0.65 & 1 \\
\hline aboave60 & 0.13 & 0.16 & 0.15 & 0.17 & 0 \\
\hline prun15 & 0.13 & 0.10 & 0.09 & 0.11 & 0 \\
\hline pr15to59 & 0.31 & 0.30 & 0.29 & 0.31 & 1 \\
\hline pr60ab & 0.04 & 0.06 & 0.05 & 0.07 & 0 \\
\hline practive & 0.33 & 0.41 & 0.40 & 0.43 & 0 \\
\hline tot_area & 51.47 & 54.65 & 53.81 & 55.49 & 0 \\
\hline thh6 & 0.36 & 0.23 & 0.21 & 0.25 & 0 \\
\hline thh7_12 & 0.53 & 0.37 & 0.34 & 0.40 & 0 \\
\hline thh13_17 & 0.33 & 0.30 & 0.28 & 0.33 & 1 \\
\hline thhabo60 & 2.81 & 2.72 & 2.67 & 2.78 & 0 \\
\hline ae & 3.21 & 3.03 & 2.98 & 3.09 & 0 \\
\hline mar & 0.72 & 0.68 & 0.66 & 0.70 & 0 \\
\hline hh_sec & 0.91 & 0.92 & 0.91 & 0.93 & 1 \\
\hline hh_high & 0.29 & 0.31 & 0.29 & 0.33 & 1 \\
\hline Number of hh & 46997 & 2192 & & & 6 \\
\hline
\end{tabular}


Table 2: Descriptive statistics, rural strata.

\begin{tabular}{|c|c|c|c|c|c|c|c|c|c|c|c|c|c|c|c|c|c|c|c|c|}
\hline \multirow[t]{2}{*}{ rural } & \multicolumn{5}{|c|}{ Nakhchivan } & \multicolumn{5}{|c|}{ Absheron } & \multicolumn{5}{|l|}{ Mugan- } & \multicolumn{5}{|l|}{ Ganja- } \\
\hline & Census & HBS & $195 b$ & u95b & & Census & HBS & $195 b$ & u95b & & Census & & $195 b$ & u95b & & Census & & 195b & u95b & \\
\hline HH size & 4.59 & 4.03 & 3.84 & 4.23 & 0 & 5.05 & 4.33 & 4.11 & 4.55 & 0 & 5.42 & $\begin{array}{c}\mathrm{HBS} \\
4.89\end{array}$ & 4.72 & 5.06 & 0 & 4.88 & $\begin{array}{c}\text { HBS } \\
4.08\end{array}$ & 3.94 & 4.23 & 0 \\
\hline Hh_female & 0.28 & 0.20 & 0.16 & 0.25 & 1 & 0.22 & 0.22 & 0.17 & 0.27 & 1 & 0.19 & 0.17 & 0.14 & 0.21 & 1 & 0.25 & 0.22 & 0.18 & 0.25 & 1 \\
\hline num_rom & 2.52 & 2.49 & 2.39 & 2.60 & 1 & 2.75 & 2.99 & 2.86 & 3.12 & 0 & 2.57 & 3.09 & 2.97 & 3.20 & 0 & 2.17 & 2.58 & 2.49 & 2.67 & 0 \\
\hline strdwe & 0.58 & 0.96 & 0.94 & 0.98 & 0 & 0.93 & 0.95 & 0.93 & 0.98 & 1 & 0.86 & 0.68 & 0.63 & 0.72 & 0 & 0.95 & 0.97 & 0.95 & 0.98 & 1 \\
\hline owndwe & 0.72 & 0.96 & 0.94 & 0.98 & 0 & 0.94 & 0.94 & 0.91 & 0.97 & 1 & 0.92 & 0.65 & 0.60 & 0.70 & 0 & 0.95 & 0.97 & 0.95 & 0.98 & 1 \\
\hline eleove & 0.64 & 0.87 & 0.83 & 0.91 & 0 & 0.09 & 0.64 & 0.58 & 0.70 & 0 & 0.50 & 0.72 & 0.67 & 0.76 & 0 & 0.41 & 0.95 & 0.93 & 0.96 & 0 \\
\hline telep & 0.07 & 0.19 & 0.14 & 0.23 & 0 & 0.06 & 0.15 & 0.11 & 0.19 & 0 & 0.05 & 0.07 & 0.05 & 0.10 & 1 & 0.08 & 0.10 & 0.08 & 0.13 & 1 \\
\hline gascyl & 0.59 & 0.71 & 0.66 & 0.76 & 0 & 0.14 & 0.13 & 0.10 & 0.17 & 1 & 0.28 & 0.25 & 0.21 & 0.30 & 1 & 0.38 & 0.74 & 0.71 & 0.78 & 0 \\
\hline gasline & 0.09 & 0.00 & 0.00 & 0.00 & 0 & 0.44 & 0.34 & 0.28 & 0.39 & 0 & 0.28 & 0.01 & 0.00 & 0.01 & 0 & 0.39 & 0.01 & 0.00 & 0.01 & 0 \\
\hline haeti & 0.09 & 0.00 & 0.00 & 0.00 & 0 & 0.05 & 0.00 & 0.00 & 0.00 & 0 & 0.04 & 0.00 & 0.00 & 0.00 & 0 & 0.06 & 0.01 & 0.01 & 0.01 & 0 \\
\hline water & 0.19 & 0.26 & 0.21 & 0.31 & 0 & 0.36 & 0.38 & 0.33 & 0.44 & 1 & 0.28 & 0.44 & 0.39 & 0.49 & 0 & 0.24 & 0.23 & 0.19 & 0.26 & 1 \\
\hline hotwa & 0.01 & 0.00 & 0.00 & 0.10 & 0 & 0.01 & 0.29 & 0.24 & 0.34 & 0 & 0.00 & 0.01 & 0.00 & 0.02 & 0 & 0.00 & 0.05 & 0.03 & 0.07 & 0 \\
\hline sewa & 0.07 & 0.73 & 0.68 & 0.79 & 0 & 0.05 & 0.69 & 0.64 & 0.75 & 0 & 0.03 & 0.59 & 0.54 & 0.64 & 0 & 0.05 & 0.70 & 0.66 & 0.74 & 0 \\
\hline bath & 0.10 & 0.01 & 0.00 & 0.02 & 0 & 0.08 & 0.31 & 0.25 & 0.36 & 0 & 0.07 & 0.27 & 0.23 & 0.32 & 0 & 0.09 & 0.21 & 0.18 & 0.24 & 0 \\
\hline under15 & 0.31 & 0.23 & 0.21 & 0.26 & 0 & 0.31 & 0.23 & 0.20 & 0.25 & 0 & 0.33 & 0.28 & 0.25 & 0.30 & 0 & 0.29 & 0.24 & 0.22 & 0.25 & 0 \\
\hline b15to59 & 0.56 & 0.53 & 0.49 & 0.56 & 1 & 0.54 & 0.54 & 0.51 & 0.58 & 1 & 0.55 & 0.56 & 0.53 & 0.58 & 1 & 0.55 & 0.55 & 0.53 & 0.58 & 1 \\
\hline aboave60 & 0.12 & 0.23 & 0.10 & 0.13 & 0 & 0.14 & 0.54 & 0.51 & 0.58 & 0 & 0.10 & 0.15 & 0.13 & 0.18 & 0 & 0.15 & 0.20 & 0.17 & 0.22 & 0 \\
\hline prun15 & 0.16 & 0.12 & 0.10 & 0.13 & 0 & 0.16 & 0.21 & 0.18 & 0.25 & 0 & 0.17 & 0.13 & 0.12 & 0.15 & 0 & 0.15 & 0.11 & 0.10 & 0.13 & 0 \\
\hline pr15to59 & 0.28 & 0.24 & 0.22 & 0.26 & 0 & 0.26 & 0.27 & 0.25 & 0.30 & 1 & 0.26 & 0.27 & 0.25 & 0.29 & 1 & 0.27 & 0.28 & 0.26 & 0.29 & 1 \\
\hline pr60ab & 0.04 & 0.09 & 0.07 & 0.12 & 0 & 0.05 & 0.08 & 0.06 & 0.10 & 0 & 0.04 & 0.06 & 0.05 & 0.07 & 0 & 0.06 & 0.07 & 0.06 & 0.09 & 0 \\
\hline practive & 0.41 & 0.40 & 0.37 & 0.43 & 1 & 0.39 & 0.40 & 0.37 & 0.43 & 1 & 0.38 & 0.43 & 0.41 & 0.46 & 0 & 0.46 & 0.49 & 0.47 & 0.52 & 0 \\
\hline tot_area & 79.62 & 83.44 & 80.41 & 86.48 & 0 & 78.12 & 94.00 & 0.90 & 0.97 & 0 & 81.33 & 94.00 & 90.91 & 97.27 & 0 & 74.70 & 74.40 & 72.69 & 76.12 & 1 \\
\hline thh6 & 0.69 & 0.33 & 0.25 & 0.41 & 0 & 0.65 & 0.34 & 0.26 & 0.42 & 0 & 0.61 & 0.41 & 0.34 & 0.49 & 0 & 0.61 & 0.32 & 0.26 & 0.37 & 0 \\
\hline thh7_12 & 0.74 & 0.55 & 0.45 & 0.65 & 0 & 0.75 & 0.54 & 0.45 & 0.64 & 0 & 0.67 & 0.67 & 0.58 & 0.76 & 1 & 0.67 & 0.53 & 0.47 & 0.59 & 0 \\
\hline thh13_17 & 0.42 & 0.41 & 0.33 & 0.50 & 1 & 0.41 & 0.43 & 0.34 & 0.51 & 1 & 0.38 & 0.51 & 0.43 & 0.58 & 0 & 0.38 & 0.43 & 0.37 & 0.49 & 1 \\
\hline thhabo60 & 3.13 & 2.72 & 2.59 & 2.86 & 0 & 3.10 & 3.00 & 2.85 & 3.15 & 1 & 3.09 & 3.29 & 3.14 & 3.43 & 0 & 3.09 & 2.79 & 2.69 & 2.89 & 0 \\
\hline ae & 3.71 & 3.17 & 3.03 & 3.30 & 0 & 3.67 & 3.45 & 3.29 & 3.61 & 0 & 3.62 & 3.83 & 3.68 & 3.97 & 0 & 3.62 & 3.23 & 3.13 & 3.34 & 0 \\
\hline mar & 0.77 & 0.77 & 0.72 & 0.82 & 1 & 0.76 & 0.73 & 0.68 & 0.78 & 1 & 0.74 & 0.80 & 0.77 & 0.84 & 0 & 0.74 & 0.71 & 0.68 & 0.75 & 1 \\
\hline hh_sec & 0.87 & 0.78 & 0.73 & 0.83 & 0 & 0.78 & 0.74 & 0.69 & 0.79 & 1 & 0.83 & 0.71 & 0.67 & 0.76 & 0 & 0.83 & 0.75 & 0.71 & 0.78 & 0 \\
\hline hh_high & 0.09 & 0.07 & 0.04 & 0.10 & 1 & 0.07 & 0.08 & 0.05 & 0.11 & 1 & 0.10 & 0.06 & 0.03 & 0.08 & 0 & 0.09 & 0.07 & 0.05 & 0.09 & 1 \\
\hline Number of hh & 50327 & 284 & & & 7 & 66346 & 287 & & & 13 & 100264 & 389 & & & 5 & 121691 & 591 & & & 11 \\
\hline
\end{tabular}


Table 3: Descriptive statistics, rural strata.

\begin{tabular}{|c|c|c|c|c|c|c|c|c|c|c|c|c|c|c|c|c|c|c|c|c|}
\hline \multirow[t]{2}{*}{ rural } & \multicolumn{5}{|l|}{ Sheki } & \multicolumn{5}{|c|}{ Lankaran } & \multicolumn{5}{|l|}{ Shirvan } & \multicolumn{5}{|c|}{ Karabah } \\
\hline & Census & HBS & $195 b$ & u95b & & Census & HBS & $195 b$ & u95b & & Census & HBS & $195 b$ & u95b & & Census & HBS & $195 b$ & u95b & \\
\hline HH_size & 4.98 & 4.25 & 4.08 & 4.43 & 0 & 5.66 & 4.74 & 4.57 & 4.91 & 0 & 5.16 & 4.68 & 4.46 & 4.90 & 0 & 4.93 & 4.28 & 4.15 & 4.40 & 0 \\
\hline Hh_female & 0.20 & 0.21 & 0.17 & 0.25 & 1 & 0.20 & 0.23 & 0.19 & 0.27 & 1 & 0.23 & 0.20 & 0.15 & 0.24 & 1 & 0.19 & 0.21 & 0.18 & 0.24 & 1 \\
\hline num_rom & 2.37 & 2.66 & 2.56 & 2.76 & 0 & 2.58 & 2.93 & 2.84 & 3.02 & 0 & 2.34 & 2.49 & 2.39 & 2.59 & 0 & 2.04 & 2.58 & 2.50 & 2.66 & 0 \\
\hline strdwe & 0.95 & 0.91 & 0.89 & 0.94 & 0 & 0.94 & 0.97 & 0.96 & 0.98 & 0 & 0.93 & 0.93 & 0.90 & 0.96 & 1 & 0.77 & 0.73 & 0.70 & 0.77 & 1 \\
\hline owndwe & 0.97 & 0.97 & 0.96 & 0.99 & 1 & 0.98 & 0.97 & 0.96 & 0.99 & 1 & 0.95 & 0.97 & 0.95 & 0.99 & 1 & 0.83 & 0.72 & 0.69 & 0.75 & 0 \\
\hline eleove & 0.10 & 0.98 & 0.97 & 0.99 & 0 & 0.16 & 0.99 & 0.99 & 1.00 & 0 & 0.11 & 0.98 & 0.96 & 0.99 & 0 & 0.39 & 0.68 & 0.64 & 0.71 & 0 \\
\hline telep & 0.07 & 0.15 & 0.11 & 0.18 & 0 & 0.17 & 0.41 & 0.37 & 0.46 & 0 & 0.11 & 0.25 & 0.20 & 0.30 & 0 & 0.04 & 0.12 & 0.10 & 0.15 & 0 \\
\hline gascyl & 0.23 & 0.30 & 0.25 & 0.34 & 0 & 0.36 & 0.61 & 0.57 & 0.65 & 0 & 0.13 & 0.51 & 0.45 & 0.56 & 0 & 0.29 & 0.58 & 0.54 & 0.62 & 0 \\
\hline gasline & 0.21 & 0.01 & 0.00 & 0.01 & 0 & 0.34 & 0.00 & 0.00 & 0.01 & 0 & 0.60 & 0.06 & 0.03 & 0.09 & 0 & 0.17 & 0.18 & 0.15 & 0.21 & 1 \\
\hline haeti & 0.17 & 0.00 & 0.00 & 0.00 & 0 & 0.03 & 0.00 & 0.00 & 0.01 & 0 & 0.05 & 0.00 & 0.00 & 0.01 & 0 & 0.04 & 0.03 & 0.02 & 0.05 & 1 \\
\hline water & 0.37 & 0.52 & 0.47 & 0.57 & 0 & 0.24 & 0.01 & 0.00 & 0.02 & 0 & 0.27 & 0.24 & 0.19 & 0.29 & 1 & 0.17 & 0.30 & 0.27 & 0.34 & 0 \\
\hline hotwa & 0.00 & 0.02 & 0.01 & 0.03 & 0 & 0.00 & 0.09 & 0.06 & 0.11 & 0 & 0.00 & 0.08 & 0.05 & 0.11 & 0 & 0.00 & 0.20 & 0.17 & 0.23 & 0 \\
\hline sewa & 0.02 & 0.70 & 0.66 & 0.75 & 0 & 0.04 & 0.64 & 0.60 & 0.68 & 0 & 0.04 & 0.85 & 0.81 & 0.89 & 0 & 0.02 & 0.67 & 0.64 & 0.71 & 0 \\
\hline bath & 0.06 & 0.22 & 0.18 & 0.27 & 0 & 0.06 & 0.36 & 0.31 & 0.40 & 0 & 0.07 & 0.33 & 0.28 & 0.39 & 0 & 0.04 & 0.37 & 0.33 & 0.41 & 0 \\
\hline under15 & 0.30 & 0.25 & 0.23 & 0.28 & 0 & 0.32 & 0.26 & 0.24 & 0.29 & 0 & 0.30 & 0.27 & 0.24 & 0.30 & 1 & 0.30 & 0.24 & 0.22 & 0.26 & 0 \\
\hline b15to59 & 0.56 & 0.56 & 0.53 & 0.59 & 1 & 0.56 & 0.57 & 0.55 & 0.60 & 1 & 0.54 & 0.53 & 0.50 & 0.56 & 1 & 0.56 & 0.56 & 0.54 & 0.58 & 1 \\
\hline aboave60 & 0.13 & 0.17 & 0.14 & 0.20 & 0 & 0.11 & 0.15 & 0.13 & 0.18 & 0 & 0.15 & 0.18 & 0.15 & 0.21 & 1 & 0.13 & 0.18 & 0.16 & 0.21 & 0 \\
\hline prun15 & 0.15 & 0.12 & 0.10 & 0.13 & 0 & 0.17 & 0.13 & 0.12 & 0.15 & 0 & 0.16 & 0.16 & 0.14 & 0.18 & 1 & 0.16 & 0.12 & 0.11 & 0.13 & 0 \\
\hline pr15to59 & 0.27 & 0.27 & 0.25 & 0.29 & 1 & 0.27 & 0.26 & 0.25 & 0.28 & 1 & 0.26 & 0.24 & 0.22 & 0.27 & 1 & 0.27 & 0.26 & 0.24 & 0.27 & 1 \\
\hline pr60ab & 0.05 & 0.07 & 0.05 & 0.08 & 1 & 0.04 & 0.06 & 0.04 & 0.07 & 1 & 0.06 & 0.07 & 0.05 & 0.08 & 1 & 0.05 & 0.07 & 0.05 & 0.08 & 1 \\
\hline practive & 0.44 & 0.51 & 0.48 & 0.53 & 0 & 0.43 & 0.47 & 0.44 & 0.49 & 0 & 0.41 & 0.43 & 0.40 & 0.46 & 1 & 0.41 & 0.42 & 0.40 & 0.44 & 1 \\
\hline tot_area & 73.89 & 79.82 & 77.31 & 82.33 & 0 & 83.27 & 89.78 & 87.55 & 92.01 & 0 & 75.55 & 88.55 & 85.39 & 91.70 & 0 & 64.51 & 80.36 & 78.18 & 82.53 & 0 \\
\hline thh6 & 0.64 & 0.40 & 0.33 & 0.47 & 0 & 0.73 & 0.40 & 0.34 & 0.46 & 0 & 0.66 & 0.47 & 0.38 & 0.56 & 0 & 0.62 & 0.37 & 0.31 & 0.42 & 0 \\
\hline thh7_12 & 0.71 & 0.53 & 0.46 & 0.61 & 0 & 0.84 & 0.67 & 0.59 & 0.75 & 0 & 0.73 & 0.73 & 0.63 & 0.84 & 1 & 0.71 & 0.54 & 0.48 & 0.61 & 0 \\
\hline thh13__17 & 0.39 & 0.45 & 0.37 & 0.52 & 1 & 0.50 & 0.47 & 0.40 & 0.54 & 1 & 0.41 & 0.39 & 0.31 & 0.46 & 1 & 0.41 & 0.42 & 0.36 & 0.47 & 1 \\
\hline thhabo60 & 3.12 & 2.86 & 2.73 & 2.90 & 0 & 3.43 & 3.18 & 3.05 & 3.31 & 0 & 3.22 & 3.08 & 2.92 & 3.23 & 1 & 3.06 & 2.93 & 2.83 & 3.03 & 0 \\
\hline ae & 3.66 & 3.33 & 3.19 & 3.46 & 0 & 4.09 & 3.70 & 3.57 & 3.83 & 0 & 3.78 & 3.59 & 3.43 & 3.75 & 0 & 3.61 & 3.38 & 3.28 & 3.49 & 0 \\
\hline mar & 0.78 & 0.72 & 0.68 & 0.76 & 0 & 0.80 & 0.75 & 0.72 & 0.79 & 1 & 0.76 & 0.75 & 0.70 & 0.80 & 1 & 0.79 & 0.77 & 0.74 & 0.80 & 1 \\
\hline hh_sec & 0.76 & 0.72 & 0.68 & 0.77 & 1 & 0.79 & 0.78 & 0.75 & 0.82 & 1 & 0.76 & 0.77 & 0.72 & 0.82 & 1 & 0.79 & 0.80 & 0.77 & 0.83 & 1 \\
\hline hh_high & 0.07 & 0.07 & 0.04 & 0.09 & 1 & 0.10 & 0.17 & 0.14 & 0.21 & 0 & 0.06 & 0.07 & 0.04 & 0.11 & 1 & 0.08 & 0.11 & 0.09 & 0.14 & 0 \\
\hline $\begin{array}{l}\text { Number of hh } \\
\text { Number of hh }\end{array}$ & 78286 & 393 & & & 8 & 6103 & 497 & & & 8 & 61034 & 294 & & & 17 & 149777 & 672 & & & 11 \\
\hline
\end{tabular}


Table 3: Urban Strata

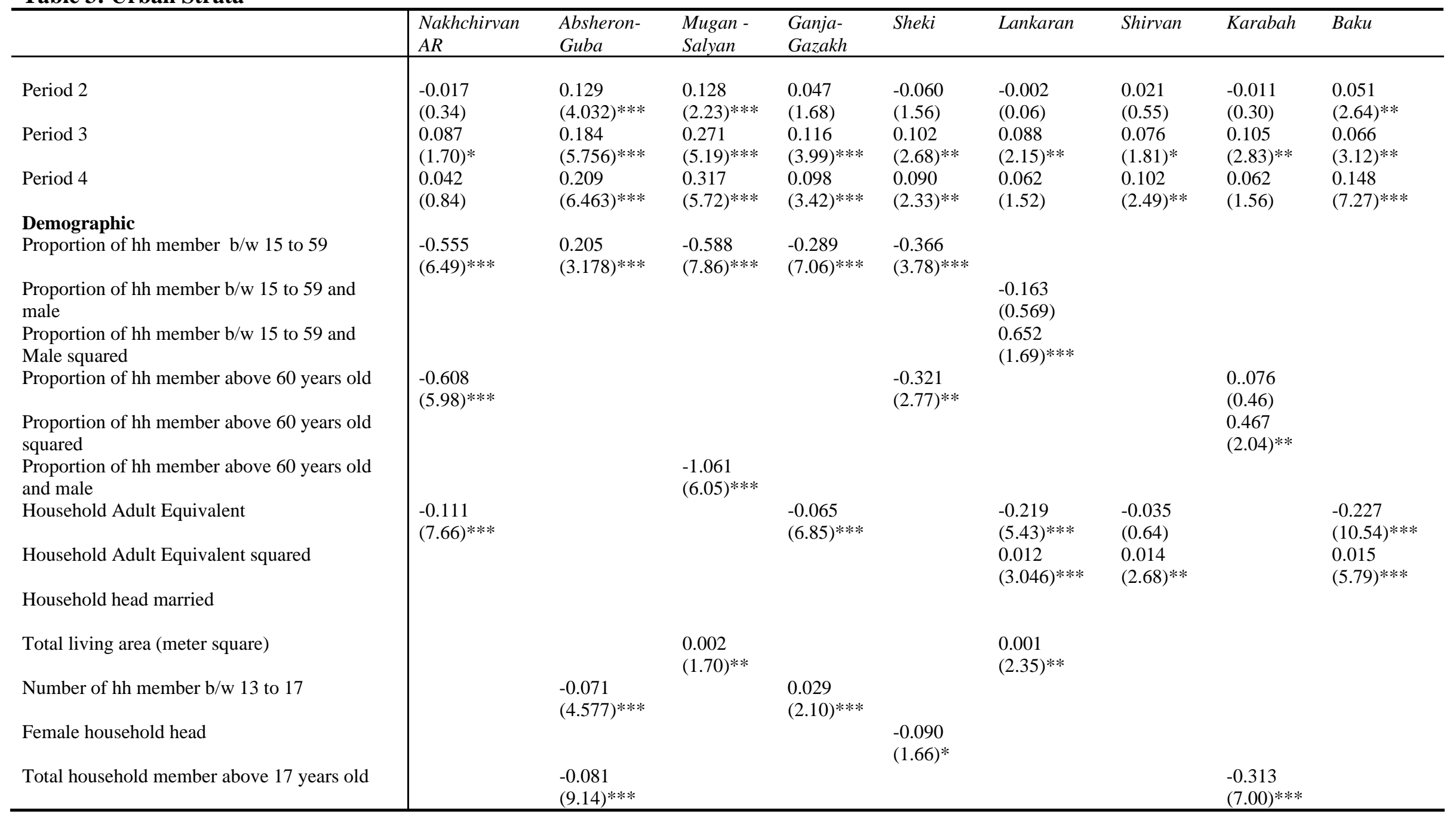




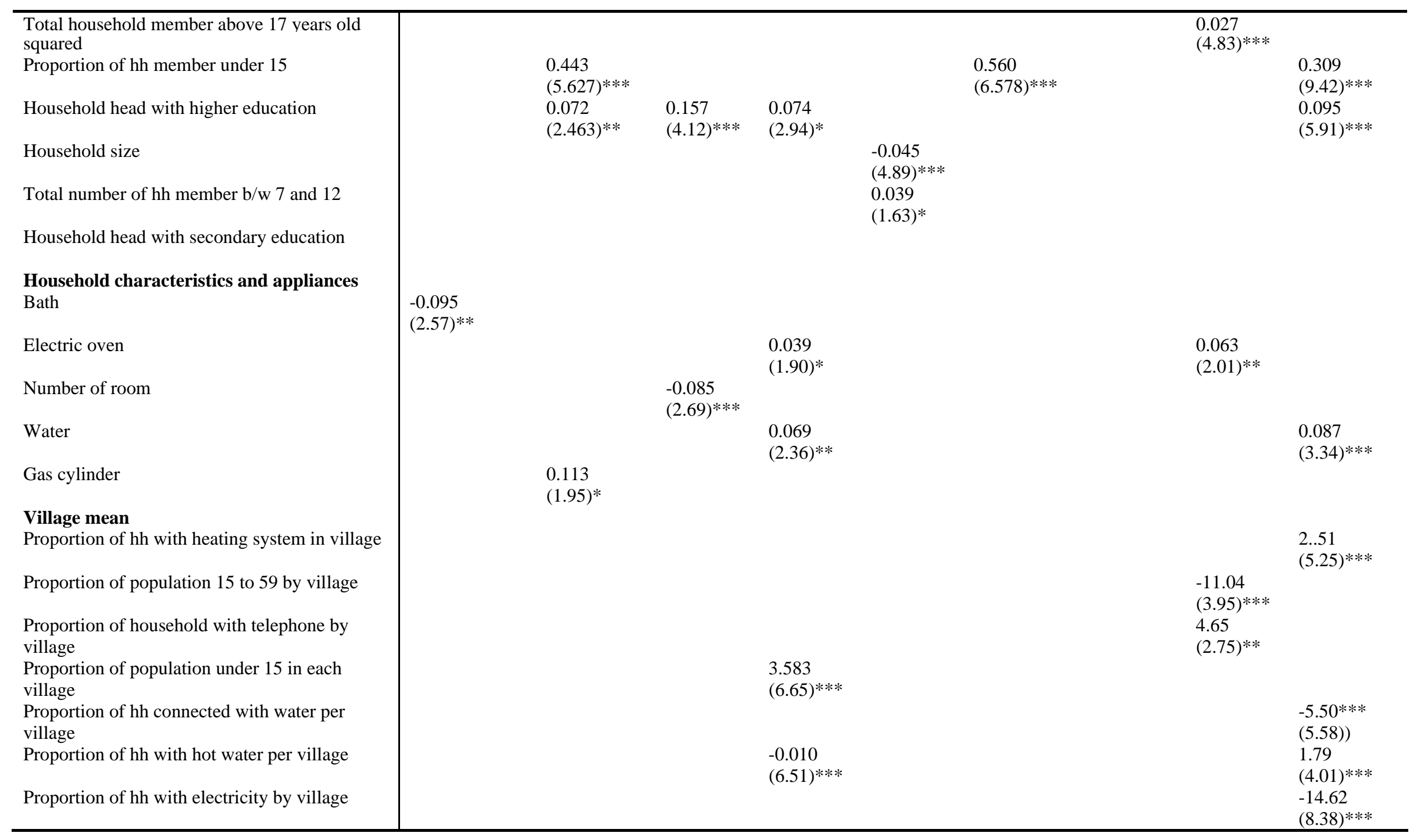




\begin{tabular}{|c|c|c|c|c|c|c|c|c|c|}
\hline Mean household size per village & & $\begin{array}{l}-0.123 \\
(5.367)^{* * *}\end{array}$ & & & & & & & \\
\hline Constant & $\begin{array}{l}13.189 \\
(159.2)^{* * *}\end{array}$ & $\begin{array}{l}12.847 \\
(100.06)^{* * *}\end{array}$ & $\begin{array}{l}12.628 \\
(204.5)^{* *}\end{array}$ & $\begin{array}{l}12.066 \\
(99.28)^{* *}\end{array}$ & $\begin{array}{l}12.826 \\
(117.13)^{*}\end{array}$ & $\begin{array}{l}12.663 \\
(117.64)^{* * *}\end{array}$ & $\begin{array}{l}12.737 \\
(126.09) *\end{array}$ & $\begin{array}{l}19.11 \\
(12.26)^{* *}\end{array}$ & $\begin{array}{l}10.85 \\
(17.62)^{* * *}\end{array}$ \\
\hline Observations & 187 & 601 & 287 & 490 & 194 & 195 & 206 & 398 & 2192 \\
\hline Number of cluster in HBS & 2 & 6 & 3 & 5 & 2 & 3 & 2 & 5 & 19 \\
\hline Weight applied & NO & YES & YES & YES & YES & NO & NO & YES & NO \\
\hline Location Effect modelled & NO & NO & $\mathrm{NO}$ & NO & NO & $\mathrm{NO}$ & $\mathrm{NO}$ & NO & YES \\
\hline R-squared & 0.45 & 0.33 & 0.42 & 0.36 & 0.31 & 0.56 & 0.32 & 0.36 & 0.29 \\
\hline
\end{tabular}

Absolute value of $\mathrm{t}$ statistics in parentheses

significant at $10 \%$; ** significant at $5 \%$; *** significant at $1 \%$

\section{Table 4: Rural Strata}

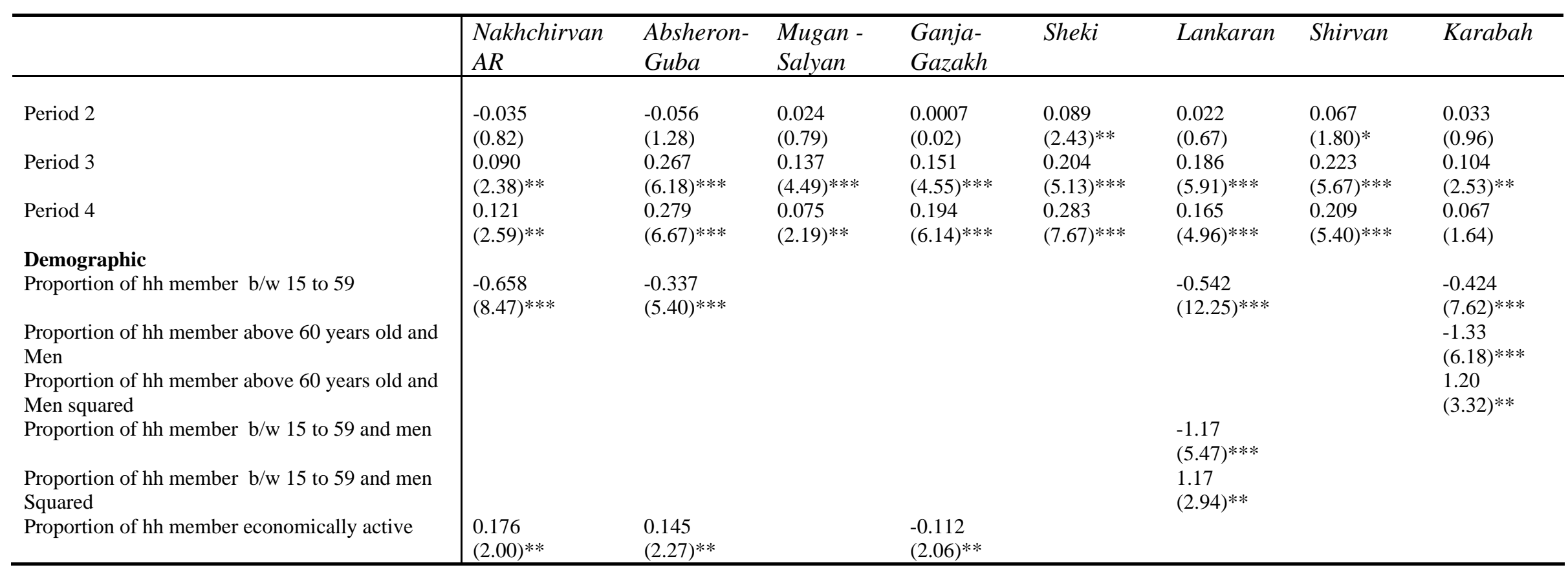




\begin{tabular}{|c|c|c|c|c|c|c|c|c|}
\hline Number of hh member b/w 7 and 12 & & & $\begin{array}{l}0.104 \\
(8.35) * * *\end{array}$ & & & & & \\
\hline Number of hh member b/w 13 to 17 & & & & $\begin{array}{l}-0.061 \\
(3.62)^{* * *}\end{array}$ & $\begin{array}{l}-0.030 \\
(2.24)^{* *}\end{array}$ & & $\begin{array}{l}-0.075 \\
(3.92)^{* * *}\end{array}$ & \\
\hline Number of hh member above 17 & & $\begin{array}{l}-0.079 \\
(7.77)^{* * *}\end{array}$ & & & & & $\begin{array}{l}-0.060 \\
(5.97)^{* * *}\end{array}$ & \\
\hline Household head with higher education & & & $\begin{array}{l}0.111 \\
(1.83)^{*}\end{array}$ & $\begin{array}{l}0.111 \\
(2.04)^{* *}\end{array}$ & & & & \\
\hline Household Adult Equivalent & & & $\begin{array}{l}-0.072 \\
(8.44)^{* * *}\end{array}$ & & & & & \\
\hline Household head with secondary education & & $\begin{array}{l}0.124 \\
(3.87)^{* * *}\end{array}$ & & & & $\begin{array}{l}0.103 \\
(4.13)^{* * *}\end{array}$ & $\begin{array}{l}0.077 \\
(2.61)^{* *}\end{array}$ & \\
\hline Female household head & $\begin{array}{l}-0.070 \\
(1.64)^{*}\end{array}$ & & & & $\begin{array}{l}-0.053 \\
(2.16)^{* *}\end{array}$ & & & $\begin{array}{l}-0.104 \\
(2.67)^{* *}\end{array}$ \\
\hline Proportion of hh member under 15 & & & & $\begin{array}{l}0.477 \\
(7.79) * * *\end{array}$ & $\begin{array}{l}0.660 \\
(11.18)^{* * *}\end{array}$ & & $\begin{array}{l}0.404 \\
(5.98) * * *\end{array}$ & \\
\hline Household head married & & $\begin{array}{l}0.056 \\
(1.81)^{*}\end{array}$ & & $\begin{array}{l}-0.062 \\
(2.13)^{* *}\end{array}$ & & & & \\
\hline Household characteristics and appliances & & & & & & & & \\
\hline Household is in a separate household & & & & & $\begin{array}{l}-0.134 \\
(3.48)^{* *}\end{array}$ & & & \\
\hline Number of room & $\begin{array}{l}-0.050 \\
(3.31)^{* *}\end{array}$ & & & & & & & \\
\hline Gas cylinder & $\begin{array}{l}0.105 \\
(2.54)^{* *}\end{array}$ & & $\begin{array}{l}0.067 \\
(2.32)^{* *}\end{array}$ & & & & & \\
\hline Village mean & & & & & & & & \\
\hline Proportion of hh with gas cylinder per village & $\begin{array}{l}1.69 \\
(3.11)^{* *}\end{array}$ & & $\begin{array}{l}-0.771 \\
(4.86)^{* * *}\end{array}$ & $\begin{array}{l}-2.328 \\
(3.96)^{* * *}\end{array}$ & $\begin{array}{l}2.34 \\
(3.60)^{* * *}\end{array}$ & & & \\
\hline Proportion of hh with gas line per village & & & & & & & & $\begin{array}{l}0.970 \\
(3.01)^{* *}\end{array}$ \\
\hline Mean household living area per village & & & & $\begin{array}{l}0.008 \\
(4.73)^{* * *}\end{array}$ & & & $\begin{array}{l}-0.006 \\
(5.07)^{* * *}\end{array}$ & \\
\hline Population per village & & & & $\begin{array}{l}-0.0002 \\
(3.68)^{* * *}\end{array}$ & & & & \\
\hline Average hh sixe per village & & & & & & & & $\begin{array}{l}0.065 \\
(1.90)^{*}\end{array}$ \\
\hline Total number of household per village & & & & 0.001 & & & -0.0002 & \\
\hline
\end{tabular}




\begin{tabular}{|c|c|c|c|c|c|c|c|c|}
\hline \multirow{3}{*}{$\begin{array}{l}\text { Mean number of room per hh per village } \\
\text { Average proportion of hh member economically } \\
\text { active per village }\end{array}$} & & \multicolumn{4}{|c|}{$(4.15)^{* * *}$} & \multicolumn{3}{|c|}{$(9.54)^{* * *}$} \\
\hline & & $\begin{array}{l}0.104 \\
(1.85)^{*}\end{array}$ & & & & & & $\begin{array}{l}-0.115 \\
(3.87)^{* * *}\end{array}$ \\
\hline & -0.833 & & & & 0.572 & & & \\
\hline Proportion of electric oven per village & $(1.99)^{* *}$ & & & $\begin{array}{l}-1.38 \\
(3.59)^{* *}\end{array}$ & $(1.98)^{* *}$ & & & \\
\hline Proportion of population under 15 per village & & & & & & & & $\begin{array}{l}2.66 \\
(3.68)^{* * *}\end{array}$ \\
\hline Constant & $\begin{array}{l}12.73 \\
(60.53)^{* * *}\end{array}$ & $\begin{array}{l}12.20 \\
(67.11)^{* * *}\end{array}$ & $\begin{array}{l}12.57 \\
(270.05)^{* * *}\end{array}$ & $\begin{array}{l}11.80 \\
(92.96)^{* * *}\end{array}$ & $\begin{array}{l}11.87 \\
(84.3)^{* * *}\end{array}$ & $\begin{array}{l}12.54 \\
(318.8)^{* * *}\end{array}$ & $\begin{array}{l}12.94 \\
(115.97)^{* * *}\end{array}$ & $\begin{array}{l}11.67 \\
(50.14)^{* * *}\end{array}$ \\
\hline Observations & 284 & 287 & 389 & 591 & 393 & 497 & 294 & 672 \\
\hline Number of cluster in HBS & 9 & 3 & 9 & 15 & 6 & 10 & 5 & 16 \\
\hline Weight applied & YES & NO & NO & NO & YES & NO & NO & YES \\
\hline Location effect modelled & NO & NO & NO & NO & NO & NO & NO & YES \\
\hline R-squared & 0.46 & 0.52 & 0.38 & 0.28 & 0.45 & 0.31 & 0.52 & 0.24 \\
\hline
\end{tabular}

Absolute value of $\mathrm{t}$ statistics in parentheses

significant at $10 \%$; ** significant at $5 \%$; *** significant at $1 \%$ 


\section{Technical Note 2: Creating a poverty map using the Asset index method}

\section{Data and Methods}

In order to create poverty map in this section we apply the asset index methods using data from the 1999 Census of Azerbaijan collected from the State Statistical Committee of Azerbaijan. With this technique the socio economic status of households is defined in terms of assets or wealth, rather than in terms of income or consumption. The 1999 Census included several questions regarding the ownership of consumer durables and the materials used in the construction of the household, along with basic demographic information concerning household size and composition. Table 1 presents some basic descriptive statistics of the potential components of the asset index.

Table 1: Ownership of assets and household characteristics, Azerbaijan 1999

\begin{tabular}{l|lllc}
\hline & Mean & $\begin{array}{l}\text { Standard } \\
\text { Deviation }\end{array}$ & Min & Max \\
\hline 1. Gas Line & 0.584 & 0.492 & 0 & 1 \\
2. Gas Cylinder & 0.209 & 0.407 & 0 & 1 \\
3. Electric Oven & 0.245 & 0.430 & 0 & 1 \\
4. Heating system (private, public) & 0.09 & 0.286 & 0 & 1 \\
5. Stove & 0.391 & 0.487 & 0 & 1 \\
6. Water & 0.588 & 0.492 & 0 & 1 \\
7. Hot water & 0.04 & 0.196 & 0 & 1 \\
8. Sewage System & 0.412 & 0.492 & 0 & 1 \\
9. Bathroom & 0.385 & 0.486 & 0 & 1 \\
10. Telephone & 0.269 & 0.443 & 0 & 1 \\
11. Total living area (square meters) & 65.24 & 47.929 & 0 & 2000 \\
12. Number of rooms & 2.371 & 1.498 & 0 & 96 \\
13. Dwelling Structure(separate house, no) & 0.637 & 0.480 & 0 & 1 \\
14. Ownership of dwelling & 0.739 & 0.438 & 0 & 1 \\
15. Rural household & 0.430 & 0.495 & 0 & 1 \\
\hline
\end{tabular}

Each household asset for which the information was collected though the 1999 Azerbaijan Census was assigned a weight or factor score generated through principal components analysis. The principal components analysis (PCA) is a dimension reduction technique (Chatfield and Collins 1980). This multivariate statistical technique is used to examine the relationships between a set of correlated variables. 
In this analysis it was decided to include a dummy for urban and rural area, the idea being that the inclusion of this extra dummy will capture part of the local variation due to differences in durable ownership and housing characteristics due to the place of residence. To our knowledge no other previous studies have included locational dummies in the model. An alternative would be to estimate two separate asset indices, one for rural area and one for urban area. This would allow us to rank urban and rural differences in ownership of amenities. However, this approach would preclude any national analysis as the ranking of urban and rural household would necessarily need be performed separately (see Appendix A, Table A1-A4 for the results of principal components analysis done separately for urban and rural area and Figure A1-A4 for the comparisons of the household ranking between the per capita monthly consumption expenditure and urban or rural asset indices).

Given that the Census collects information on 15 asset type variables, the potential range of combinations is $2^{15}$ (i.e. 15 dimensions). As it is not straightforward to visualize any data with more than three dimensions, the PCA allows the reduction of the number of variables, and thus dimensionality without losing too much information in the process. The PCA technique achieves this by creating a smaller number of variables which explain most of the variation in the original variables. The new variables (which are created such that they are uncorrelated with each other) are linear combinations of the original variables (factor score). They are derived in decreasing order of importance so that, for example, the first new variable will account for as much as possible of the variation in the original data. An illustration of PCA is presented below.

Suppose we have $p$ variables (in our case $p$ data on household asset), $X_{1}, X_{2}, \ldots, X_{p}$, for $n$ individuals.

The first principal component is the linear combination of these variables

$$
Z_{1}=a_{11} X_{1}+a_{12} X_{2}+a_{13} X_{3}+\ldots \ldots \ldots+a_{1 p} X_{p}
$$

The coefficients $a_{11}, a_{12}, \ldots, a_{1 p}$ are chosen such that the variance of $Z_{1}$ is maximised. 
The coefficients are subject to the constraint that:

$$
a_{11}^{2}+a_{12}^{2}+\ldots+a_{1 p}^{2}=1
$$

If this constraint is not introduced then the variance of $Z_{1}$ can be increased simply by increasing any one of the coefficient.

The second principal component is the linear combination

$$
Z_{2}=a_{21} X_{1}+a_{22} X_{2}+a_{23} X_{3}+\ldots \ldots \ldots+a_{2 p} X_{p}
$$

such that the variance of $Z_{2}$ is maximised subject to the constraint that

$$
a_{21}^{2}+a_{22}^{2}+\ldots+a_{2 p}^{2}=1
$$

and also that $Z_{1}$ and $Z_{2}$ are uncorrelated.

The third principal component is the linear combination

$$
Z_{3}=a_{31} X_{1}+a_{32} X_{2}+a_{33} X_{3}+\ldots \ldots \ldots+a_{3 p} X_{p}
$$

such that the variance of $Z_{3}$ is maximized subject to the constraint that

$$
a_{31}^{2}+a_{32}^{2}+\ldots+a_{3 p}^{2}=1
$$

and also that $Z_{3}$ is uncorrelated with $Z_{1}$ and $Z_{2}$.

Further principal components (up to the maximum of $p$ ) are defined in a similar way. Each principal component is uncorrelated with all the others and the squares of its coefficients sums to one.

The principal components analysis involves finding the eigenvalues and eigenvectors of the covariance matrix. These are just special function of the covariance matrix.

If we consider the ith principal component (PC),

$$
Z_{i}=a_{i 1} X_{1}+a_{i 2} X_{2}+a_{i 3} X_{3}+\ldots \ldots \ldots+a_{i p} X_{p}
$$

the variance of $Z_{i}$ is the ith eigenvalue ,i.e. $\operatorname{Var}\left(Z_{i}\right)=\lambda 1$; 
One important property of PCs is that the total variation in the data is preserved. The sum of the variances of the PCs is equal to the sum of the variance of the original variables,

$$
\begin{gathered}
\operatorname{var}\left(X_{1}\right)+\operatorname{var}\left(X_{2}\right)+\ldots+\operatorname{var}\left(X_{p}\right)=\operatorname{var}\left(Z_{1}\right)+\operatorname{var}\left(Z_{2}\right)+\ldots .+\operatorname{var}\left(Z_{p}\right) \\
=\lambda 1+\lambda 2+\ldots+\lambda p
\end{gathered}
$$

The variables used in this analysis are measured in different scales (some of the variables are binary, some other categorical and some other continuous). This can lead to one variable having an undue influence on the principal components simply because of the scale of measurement. To avoid this problem usually the original variables are $X_{1}, X_{2}, \ldots, X_{p}$ are standardized before performing PCA.

The covariance matrix of the standardised variables, which we shall label $X_{1}^{*}, X_{2}^{*}, \ldots X_{p}^{*}$ is simply the correlation matrix of the original variables $X_{1}, X_{2}, \ldots, X_{p}$. In other words we could carry out PCA by obtaining the eigenvalues and eigenvectors of the correlation matrix (rather than covariance matrix).

Therefore the sum of the variance of the standardized variables is

$$
\operatorname{var}\left(X_{1}^{*}\right)+\operatorname{var}\left(X_{2}^{*}\right)+\ldots . .+\operatorname{var}\left(X_{p}^{*}\right)=1+1+1+\ldots .+1=p
$$

which means that the sum of the variances of the PCs is

$$
\lambda 1+\lambda 2+\ldots+\lambda p=p
$$

It is important to consider that the proportion of variance explained by the first principal component will depend on the number of variables included in the analysis. As our aim is to explore the maximum variation amongst household score in order to obtain a "better measure of wealth inequalities” we will try in this analysis to include all the variables related to household economics for constructing an household asset, as in this way we will obtain a more regular distribution of households across quintiles. 


\section{Results}

Including all the asset variables of the 1999 Census dataset that are related to household economics (presented in Table 1 above) results in an asset index with 15 components. Thus when we perform the PCA the dimension of the variable will be 15, and the proportion of variance explained from the first PC will be compared with the total variance with 15 variables. If a smaller number of variables are used, the proportion of the variance explained from the first PC will be higher, but this PC will be based on a small number of variables with supposedly smaller variance, but also with less information about the household. In this paper we apply the PCA to the full correlation matrix of all 15 variables. Table 2 presents the result of the variance of the principal components analysis.

Table 2: Total variance explained by each component.

\begin{tabular}{|c|c|c|c|c|}
\hline Component & Eigenvalues & Differences & Proportion & Cumulative \\
\hline 1 & 4.767 & 2.881 & 0.3178 & 0.3178 \\
\hline 2 & 1.885 & 0.653 & 0.1257 & 0.4436 \\
\hline 3 & 1.231 & 0.105 & 0.0821 & 0.5257 \\
\hline 4 & 1.125 & 0.143 & 0.0751 & 0.6008 \\
\hline 5 & 0.982 & 0.180 & 0.0655 & 0.6662 \\
\hline 6 & 0.801 & 0.040 & 0.0534 & 0.7197 \\
\hline 7 & 0.760 & 0.115 & 0.0507 & 0.7704 \\
\hline 8 & 0.645 & 0.088 & 0.0430 & 0.8134 \\
\hline 9 & 0.556 & 0.064 & 0.0371 & 0.8505 \\
\hline 10 & 0.491 & 0.036 & 0.0328 & 0.8833 \\
\hline 11 & 0.455 & 0.023 & 0.0303 & 0.9136 \\
\hline 12 & 0.431 & 0.059 & 0.0288 & 0.9424 \\
\hline 13 & 0.371 & 0.097 & 0.0248 & 0.9672 \\
\hline 14 & 0.274 & 0.057 & 0.0183 & 0.9855 \\
\hline 15 & 0.217 & 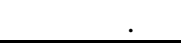 & 0.0145 & 1.0000 \\
\hline
\end{tabular}

The principal components is a technique for extracting from a large number of variables those few orthogonal linear combinations of the variables that best capture the common information. The first principal component is a linear index of variables with the largest amount of information common to all of variables. In the present analysis, the first principal component explains more than 30 percent of the variation of the original variables and each subsequent 
component explains a decreasing proportion of variance. The scree plot shown in Figure 1 displays the proportion of variance explained by each principal component; on the x-axis are the components and the y-axis depicts the eigenvalues of each component.

Figure 1: Scree-plot for results of principal component using household variable in 1999 Azerbaijan census household questionnaire.

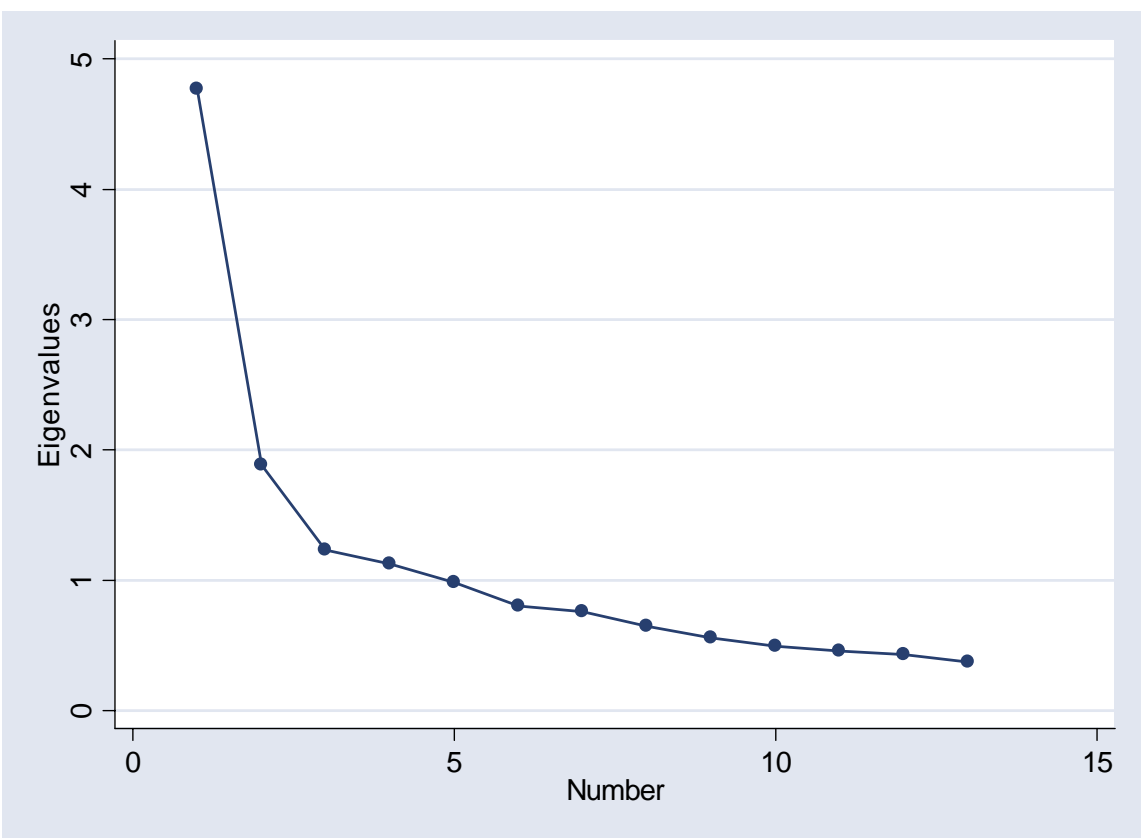

In calculating the household index, only the factor score (eigenvectors) of the first principal component were considered. Table 3 column (4) shows the results of the principal component on the correlation matrix of the 15 variable considered.

The asset score (A) for the jth household considering $\mathrm{N}$ variables is given by:

$$
A_{j}=f_{1}\left(a_{j 1}-a_{1}\right) /\left(s_{1}\right)+\ldots+f_{N}\left(a_{j N}-a_{j n}\right) /\left(s_{N}\right)
$$

where $f_{1}$ is the eigenvector for the first asset as determined by the procedure, $a_{j 1}$ is the jth household's value for the first asset and $a_{1}$ and $s_{1}$ are the mean and standard deviation of the first asset variable over all households.

The mean value of the index is zero by construction. The standard deviation in this case is 1.90 since all asset variables (except “number of room”, and “total living area”) take only the 
values of zero or one, the weights have an easy interpretation. A move 0 to 1 (if household not owns or owns an asset) changes the index by $f_{1} / s_{1}$, for example a household that owns a telephone has an asset index higher by 0.38 than that one that does not. Being a rural household lowers the index by 0.40 per cent (see column 6 and 7 to see the change in the index due to each asset variable).

Each household was assigned a standardized score for each asset, where the scores differed depending on whether or not the household owned that asset. Column 6 of Table 3 below shows the value of score if household owned the asset, and Column 7 shows the value of score if the household does not have the asset.

Table 3: Result of household economic index.

\begin{tabular}{|c|c|c|c|c|c|c|}
\hline & $\begin{array}{c}(2) \\
\text { Mean }\end{array}$ & $\begin{array}{c}\text { (3) } \\
\text { Standard } \\
\text { Deviation }\end{array}$ & $\begin{array}{c}\text { (4) } \\
\text { Eigenvectors } \\
\text { of first } \\
\text { principal } \\
\text { components }\end{array}$ & $\begin{array}{l}\text { (5) } \\
\text { Scoring } \\
\text { factor/ } \\
\text { Std. } \\
\text { Dev. }\end{array}$ & $\begin{array}{c}\text { (6) } \\
\text { Score if } \\
\text { they } \\
\text { have } \\
\text { asset }\end{array}$ & $\begin{array}{c}\text { (7) } \\
\text { Score if } \\
\text { they don't } \\
\text { have asset }\end{array}$ \\
\hline 1. Gas Line & 0.584 & 0.492 & 0.299 & 0.608 & 0.253 & -0.355 \\
\hline 2. Gas Cylinder & 0.209 & 0.407 & -0.176 & -0.432 & -0.342 & 0.090 \\
\hline 3. Electric Oven & 0.245 & 0.430 & -0.143 & -0.333 & -0.251 & 0.081 \\
\hline 4. Heating System (private, public) & 0.09 & 0.286 & 0.078 & 0.273 & 0.248 & -0.025 \\
\hline 5. Stove & 0.391 & 0.487 & -0.308 & -0.632 & -0.385 & 0.247 \\
\hline 6. Water & 0.588 & 0.492 & 0.327 & 0.665 & 0.274 & -0.391 \\
\hline 7. Hot water & 0.04 & 0.196 & 0.132 & 0.673 & 0.647 & -0.027 \\
\hline 8. Sewage System & 0.412 & 0.492 & 0.391 & 0.795 & 0.467 & -0.327 \\
\hline 9. Bathroom & 0.385 & 0.486 & 0.355 & 0.730 & 0.449 & -0.281 \\
\hline 10. Telephone & 0.269 & 0.443 & 0.233 & 0.526 & 0.384 & -0.141 \\
\hline 11. Total living area (square meters) & 65.24 & 47.929 & -0.114 & -0.002 & $* *$ & $* *$ \\
\hline 12. Number of room & 2.371 & 1.498 & -0.009 & -0.006 & ** & ** \\
\hline 13. Dwelling Structure (separate house, no) & 0.637 & 0.48 & -0.301 & -0.627 & -0.228 & 0.399 \\
\hline 14. Ownership of dwelling & 0.739 & 0.438 & -0.243 & -0.555 & -0.145 & 0.410 \\
\hline \multirow[t]{2}{*}{ 15. Rural household } & 0.430 & 0.495 & -0.367 & -0.741 & -0.423 & 0.319 \\
\hline & 0 & 1.90 & & & & \\
\hline
\end{tabular}

**: Household score for number of room are calculated as follow: \{\#number of room-unweighted mean)/unweighted Standard deviation $\} / *$ asset factor score. The same applies for total living area.

These score were summed by household, and individuals ranked according to the total score of the household in which they resided. These standardized scores were then used to create the breakpoint that defines wealth quintiles as follows. The sample of household has been then divided into population quintiles (five groups with same number of individual each). Wealth 
quintiles are expressed in terms of quintiles of individuals in the population. In Table 4 below are shown the quintile boundaries of the asset index.

Table 4: Quintile of asset index, 1999 Azerbaijan Census.

\begin{tabular}{l|lll}
\hline Percentile & Centile value & $\begin{array}{l}\text { Lower Bound } \\
\text { 95\% CI }\end{array}$ & $\begin{array}{l}\text { Upper Bound } \\
\mathbf{9 5 \% ~ C I ~}\end{array}$ \\
\hline 20 & -2.387 & -2.389 & -2.387 \\
40 & -1.329 & -1.331 & -1.327 \\
60 & 0.313 & 0.306 & 0.318 \\
80 & 2.184 & 2.184 & 2.185 \\
\hline & & & \\
\hline
\end{tabular}

Note: Total number of present population 7.798 .578 according to 1999 Azerbaijan Census. 


\section{Appendix A: Constructing separate asset indices for urban and rural areas}

Tables A1 presents basic descriptive statistics for the ownership of selected assets in urban and rural areas of Azerbaijan. Given that there are marked differences in the extent of assets ownership between urban and rural areas, it could be argued that it is more appropriate to derive separate asset indices for each locality rather than a single index for the country as a whole. The drawback of doing so is that such an approach precludes any national analysis. However the advantage is that separate indices may provide better rankings of welfare within urban and rural areas than a simple national index. Tables A2 and A3 therefore present the results of the PCA within each area and these weights are used to construct two separate assets indices, one for urban households and another for rural households.

Table A1: Ownership of assets and household characteristics in urban and rural areas, Azerbaijan 1999 Census

\begin{tabular}{l|llll}
\hline & \multicolumn{3}{c}{ Urban } & \multicolumn{2}{c}{ Rural } \\
& Mean & $\begin{array}{l}\text { Standard } \\
\text { Deviation }\end{array}$ & Mean & $\begin{array}{l}\text { Standard } \\
\text { Deviation }\end{array}$ \\
1. Gas Line & 0.792 & 0.405 & 0.310 & 0.462 \\
2. Gas Cylinder & 0.139 & 0.346 & 0.303 & 0.459 \\
3. Electric Oven & 0.188 & 0.390 & 0.321 & 0.467 \\
4. Heating system (private, public) & 0.110 & 0.313 & 0.063 & 0.244 \\
5. Stove & 0.171 & 0.376 & 0.681 & 0.465 \\
6. Water & 0.835 & 0.370 & 0.261 & 0.439 \\
7. Hot water & 0.068 & 0.252 & 0.002 & 0.053 \\
8. Sewage System & 0.695 & 0.460 & 0.037 & 0.190 \\
9. Bathroom & 0.625 & 0.483 & 0.068 & 0.252 \\
10. Telephone & 0.414 & 0.492 & 0.076 & 0.265 \\
11. Total living area (square meters) & 57.82 & 46.99 & 75.07 & 47.38 \\
12. Number of rooms & 2.37 & 1.55 & 2.37 & 1.42 \\
13. Dwelling Structure(separate house, no) & 0.440 & 0.496 & 0.899 & 0.301 \\
14. Ownership of dwelling & 0.594 & 0.491 & 0.931 & 0.252 \\
\hline
\end{tabular}

A key question is how these alternative welfare rankings compare with those derived from the 'inputed welfare method'. Figures A1 and A2 present scatter diagrams of the welfare indicators at the rayon level by the two different methodologies, along with the spearman rank correlations. Interestingly, using separate indices for urban and rural areas as opposed to a single national index results in a change from a weak positive to a weak negative correlation between the asset index and material poverty in rural areas. This highlights the problem of using a single 
asset index, whilst confirming the earlier conclusion that the two approaches (imputed welfare $\mathrm{v}$ asset index) are measuring different dimensions of welfare and that the asset index may be reflecting ownership of assets laid down in the past rather than current welfare.

Table A2: Result of household economic index, urban area.

\begin{tabular}{|c|c|c|c|c|c|c|}
\hline & $\begin{array}{c}(2) \\
\text { Mean }\end{array}$ & $\begin{array}{c}\text { (3) } \\
\text { Standard } \\
\text { Deviation }\end{array}$ & $\begin{array}{c}\text { (4) } \\
\text { Eigenvectors } \\
\text { of first } \\
\text { principal } \\
\text { components }\end{array}$ & $\begin{array}{c}\text { (5) } \\
\text { Scoring } \\
\text { factor/ } \\
\text { Std. } \\
\text { Dev. }\end{array}$ & $\begin{array}{c}\text { (6) } \\
\text { Score if } \\
\text { they } \\
\text { have } \\
\text { asset }\end{array}$ & $\begin{array}{c}\text { (7) } \\
\text { Score if } \\
\text { they don't } \\
\text { have asset }\end{array}$ \\
\hline 1. Gas Line & 0.792 & 0.405 & 0.353 & 0.872 & 0.181 & -0.690 \\
\hline 2. Gas Cylinder & 0.139 & 0.346 & -0.277 & -0.801 & -0.689 & 0.111 \\
\hline 3. Electric Oven & 0.188 & 0.390 & -0.233 & -0.597 & -0.485 & 0.112 \\
\hline 4. Heating System (private, public) & 0.110 & 0.313 & 0.116 & 0.371 & 0.330 & -0.041 \\
\hline 5. Stove & 0.171 & 0.376 & -0.294 & -0.782 & -0.648 & 0.134 \\
\hline 6. Water & 0.835 & 0.370 & 0.341 & 0.922 & 0.152 & -0.770 \\
\hline 7. Hot water & 0.068 & 0.252 & 0.148 & 0.587 & 0.547 & -0.040 \\
\hline 8. Sewage System & 0.695 & 0.460 & 0.443 & 0.963 & 0.294 & -0.669 \\
\hline 9. Bathroom & 0.625 & 0.483 & 0.402 & 0.832 & 0.312 & -0.520 \\
\hline 10. Telephone & 0.414 & 0.492 & 0.213 & 0.433 & 0.254 & -0.179 \\
\hline 11. Total living area (square meters) & 57.82 & 46.99 & -0.055 & -0.001 & $* *$ & $* *$ \\
\hline 12. Number of room & 2.37 & 1.55 & 0.042 & 0.027 & $* *$ & $* *$ \\
\hline 13. Dwelling Structure (separate house, no) & 0.440 & 0.496 & -0.258 & -0.520 & -0.291 & 0.229 \\
\hline 14. Ownership of dwelling & 0.594 & 0.491 & -0.167 & -0.340 & -0.138 & 0.202 \\
\hline
\end{tabular}

Table A3: Result of household economic index, rural area.

\begin{tabular}{|c|c|c|c|c|c|c|}
\hline & $\begin{array}{c}(2) \\
\text { Mean }\end{array}$ & $\begin{array}{c}\text { (3) } \\
\text { Standard } \\
\text { Deviation }\end{array}$ & $\begin{array}{c}\text { (4) } \\
\text { Eigenvectors } \\
\text { of first } \\
\text { principal } \\
\text { components }\end{array}$ & $\begin{array}{c}\text { (5) } \\
\text { Scoring } \\
\text { factor/ } \\
\text { Std. } \\
\text { Dev. }\end{array}$ & $\begin{array}{c}(6) \\
\text { Score if } \\
\text { they } \\
\text { have } \\
\text { asset }\end{array}$ & $\begin{array}{c}\text { (7) } \\
\text { Score if } \\
\text { they don't } \\
\text { have asset }\end{array}$ \\
\hline 1. Gas Line & 0.310 & 0.462 & 0.122 & 0.264 & 0.182 & -0.082 \\
\hline 2. Gas Cylinder & 0.303 & 0.459 & 0.190 & 0.414 & 0.289 & -0.125 \\
\hline 3. Electric Oven & 0.321 & 0.467 & 0.081 & 0.173 & 0.118 & -0.056 \\
\hline 4. Heating System (private, public) & 0.063 & 0.244 & 0.018 & 0.074 & 0.069 & -0.005 \\
\hline 5. Stove & 0.681 & 0.465 & 0.161 & 0.346 & 0.110 & -0.236 \\
\hline 6. Water & 0.261 & 0.439 & 0.107 & 0.244 & 0.180 & -0.064 \\
\hline 7. Hot water & 0.002 & 0.053 & 0.032 & 0.604 & 0.603 & -0.001 \\
\hline 8. Sewage System & 0.037 & 0.190 & 0.038 & 0.200 & 0.193 & -0.007 \\
\hline 9. Bathroom & 0.068 & 0.252 & 0.127 & 0.504 & 0.470 & -0.034 \\
\hline 10. Telephone & 0.076 & 0.265 & 0.143 & 0.540 & 0.499 & -0.041 \\
\hline 11. Total living area (square meters) & 75.07 & 47.38 & 0.437 & 0.009 & $* *$ & $* *$ \\
\hline 12. Number of room & 2.37 & 1.42 & 0.406 & 0.286 & $* *$ & $* *$ \\
\hline 13. Dwelling Structure (separate house, no) & 0.899 & 0.301 & 0.506 & 1.681 & 0.170 & -1.511 \\
\hline 14. Ownership of dwelling & 0.931 & 0.252 & 0.501 & 1.988 & 0.137 & -1.851 \\
\hline
\end{tabular}


Figure A1: Scatter plot of average adult equivalent consumption per month in Manat and factor score, rural rayon (asset index for rural only, 14 variables)

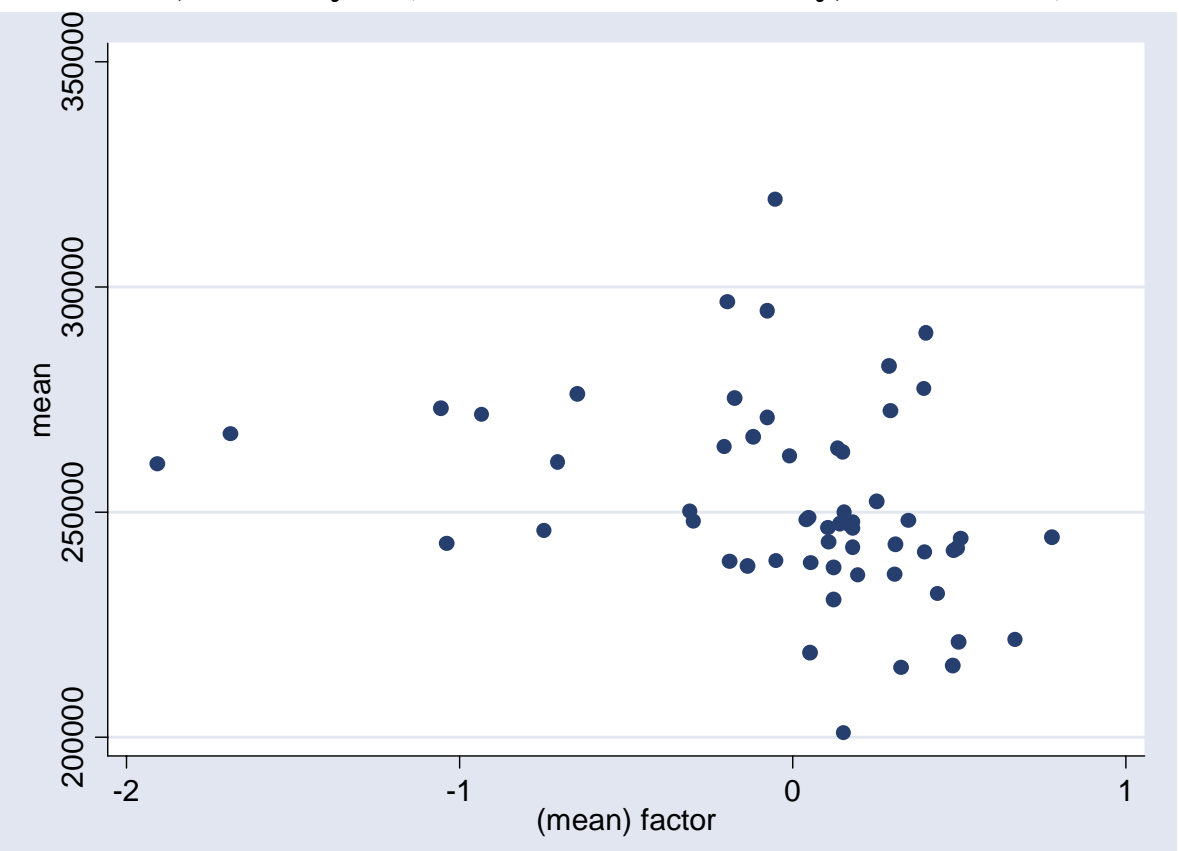

Note: Number of observation=56, Spearman's rho=-0.4143 test of Ho: mean consumption and factor score are independent Prob $>0.0014$

Figure A2: Scatter plot and average adult equivalent consumption per month in Manat and factor score, urban rayon (asset index for urban only, 14 variables)

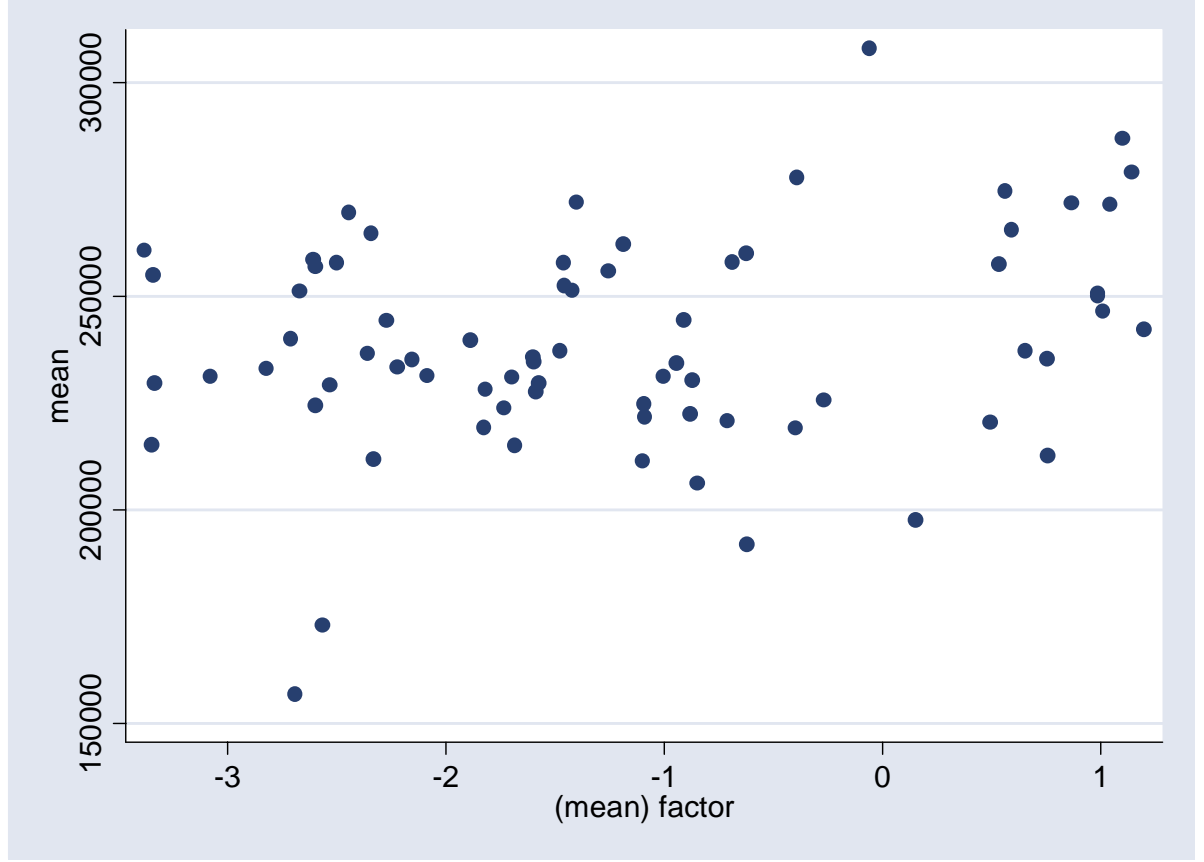

Note: Number of observation=73, Spearman's rho=0.1973 test of Ho: mean consumption and factor score are independent Prob $>0.0939$ 
Figure A3: Scatter plot and average adult equivalent consumption per month in Manat and factor score, rural administrative units (asset index for rural only, 14 variables)

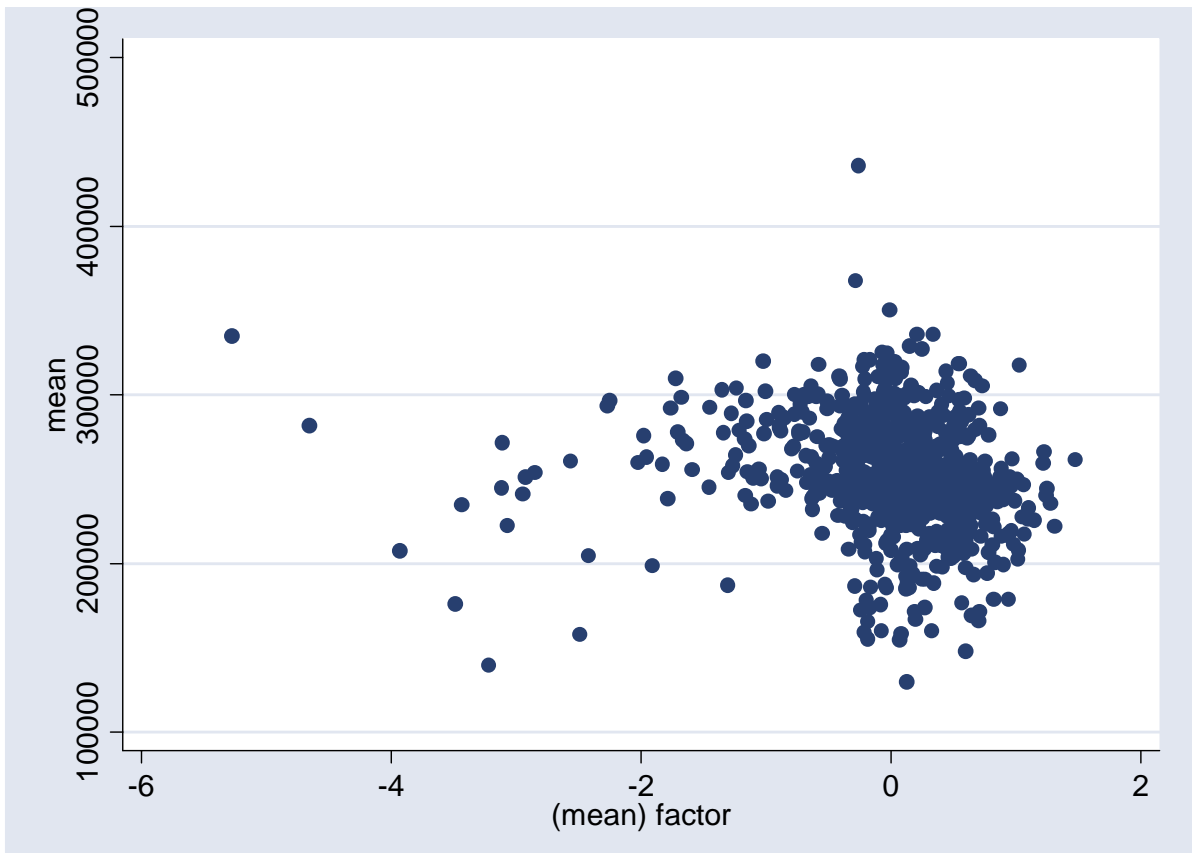

Note: Number of observation=896, Spearman's rho=-0.2768 test of Ho: mean consumption and factor score are independent Prob $>0.000$

Figure A4: Scatter plot and average adult equivalent consumption per month in Manat and factor score, urban administrative units (asset index for urban only, 14 variables)

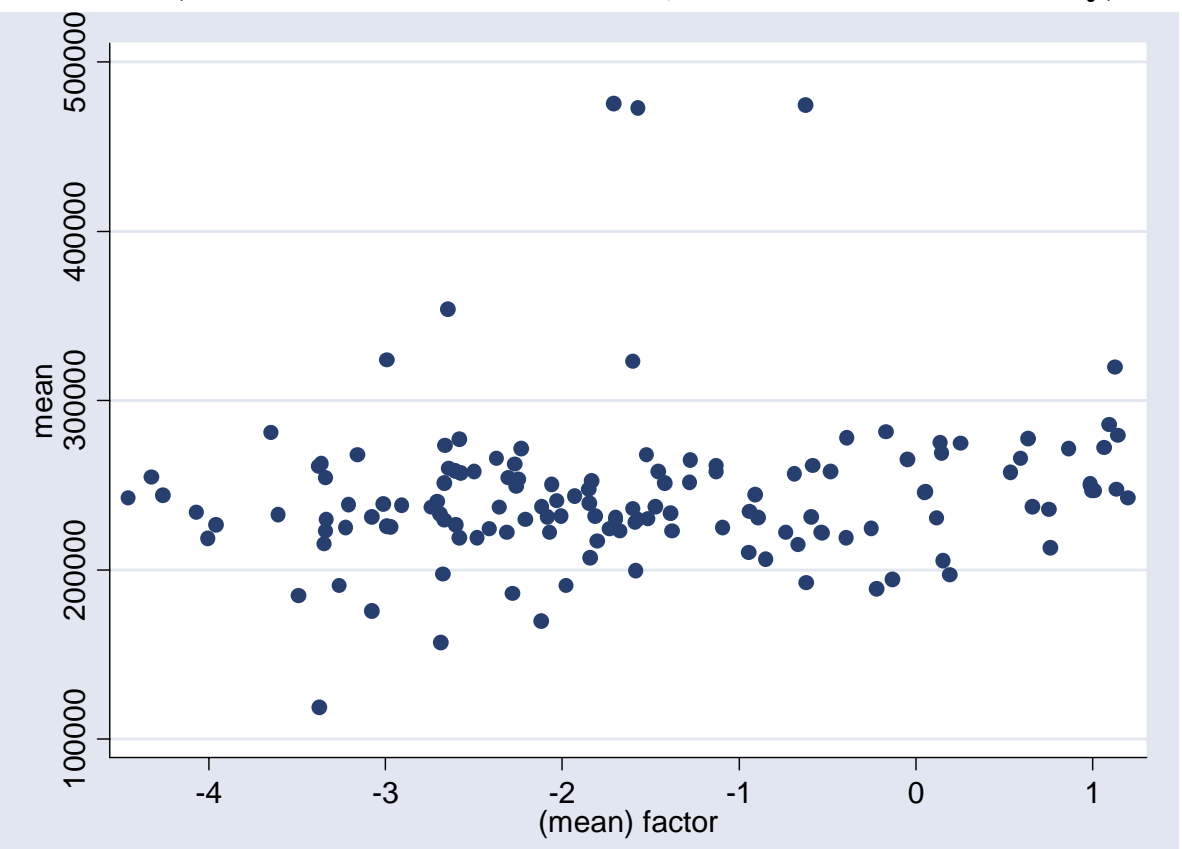

Note: Number of observation=140, Spearman's rho=0.1742 test of Ho: mean consumption and factor score are independent Prob $>0.0395$ 


\section{References}

Bigman, D.and U. Deichmann. 2002. "Geographical targeting: a review of methods and approaches." in Geographical Targeting for Poverty Alleviation: Methodology and Applications, edited by D. Bigman and H. Fofack: The World Bank.

Bollen, K.A., J. Glanville, and G. Stecklov. 2001. "Economic Status Proxies in Studies of Fertility in Developing Countries: Do the Measure Matter?" Measure Evaluation Working Papers WP-01-38.

Chatfield, C.and A.J. Collins. 1980. Introduction to Multivariate Data Analysis. London: Chapman and Hall.

Dowsett-Coirolo, D. 2003. "Azerbaijan Republic Poverty Assessment Volume I: Summary and Conclusions." in Human Development Sector unit South Caucasus Unit Europe and Central Asia: The World Bank.

Elbers, C., J.O. Lanjouw, and P. Lanjouw. 2002. "Micro-level Estimation of Welfare." Policy Research Working Paper.

Elbers, C., P. Lanjouw, J. Mistiaen, B. Özler, and K. Simler. 2003. "Are Neighbours Equal? Estimating Local Inequalities in Three Developing Countries." WIDER DP \#2003/02.

Filmer, D.and L. Pritchett. 2001. "Estimating Wealth Effects without expenditure Data or Tears: Educational enrolment in India." Demography 38(1).

Gwatkin, D.R., S. Rustein, K. Johnson, P.P. Rohini, and A. Wagstaff. 2000. "Socio-Economic Differences in Health, Nutrition, and Population." HNP/Poverty thematic Group of the World Bank.

Marnie, S., J. Lapins, and A. Zaidi. 2001. "FINAL REPORT: Grant for Strengthening of Living Standards Monotoring Capacity of Goskomostat IDF Grant No.27238."

Mistiaen, J., B. Özler, T. Razafimanantena, and J. Razafindravonona. 2002. "Putting Welfare on the Map in Madagascar." Africa Region Working Paper Series No. 34.

Montgomery, M., M. Gragnolati, K. Burke, and E. Paredes. 2000. "Measuring living standards with proxy variables." Demography 37(2):155-174.

Sahn, D.E.and D. Stifel. 2001. "Exploring Alternative Measure of Welfare in the Absence of Expenditure Data." Cornell University.

SPPRED. 2004. "Annual Report 2003. Azerbaijan Progresses Toward the achievement of the MDGs." Baku.

UNICEF. 2003. "Social Monitor 2003." in Innocenti Social Monitor. Florence: UNICEF Innocenti Research Centre. 


\section{Annex 1: Rayon Map of Azerbaijan}

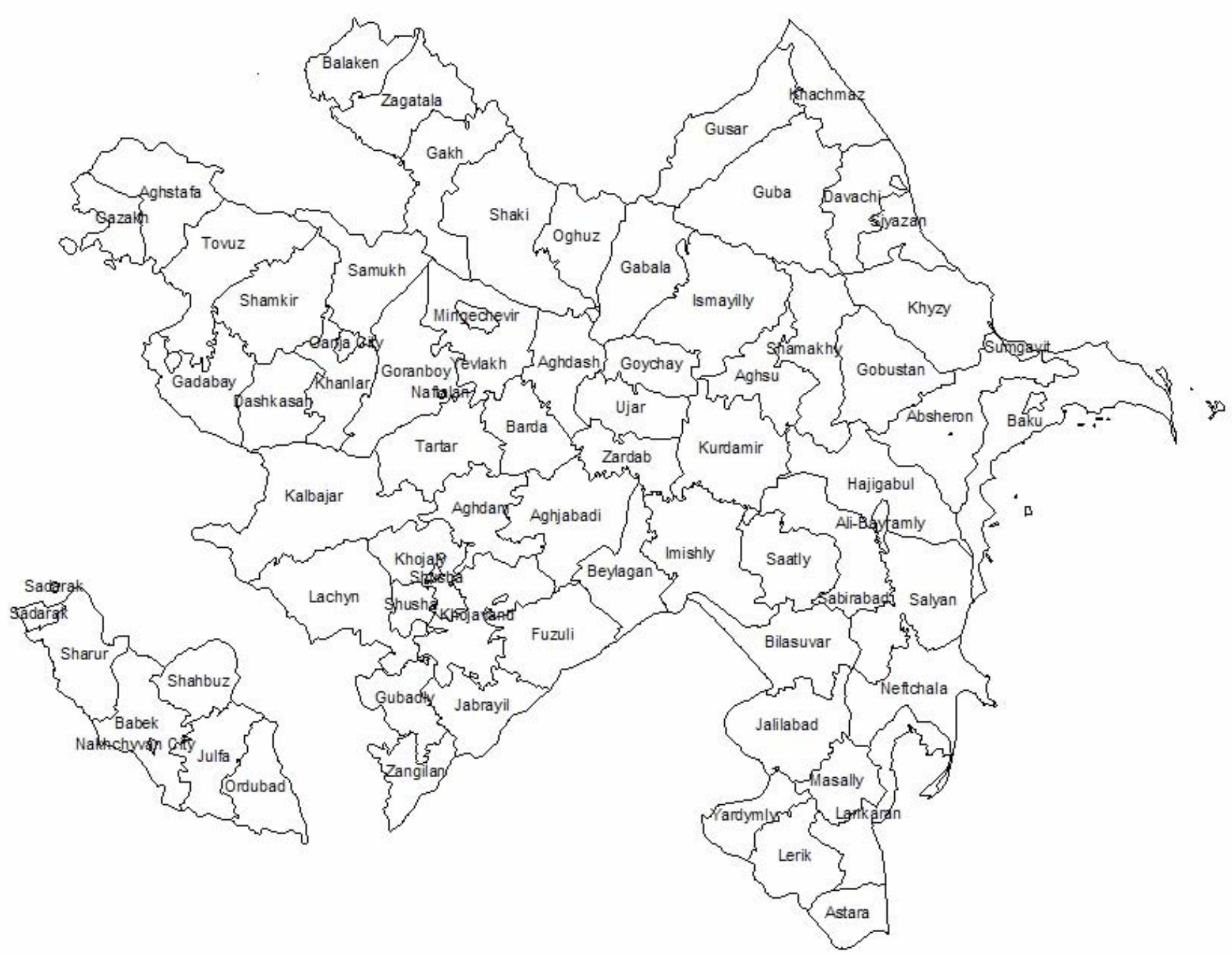

